\title{
Production Allocation of Reservoir Layers using Data-Driven Reservoir Modeling
}

\author{
Semaa Alessa \\ sha0011@mix.wvu.edu
}

Follow this and additional works at: https://researchrepository.wvu.edu/etd

Part of the Other Engineering Commons

\section{Recommended Citation}

Alessa, Semaa, "Production Allocation of Reservoir Layers using Data-Driven Reservoir Modeling" (2020). Graduate Theses, Dissertations, and Problem Reports. 7776.

https://researchrepository.wvu.edu/etd/7776

This Thesis is protected by copyright and/or related rights. It has been brought to you by the The Research Repository @ WVU with permission from the rights-holder(s). You are free to use this Thesis in any way that is permitted by the copyright and related rights legislation that applies to your use. For other uses you must obtain permission from the rights-holder(s) directly, unless additional rights are indicated by a Creative Commons license in the record and/ or on the work itself. This Thesis has been accepted for inclusion in WVU Graduate Theses, Dissertations, and Problem Reports collection by an authorized administrator of The Research Repository @ WVU. For more information, please contact researchrepository@mail.wvu.edu. 


\title{
Production Allocation of Reservoir Layers Using Data-Driven Reservoir Modeling
}

\section{Semaa Hatam Ahmed Alessa}

\author{
Thesis submitted to the \\ Benjamin M. Statler College of Engineering and Mineral Resources at \\ West Virginia University \\ in partial fulfillment of the requirements for the degree \\ of \\ Master of Science in \\ Petroleum and Natural Gas Engineering
}

Shahab D. Mohaghegh, Chair Ph.D.

Samuel Ameri, Professor

Kashy Aminian, Ph.D.

Mehrdad Zamirian, Ph.D.

\section{Department of Petroleum and Natural Gas Engineering, Morgantown, West Virginia}

2020

Keywords: Top-Down Modeling, Commingled Layers Allocation

Copyright 2020 Semaa Alessa 


\section{ABSTRACT}

\section{Production Allocation of Reservoir Layers Using Data-Driven Reservoir Modeling}

\section{SEMAA ALESSA}

The pros of having a commingled layer scheme would be considered high with successful reservoir management. If not, the cons will impact the production drastically as unfortunate consequences may result in reservoir fluids communication, well integrity issues, and production termination. Although the plane requires optimizing production with minimal capital investments and operating expenses, it is an enormous challenge considering commingled layers frequent surveillance and workover requirements.

As the value of information is a decision tool for the surveillance frequency, the oil industry often uses static assumptions as an economical replacement of dynamic measurements such as KH static modeling. However, the last is misleading for not considering the effect of dynamic attributes such as reservoir pressure and fluid properties. Simultaneously, the evolution of Artificial Intelligence (AI) and Machine Learning (ML) made the challenge of allocating commingled layers allocation possible since AI does not build assumptions based on static properties but rather pick the static and dynamic patterns associated with rock and fluid properties. Accordingly, AI and ML application was used in this research as a new approach for commingled layers allocation estimation, which is known technically as Top-Down Modeling (TDM). TDM features the entire acquired static and dynamic field measurements through Artificial Intelligence and Data Science that utilizes Machine Learning, Fuzzy and crisp Logic via Neural Networks to develop a reservoir model.

TDM was tested on a synthetic heterogeneous reservoir model with three commingled layers across 63 wells in conjunction with multi-random comingling schemes throughout wells' lifespan. As the static KH modeling proven ambiguous in picking the effect of reservoir pressure on production profile per layer, a high certainty TDM modeling was successfully achieved both horizontally and vertically on a layer basis which confirms the capability of TDM in allocating commingled layers production in terms of certainty, and operational cost. 


\section{DEDICATION}

To my parents, Dr. HATAM A. JASSIM and Dr. HANA'A M. ALI

for

their limitless support,

to THE BUREAU OF EDUCATIONAL AND CULTURAL AFFAIRS,

THE FULBRIGHT STUDENT EXCHANGE PROGRAM,

and,

to THE IRAQI MINISTRY OF OIL

for

giving me the chance to study in THE UNITED STATES OF AMERICA 


\section{ACKNOWLEDGEMENTS}

Dr. SHAHAB MOHAGHEGH! It was an honor working with you, and I wish to express my full gratitude and appreciation for your unwavering technical support, patience and for being a great master.

I also would like to show my great appreciation and extraordinary thanks to our chairman, Prof. SAMUEL AMERI! You have been a great leader and I wouldn't accomplish this work without your continuous support.

As well as, I am delighted to express my gratitude to our academic advisor Dr. KASHY AMINIAN! your broad guidance and your time dedications through this program facilitated this work and it is truly appreciated.

I would like to thank all those whose assistance proved to be a milestone in the accomplishment of my end goal especially AMIR ANSARI, JOSH DIETZ, JOHN BOYKEN, ADRIANE MATHENY and my teammates in WVU-LEADS.

I would say that I am the luckiest for being a daughter, a sister, and a friend to the most supportive, successful, and dedicated people that made this work achievable especially my PARENTS, my brother AHMED, and my sisters RAZAN and ZAHRAA and my best friends: NOOR SA'ADI, MUSTAFA QAHTAN, WALEED ABDULELAH, SAMPY HARDIN and ALBERT BARROW.

Lastly, I would like to show high gratitude for my Fulbright program advisors AYAD ZAIN, LEAH BERKEBILE, and OLIVIA GUSTAFSON for their great support and guidance in fulfilling the Fulbright program requirements. 


\section{TABLE OF CONTENTS}

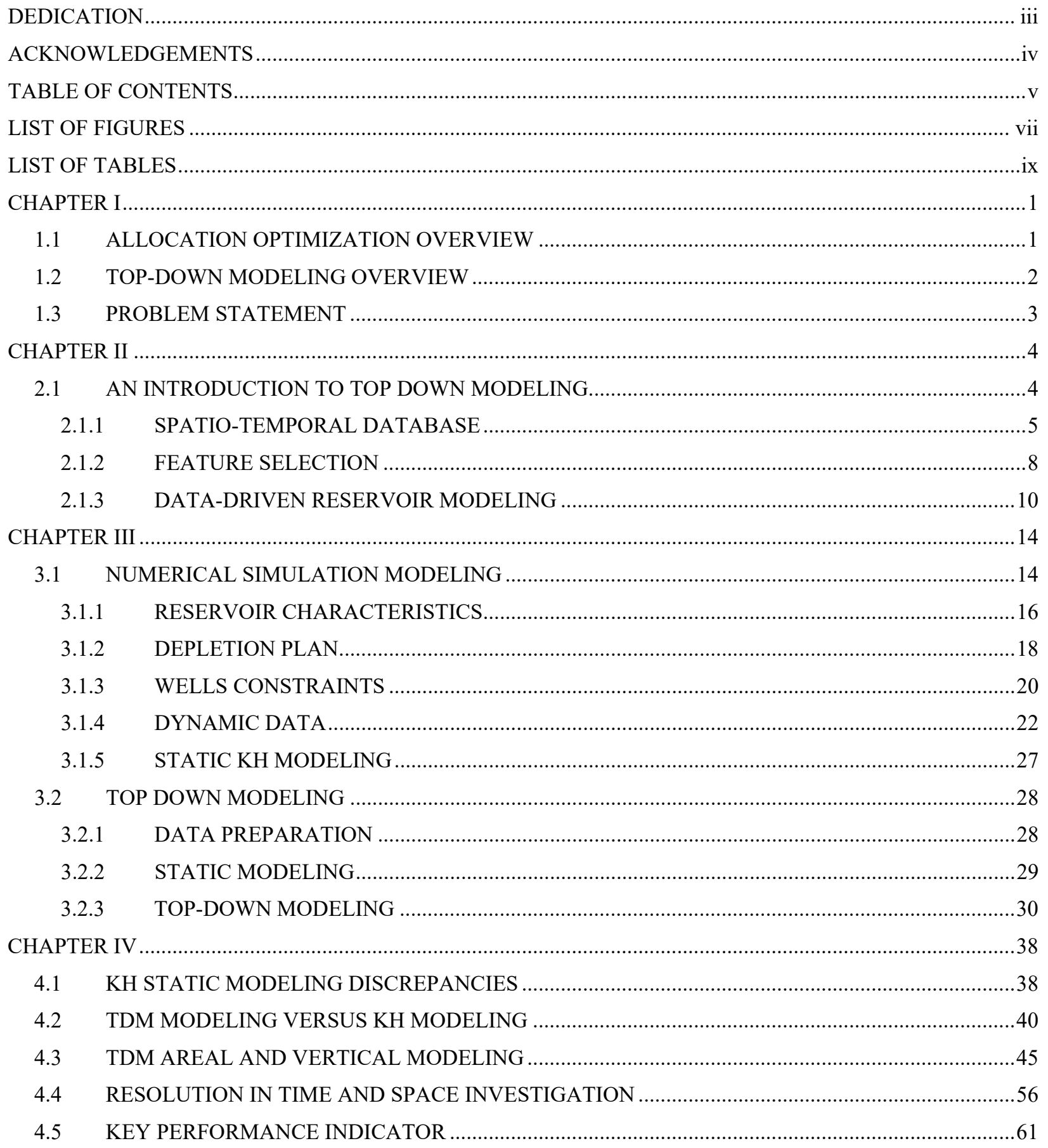


4.6 TDM'S TRAINING, VALIDATION, AND CALIBRATION ……....................................................65

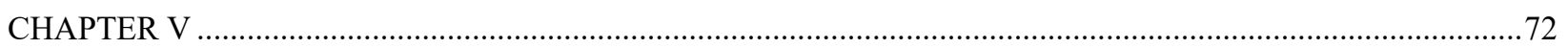

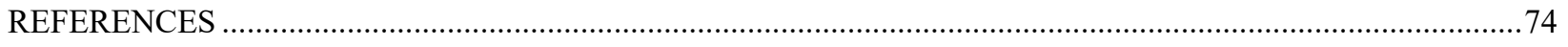

APPENDIX 


\section{LIST OF FIGURES}

FIGURE 1: EXAMPLE OF CARTESIAN AND POLYGON-BASED GRID SYSTEMS DURING FILED LIFESPAN (MOHAGHEGH, 2017)

FiguRE 2: EXAMPLE OF SPATIO-TEMPORAL DATABASE SECTORS FOR A DEVELOPED FIELD IN THE MidDLE EAST

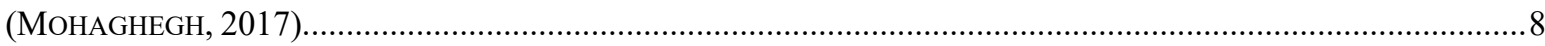

FIGURE 3: EXAMPLE OF FUZZY RULE FOR APPROXIMATION REASONING ……………..............................................9

FIGURE 4: SCHEMATIC OF MULTI-LAYER NEURAL NETWORK OPERATIONS............................................................11

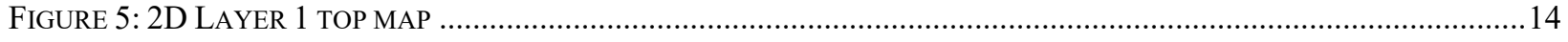

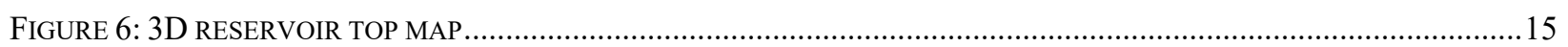

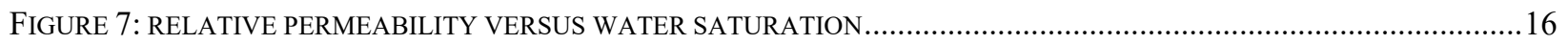

FIGURE 8: LAYERS 1, 3, AND 6 POROSITY (LEFT) AND PERMEABILITY (RIGHT) RESPECTIVELY ………......................17

FIGURE 9: RESERVOIR DEVELOPMENT PHASES ..............................................................................................

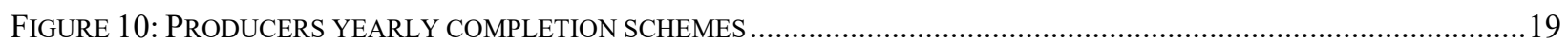

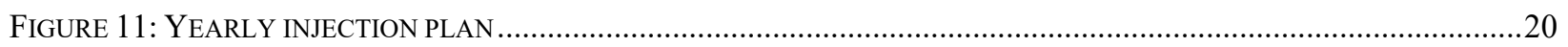

FIGURE 12: BUBBLE MAP OF THE MONTHLY OPEN LAYER'S DISTRIBUTIONS AMONG COMPLETION SCHEMES ................21

Figure 13: LAYER 1 CUMUlative BUbBle MAP ACROSS WATER SATURATION AND RESERVOIR PRESSURE ...............23

Figure 14: LAYER 3 CUMUlative BUbBle MAP ACROSS WATER SATURATION AND RESERVOIR PRESSURE ................24

FigURE 15: LAYER 6 CUMULATIVE BUBBLE MAP ACROSS WATER SATURATION AND RESERVOIR PRESSURE ................25

FIGURE 16: PRESSURE MAP IN I AND J DIRECTION SHOWING VERTICAL PRESSURE VARIATION ACROSS LAYERS ............26

Figure 17: Numerical ReSERVoir Simulation (ACtUAl RateS) VERSUS KH MOdELING (KH RATES) ................27

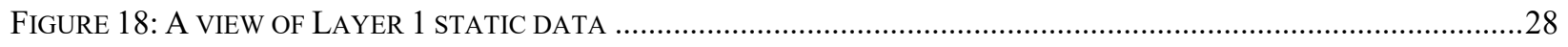

FIGURE 19: EXAMPLE OF DYNAMIC DATA (OIL RATE SC - MONTHLY (BBL/DAY)) ………………………………….....22

FIGURE 20: CARTESIAN AND POLYGON-BASED GRID SYSTEMS ACROSS THE RESERVOIR AT THE FINAL PHASE................30

FIGURE 21: TDM MODEL ATTRIBUTES SEQUENCE SELECTIONS AMONG 5 MODELS...................................................

FIGURE 22: LAYER 6 Q(T)-OIL MODEL TRAINING, VERIFICATION AND CALIBRATION ................................................34

FIGURE 23: ENTIRE RESERVOIR LAYER 6 AREAL OIL, GAS, AND WATER PRODUCTION (TDM VERSUS NUMERICAL

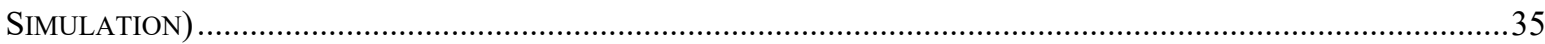

FigURE 24: WELL 30 TOTAL VERTICAL PRODUCTION (TDM VERSUS NUMERICAL SiMULATION)................................36

FIGURE 25: WELL-030 OIL, GAS, AND WATER PRODUCTION PER LAYER (L1, L3, AND L6) (TDM VERSUS NUMERICAL

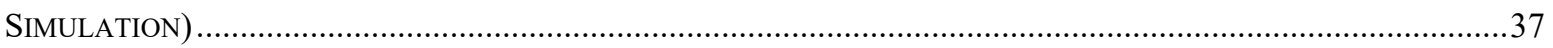

FIGURE 26: WELL-020 BIOGRAPHY SHOWING THE EFFECT OF BLOCK PRESSURE ON ALLOCATING FLOW RATE ..............39 
FIGURE 27: WELL-013 BIOGRAPHY SHOWING THE EFFECT OF BLOCK PRESSURE ON ALLOCATING FLOW RATE. 39

FIGURE 28: TDM WATER AND OIL RATE VERSUS NUMERICAL RESERVOIR SIMULATION ...........................................40

FIGURE 29: KH WATER AND OIL RATE VERSUS NUMERICAL RESERVOIR SIMULATION ...........................................41

FIGURE 30: LAYER 1 AREAL OIL KH MODELING (LEFT) VERSUS TDM MODELING (RIGHT) ....................................42

FIGURE 31: LAYER 3 AREAL OIL KH MODELING (LEFT) VERSUS TDM MODELING (RIGHT) ...................................43

FIGURE 32: LAYER 6 AREAL OIL KH MODELING (LEFT) VERSUS TDM MODELING (RIGHT) .....................................43

FIGURE 33: LAYER 1 AREAL WATER KH MODELING (LEFT) VERSUS TDM MODELING (RIGHT) ................................44

FIGURE 34: LAYER 3 AREAL WATER KH MODELING (LEFT) VERSUS TDM MODELING (RIGHT) ..............................44

FIGURE 35: LAYER 6 AREAL WATER KH MODELING (LEFT) VERSUS TDM MODELING (RIGHT) ...............................45

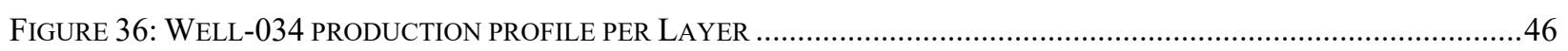

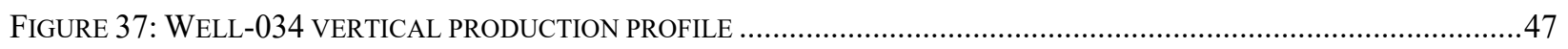

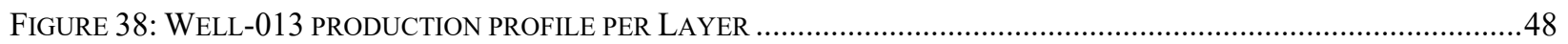

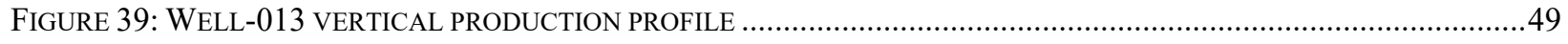

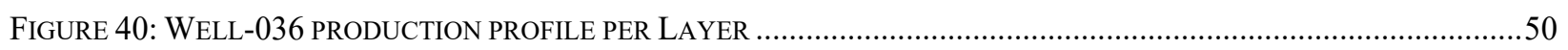

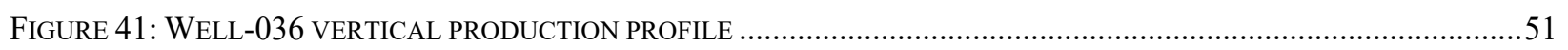

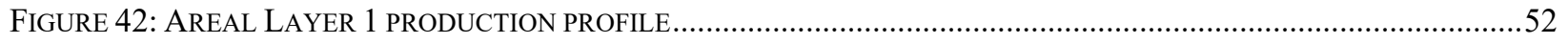

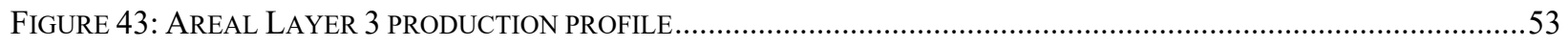

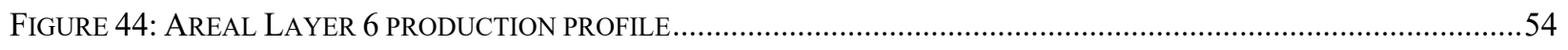

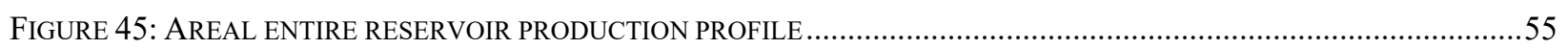

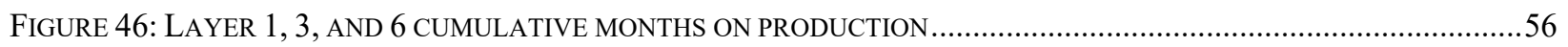

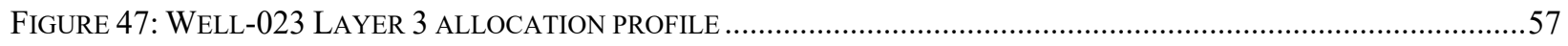

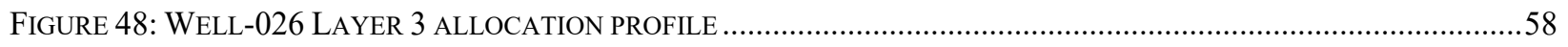

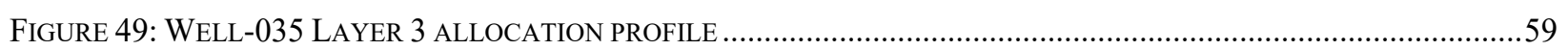

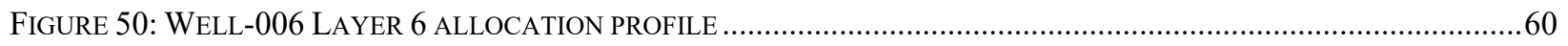

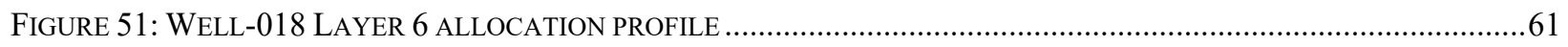

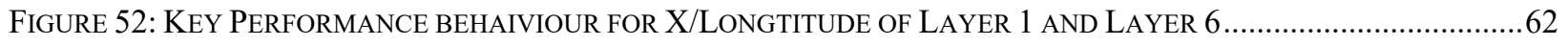

FIGURE 53: KEY PERFORMANCE FOR OFFSETS DISTANCE OF LAYER 1 AND LAYER 6 ............................................63

FIGURE 54: KEY PERFORMANCE FOR WATER INJECTION OF LAYER 1 AND LAYER 6..............................................64

FIGURE 55: LAYER 1 TDM NUMERICAL RESERVOIR SIMULATION VERSUS NEURAL NETWORKS PERDITION CROSS PLOT

FIGURE 56: LAYER 3 TDM NUMERICAL RESERVOIR SIMULATION VERSUS NEURAL NETWORKS PERDITION CROSS PLOT

FIGURE 57: LAYER 6 TDM NUMERICAL RESERVOIR SIMULATION VERSUS NEURAL NETWORKS PERDITION CROSS PLOT 70

FIGURE 58: TOTAL LAYERS TDM NUMERICAL RESERVOIR SIMULATION VERSUS NEURAL NETWORKS PERDITION CROSS PLOT 


\section{LIST OF TABLES}

Table 1: Cumulative Production and Injection Rates Per Reservoir LaYer ..............................................22

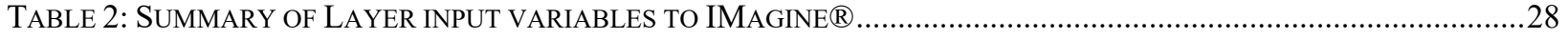

TABLE 3: THE INITIAL VARIABLE INPUT SELECTION FOR LAYER 6 OIL Q(T)-OIL MODEL...............................................32

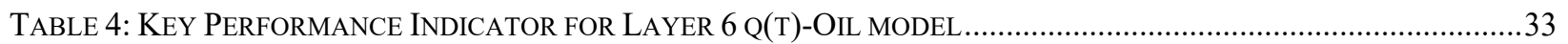

TABLE 5: CUMULATIVE PRODUCTION PER NUMERICAL RESERVOIR SIMULATION AND STATIC KH MODELING...............42

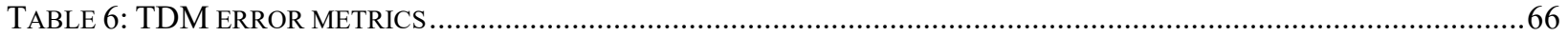

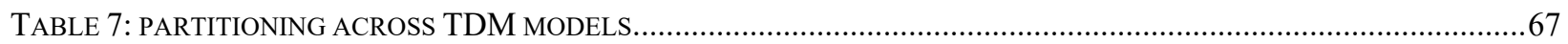




\section{CHAPTER I}

\section{INTRODUCTION}

\subsection{ALLOCATION OPTIMIZATION OVERVIEW}

Having a comingled scheme is challenging in term of allocation certainty among layers, and as obviously, the permeability derived from cores is considered the most representative, but it is rather expensive to run through the entire reservoir. Hence, oil industries prefer the least reservoir development cost approaches, which are associated with calibrating permeability models with different techniques and tools.

After calibrating permeability models, another risk factor associated with portion estimation per layer. While the typical method involves using the permeability thickness static modeling $(\mathrm{KH})$, this allocation approach can be misleading as it is unable to adjust for deferential pressure, skin build, multi-phase flow, and PVT properties. The static KH modeling assumes that the percentage of fluid distribution among layers is a function of permeability and thickness only; however, even well logs calibrated mobility model is debatable since core mobility is upscaled for a complex reservoir structure.

In this case, the most known successful technique to acquire an accurate allocation per layer is achieved with flow tests. For example, (Blekhman, Diaz, Carrica, Corbett, \& Coca, 2001) integrated well logs permeability with the Pressure Transient Analysis test (PTA), and as a result, PTA provided data within well drainage area with extended scale, counting for the dynamic layer effect.

On the other hand, other testing tools were used to calibrate the mobility models, such as production logging. (Sullivan, Belanger, Dunn, Jenkins, \& Skalinski, 2006) proven a mismatch between permeabilities derived from well logs and production logging, primarily in carbonate reservoirs and commingled layers because of the misleading upscaled core permeability in heterogeneous reservoirs.

While the latest studies have shown that permeability derived from production logging tools and cores are highly alike, driving the conclusion that production logging is the most efficient in increasing allocation 
certainty (Davarpanah, Mirshekari, Behbahani, \& Hemmati, 2018). However, due to budget constraints, it is less likely to achieve frequent testing. Hence, scientists started developing other economic approaches.

One of these approaches that might decrease the field development budget is shifting the industry forward more data investments and a higher understanding of the value of information (VOI). Multi-Phase Allocation method (MPA) is one of these investments. The last was developed by (Kechut, et al., 2017) which involved combining mathematically-described derived relative permeability water-cut trends per layer with a stochastic search engine to produce multiple allocation solutions, as an accurate allocation per layer is defined based on the minimal error between the total measured rates, and the total computed rates. MPA technique was later tested successfully by (Chia, et al., 2019).

In the past decade, the world was shifting towards data science and (Widarsono, et al., 2005), was the first to use data rather than empirical formulated models in commingled layers allocation through fuzzy logic. Later consequently, Artificial Intelligence (AI), a fuzzy logic application, has evolved to solve higher complexities through Neural Networks (NN). Machine Learning (ML) is one of AI tools that is used for pattern recognition, such as robotic systems applications that challenged humans' capabilities.

\subsection{TOP-DOWN MODELING OVERVIEW}

With VOI challenges, AI proved successfully with economic improvements in different industries such as finance, medicine, and security, and it became necessary to test this technology for some possibilities to overcome VOI restrictions to decrease uncertainties associated with modeling commingled layers allocation.

There are many Machine Learning tools used in reservoir modeling, the one that is involved in this thesis known as Top-Down Modeling (TDM). TDM is a machine learning tool invented by Intelligence Solutions Inc. as a new reservoir modeling tool; it can feature the entire static and dynamic field measurements as an alternative of empirical formulated methods in complex reservoir systems (Mohaghegh, 2017). Instead, TDM uses Artificial Intelligence and data mining by incorporating Fuzzy Logic and Neural Networks to understand the complexity of the reservoir model. Hence, modeling reservoir pressure, saturation, and rate profile at each grid block.

In 2009, TDM was successful in predicting the production profile of new wells by utilizing information from offset wells, as well as, TDM successfully identified the presence of gas cap and remaining reserve using well logs and the production data (Mohaghegh, 2009). This technology tested on different oil fields such as Niobrara Field (Haghighat, Mohaghegh, Gholami, \& Moreno, 2014); as a result, the authors were capable of generating acceptable accuracy TDM for the unconventional shale reservoir for production forecast and sensitivity analysis.

Besides, TDM used in modeling the Powder River Basin Field to identify the depletion distributions over time and sweet spots for infill drill with limited surveillance that challenged the traditional modeling techniques 
(Maysami, Gaskari, \& Mohaghegh, 2013). TDM technology was also tested successfully in modeling reservoir production profiles with low computational cost in the Scurry Area Canyon Reef Operators Committee (SACROC) (Alenezi \& Mohaghegh, 2017).

In conclusion, TDM has proven to be a reliable reservoir modeling tool for mature fields, and it is essential to test it on commingled layer allocation since the technology has proven successful in many publications in solving VOI challenges in terms of economy and time.

\subsection{PROBLEM STATEMENT}

The objective of this thesis is to test the capability of TDM in successfully allocating commingled layers production rate using Intelligence Solutions Incorporation tool IMagine ${ }^{\circledR}$ with a perplexing model scenario generated by the numerical reservoir simulation tool $\mathrm{CMG}$ : the scenario involved generating heterogeneous reservoir model with three permeable layers, three impermeable layers throughout 63 wells in conjunction with multi-random completions schemes through each well lifespan.

Chapter two enlightened brief InSite to the Top-Down Modeling, while chapter three elaborated the methodology used in setting the commingled model milestones through the numerical reservoir simulation, as well as the TDM approach. Later, chapter four conversed the comparison of KH and TDM modeling versus numerical reservoir simulation. And lastly, chapter five summarized the TDM approach findings and upcoming future work possibilities. 


\section{CHAPTER II}

\section{LITERATURE REVIEW}

It is impossible to forecasts production if the model fails to history matches. Hence, this thesis is testing the capabilities of the Top-Down Modeling in history matching commingled layers production, and this chapter covers an introduction to the Top-Down Modeling technology, along with its pros and cons.

\subsection{AN INTRODUCTION TO TOP DOWN MODELING}

Unlike numerical simulation, TDM is a data-driven reservoir modeling tool that depends on field measurements rather than mathematical formulations. It utilizes well static and dynamic data to construct a full field reservoir model using data mining, artificial intelligence, and machine learning.

Another factor that makes TDM different than numerical simulation is that it defines physics based on the complexity of the reservoir by assigning weights to data, then patterns recognize the most influential using Artificial Intelligence. This approach may give the impression that what might be considered necessary in numerical reservoir simulation, which might be consumption for time and money, might not be the case for TDM. On the contrary, both models are alike in term of representing fluid flow in the porous media, since TDM uses the Spatio-temporal database, while numerical simulation uses the diffusivity equation.

Despite the advantages of using TDM, the common question that keeps raising is "how many wells are required to have successful TDM?", to answer whether enough data is available for a successful TDM, some aspects must be considered such as reservoir complexity, the number of wells, and time resolution. For example, the number of wells is a function of age and frequency of the production, 20 wells with days' time resolution producing for 2 to 3 years may result in a successful TDM (Mohaghegh, 2017).

The TDM structure used in this thesis is divided into three significant foundations: Spatio-Temporal Database, Feature Selection, and Data-Driven Reservoir Modeling. 


\subsubsection{SPATIO-TEMPORAL DATABASE}

Since it is data-driven reservoir modeling technology, the way data is assembled and affiliated has a crucial impact on the model, here though it affiliated in a manner that represents fluid flow in porous media both in space and time. It represents sophisticated aspects that are essential in reservoir modeling and production history matching. These aspects that affect production represented by wells communication with offset wells, well operation constraints, reservoir characteristics among wells, and multi-completion among field lifespan.

The Spatio-temporal database includes two significant data types: Static data that doesn't change with time (such as formation thickness, and well location), and dynamic data that are time-dependent (such as reservoir pressure, and flow rate). These data are provided for both focal wells and offset wells, as the nearby offset wells impact production.

The Spatio-temporal database is advantageous in term of eliminating time steps required to be solved in the partial differential equation because of the ultimate size of the Spatio-temporal database that is a direct outcome of the decisions made in time and space.

\subsubsection{STATIC DATA}

Static data are time-independent and represent the role of the complex and isotropic geology on production by defining the drainage area and well impaction on other offset wells based on reservoir characteristics. These characteristics are summarized by the factors that control hydrocarbon storage and transport such as water saturation, porosity, permeability, top, and thickness of the formation.

It is important to notate that TDM also have the capabilities of determining the distributions of reservoir characteristics and populate the geological model using geostatistical and interpolative algorithms in the Spatiotemporal database stage, while it is up to the modeler whether to use them in data-driven modeling since it might help TDM learning and correlating wells with the reservoir characteristics.

\subsubsection{DYNAMIC DATA}

Dynamic data consisted of two categories: dynamic data and dynamically modified static data. While production and injection data configure the dynamic data, dynamically modified static data may get represented by wellhead pressure, the number of days of production, chock size, change in completion length. Statically dynamic data represents human intervention with the well. Another factor that shows that the Spatio-temporal database is not merely a data entry tool. 
TDM can distinguish between the different impacts related to reservoir characteristics and operational constraints implicitly during the training process as well as, in case of having production fluctuation related operational issues that are not related to the reservoir characteristics, TDM is capable of deconvoluting the training process to better history match this operation constraint.

\subsubsection{RESOLUTION IN TIME AND SPACE}

Resolution in time and space is a function of the total number of wells and the length of their production; it signifies that TDM is appropriate for mature fields only with a reasonable amount of production history to learn.

TDM accounts for field development phases since not all wells drilled in the same time; therefore data is presented into different fashions: static data, dynamically modified static data, and dynamic data, hence drainage area in TDM changes with these bases using two interconnected grid systems; Cartesian and polygon-based; the Cartesian used for well-based static characteristics and the polygon-based grid system used for dynamically modified that represent the average static characteristics of the drainage volume.

The first grid system divides the field into fine squares approximately 1 acre. The grid at the well location includes the static properties of that well, and then data is populated using geostatistics entirely. Alternatively, the second grid system represents an ultimate drainage area accessible to a well during the different development phases of the field.

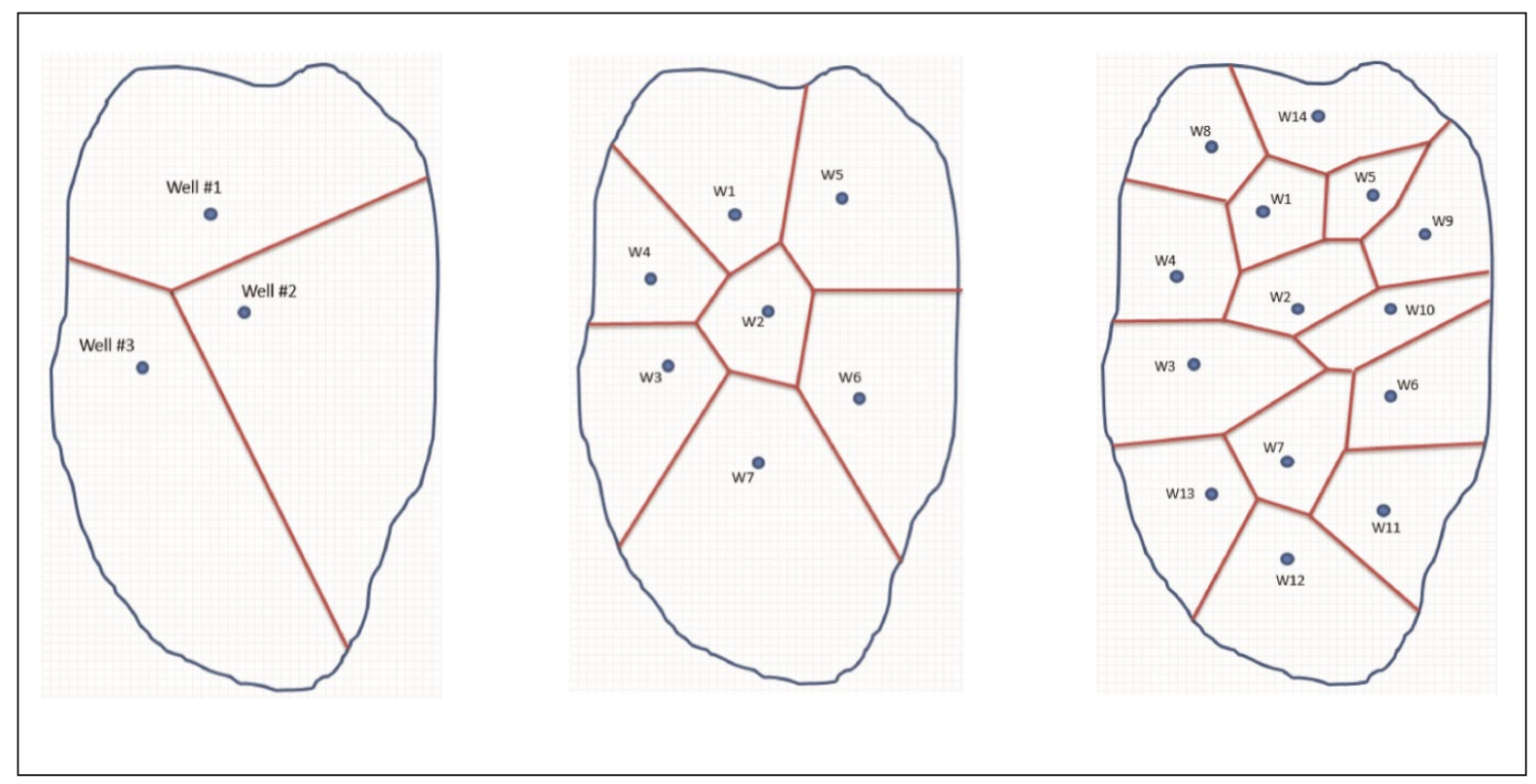

Figure 1: Example of Cartesian and polygon-based grid systems during filed lifespan (Mohaghegh, 2017) 


\subsubsection{SPATIO-TEMPORAL DATABASE STRUCTURE}

Having offsets for each well increases the understanding of the fluid flow as all wells get involved multiple times as offset to their surroundings. What makes TDM advantageous over numerical streamline simulation is that it doesn't use specific formulation that is constant among all simulations; instead, TDM learns the communication between wells in each reservoir differently based on reservoir characteristics, including geological nuances such as faults. Not limited to geology, TDM understands well trajectories and completions, as well as the operational constraints.

The number of offset wells for TDM is selected based on reservoir engineering commonsense; a reservoir with a higher permeability expects more offsets as compared to a tight reservoir. The same applies to the field age, wells spacing, and formation thickness. The Spatio-temporal database generates sectors based on focal wells number. Each sector includes the focal well and the offset wells, generating two sets of records; the first classified as time-independent such as: well construction and trajectory characteristics, static parameters, polygon-based static parameters for focal wells, and offsets, and completion characteristics. While the other is time-dependent, generated as a series of records at a time ( $t$ ) for the first sets of records such as the operational constraints for focal and offset wells, production and injection rates, completion changes, and the number of days of production. Figure 2 shows multiple examples of sectors for a developed field in the Middle East. The green and grey shades represent the focal and offsets, respectively. 


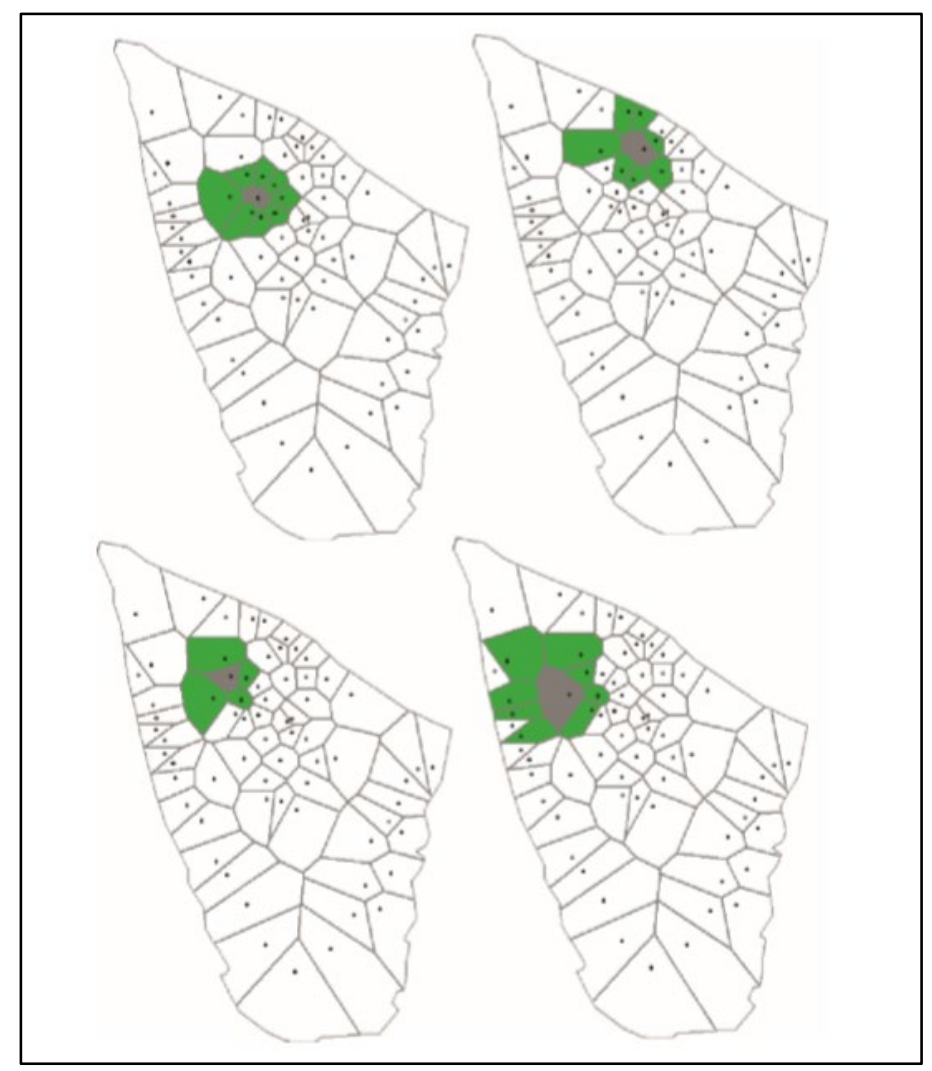

Figure 2: Example of Spatio-temporal database sectors for a developed field in the Middle East (Mohaghegh, 2017)

\subsubsection{FEATURE SELECTION}

Once data generated using the Spatio-temporal database, an option in TDM allows for feature selection to exclude the parameters that have the least impact on the time-dependent variables because as robustness increases, TDM validity decreases, which are known for TDM as the curse of dimensionality (Mohaghegh, 2017).

The technology used to accomplish feature reduction in TDM is fuzzy cluster analysis. To better understand this approach, we understand that porosity, oil saturation, pay thickness together accounts for hydrocarbon pore volume (HPV), TDM uses feature selection algorithm to decide the most influential parameter among the four variables. 


\subsubsection{FUZZY LOGIC}

Inspired by the human brain, Fuzzy logic approximate reasoning by defining the degree of membership in vague data instead of the crisp bivalent manner. Approximating reasoning is held through fuzzy rule; using operators and ("If," "Then") to assign membership to fuzzy linguistics ("High," "Low," "Good"), while the engine that assists in defining relations based on fuzzy rules sets is called Fuzzy Inference (Mohaghegh, 2017)

Given the following example: using Mamdani's inference method (Jamshidi, Vadiee, \& Ross, 1993) to find the relationship between reservoir development cost and total reserve to estimate the likelihood of reservoir development. Based on fuzzy membership, reservoir development costs defined as ("Low," "Moderate," and "High"). On the other hand, the total reserve is represented by its membership "Low," "Moderate," and "High". With having 9 memberships, 9 rules fires in parallel. The output is a result of the intersection between the two input variables using the operator "And" at every 2 memberships rule.

In Figure 3, crisp values for reservoir development cost and total revenue were used as an input, fuzzified later to a membership between 0 and 1 followed by firing parallel rules using fuzzy operators for approximating reasoning. Results are combined and defuzzied Later to produce crisp results.

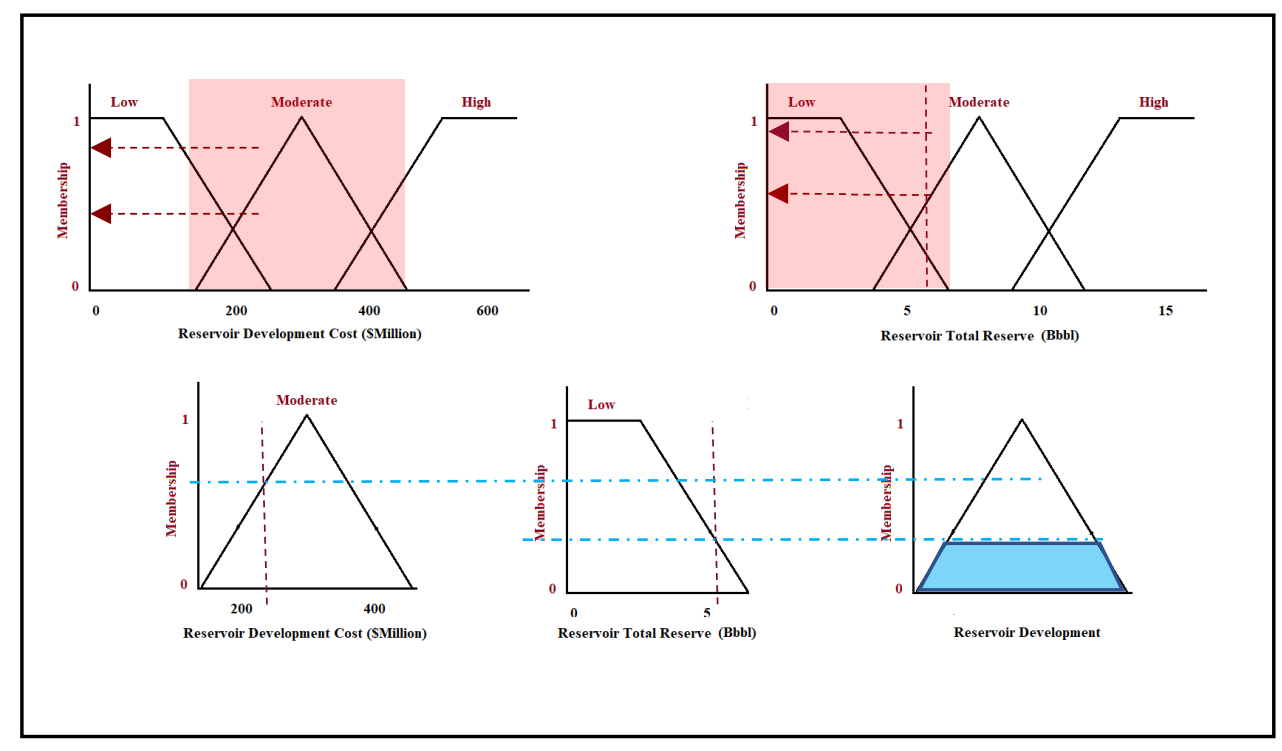

Figure 3: Example of fuzzy rule for approximation Reasoning 


\subsubsection{DATA-DRIVEN RESERVOIR MODELING}

Having observed that most of the reservoir engineers may question field measurement certainty rather than the numerical simulation approach during modeling if the results don't match the reality. TDM takes a different approach in a manner that doesn't assign deterministic nonflexible functional relationships among field static and dynamic measurements; instead, TDM finds relationships between inputs and outputs that explained in the Spatio-temporal database. This approach accomplished using machine learning artificial neural networks, and the output is a matrix of coefficients that are used later for deploying the TDM. After feature and input selection, TDM requires toning: dataset partitioning, neural network topology, and the structure. And lastly, TDM is trained and deployed. Yet, it is imperative to understand the basics of artificial neural networks first (Mohaghegh, 2017).

\subsubsection{ARTIFICIAL NEURAL NETWORK TRAINING}

Understanding Neural Networks requires Neuroscience understanding. Neuroscience explains how the brain learns at the molecular level; the human brain consists of a dense network of fibers pathways with more than 1010 neurons. Information gathered by different senses is carried through the synapses within the network pathway to short-term memory. After processing the short-term memory, the human brain compares the inputs with the previously stored in the long-term memory; however, degradation of memory can occur due to the billions of neurons that race in the same time with different information from the axons through the synapses to the other axon which is the reasoning why our memories are fake or not complete. The last may overcome by strengthening the connections. Scientists believe that strengthened connection between brain cells improves learning, this is easily understood while comparing the fact of our daily basis practices, since the neurons communicated so often, they formed a tight bond connection, and they comprehend their path so that they can be retrieved when needed (Donald J. Ford, 2011).

Artificial neural networks mimic the human brain; it consists of collections of neurons that organized in a multi-layer network: the input layer, hidden layer, and output layer. The input layer consists of neurons that correspond to the input variables, and the same applies to the output layer. While the neurons in the hidden layer are responsible for featuring and pattern recognition, while the strength of connections between neurons defines the learning.

One of the most popular Neural Networks used in the oil industry is the Supervised Learning after feeding inputs and outputs, using a specific topology and algorithm, the neural network trained until the network output converges to actual output (Schuld \& Petruccione, 2016). Supervised learning divided into 3 portions: training, calibration, and verification. In the training process, weights between neurons are adjusted until convergence is achieved through backpropagations iterative process (Haykin, 2009); however, If the model over trained, memorization occurs, and generalization is difficult to achieve. Nevertheless, Since the calibration data 
absent in training, it can help to verify training generalization capabilities (Hernandez, 2016). Once calibration is done, validation can take place to verify the entire model.

Figure 4 show several interconnected layers with different sets of neurons. The neuron works as a processing element that analyzes inputs and assigns weight (wi) to them, weights represented by the strength of the connection between the neuron and the next layer. Once the weight is assigned, the total input signal at neuron level summed, comparing them with other hidden neurons threshold levels through an activation function to decide what neuron to fire to the next level (Haykin, 2009).

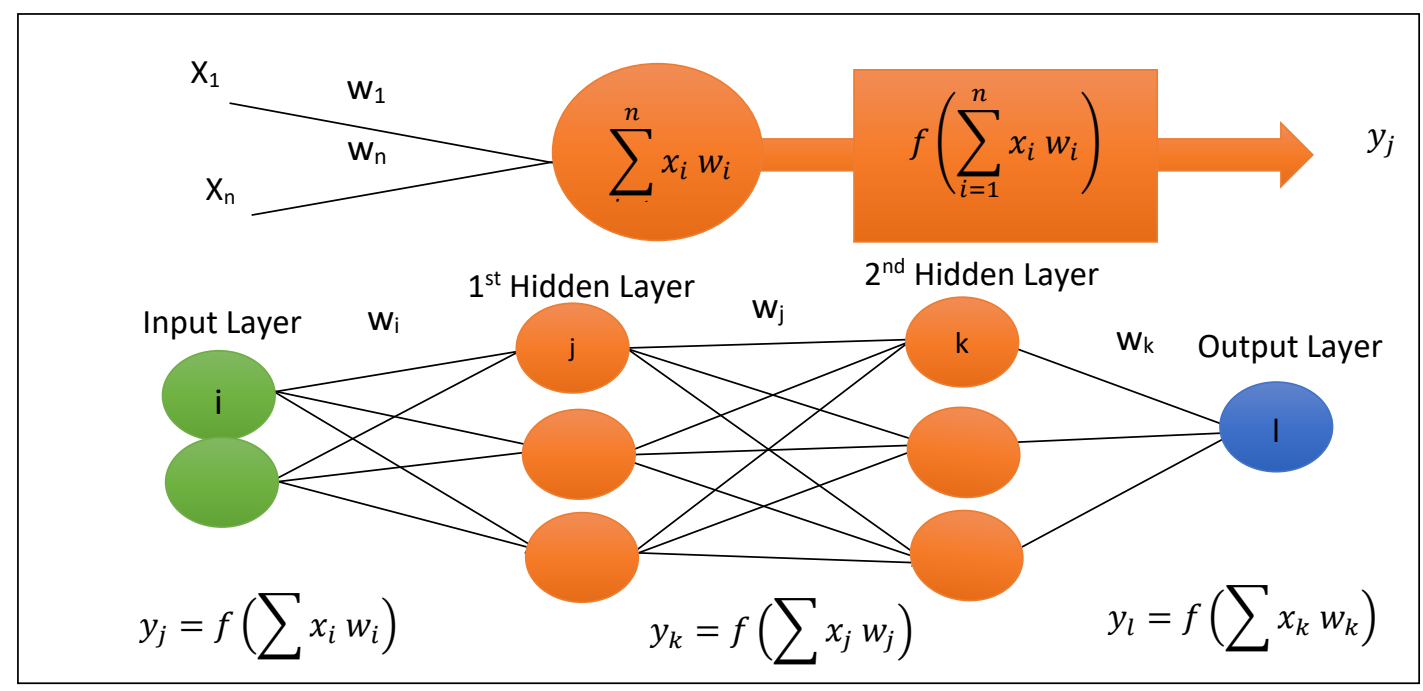

Figure 4: Schematic of multi-Layer neural network operations

\subsubsection{DATASET PARTITIONING}

When inputs for the neural network are selected, the next step is to assign portions of the dataset for training, calibration, and validation. The role of the training is to define the strength of the connection between neurons, represented by weight in each connection, and the optimal value of weights used to calculate the output. Partitioning dataset for training could fall in range (40-80) \%.

On the other hand, calibration could fall between 10 and $30 \%$, and it play a role in checking training generalization capabilities that are represented by the metric correlation coefficient R2 or the mean square error MSE; however, calibration play no role in defining weights between neurons, it only decides when to stop the training.

The third relevant category that defines the success of the predictive models in history matching is called verification. The verification data set is set aside during the entire training process; therefore, it validates the 
predictive model capabilities in history matching an utterly new dataset. Verification partitioning in history matching divided into 3 categories: Sequential history matching, random history matching, and mixed history matching.

Sequential history matching is done through dividing training, calibration, and verification dataset sequentially, while random history matching selects training, calibration, and verification in a completely random manner. On the contrary, mixed history matching is a combination of the 2 methods that have the same assets for the verification; however, training and calibration randomly selected (Mohaghegh, 2017).

\subsubsection{TOPOLOGY AND STRUCTURE}

Generally, within neural networks, the structure and topology are a function of different factors, including the number of hidden layers, number of hidden neurons, the combination of the activation functions, the structure, and the nature of the connection between neurons which result in an infinite number of approaches.

TDM uses fully connected neural networks, and it consists of 3 layers: an input layer, hidden layer, output layer. The structure of neural networks in TDM considered a simple structure, so a significant part of the success is related to the assimilation and the affiliation of the Spatio-temporal database (Mohaghegh, 2017), and that why data-driven reservoir modeling require reservoir engineer rather than a computer engineer.

The parameters that adjusted in TDM neural networks: the learning rate, momentum, number of hidden neurons, and the activation functions. The learning algorithm used by TDM is known as "backpropagation" (Haykin, 2009) which involve calculating outputs based on the strength of the connections between the synapses, comparing the calculated output to the actual ones, then backpropagate to enhance the strength of the connection till convergence occur.

\subsubsection{TDM DESIGN AND DEPLOYMENT}

Once predictive models generated, crisp and fuzzy rules known as the intelligent agent in TDM evaluates and initiates the execution and implementation of the generated predictive models to fulfill the multiple constraints for the entire field as well as honoring the effect of physics and geology, reservoir management and surface facilities (Mohaghegh, 2017).

The predictive model's key output depends on the project objective, and it is a function of cause and effect; for example, when oil produce at time $t$, reservoir pressure decreases at time $t-1$, as well as, water saturation increases at time $\mathrm{t}-1$. So, when we generate predictive models, oil at time $\mathrm{t}$ doesn't have water saturation at a time 
$\mathrm{t}$; instead, it has it at time $\mathrm{t}-1$. Then when predictive models generated, an intelligent agent controls data trafficking among the generated models and implies the constraints stated previously. Another example explained if the objective of the model is to model reservoir pressure, reservoir engineer understands that deferential pressure allows well to flow, hence, oil and water rate can choose at time $t$ and $t-n$ for focal wells; however, offset wells production affects the focal well at time $\mathrm{t}-1$ because of their drainage area.

In conclusion, the author's impression on TDM is that it is a tool that is far away from statistics; it is a form of evolution of numerical reservoir simulation using data. Since empirical formulations built-in laboratories based on tests and statistics, they were then followed by upscaling on field level that is way more complex, especially in unconventional reservoirs. Instead, data-driven reservoir modeling is considered a reservoir modeling tool on the actual scale. 


\section{CHAPTER III}

\section{METHODOLOGY}

Testing TDM capabilities in history matching commingled layers allocation achieved in three stages, the first involved developing numerical reservoir model that satisfies the objectives. Secondly, developing the TDM, and lastly comparing both TDM and Numerical reservoir simulation results to test if TDM was successful in matching the numerical reservoir simulation model.

\subsection{NUMERICAL SIMULATION MODELING}

A black oil model developed with a heterogenous anticline structure consisted of $67,600 * 6$ grid blocks with $55.25 \mathrm{ft} * 50.05 \mathrm{ft}$ grid size. The model encompasses three permeable layers sealed with three impermeable layers with both aquifer and injector support, as shown in Figures 5 and 6 .

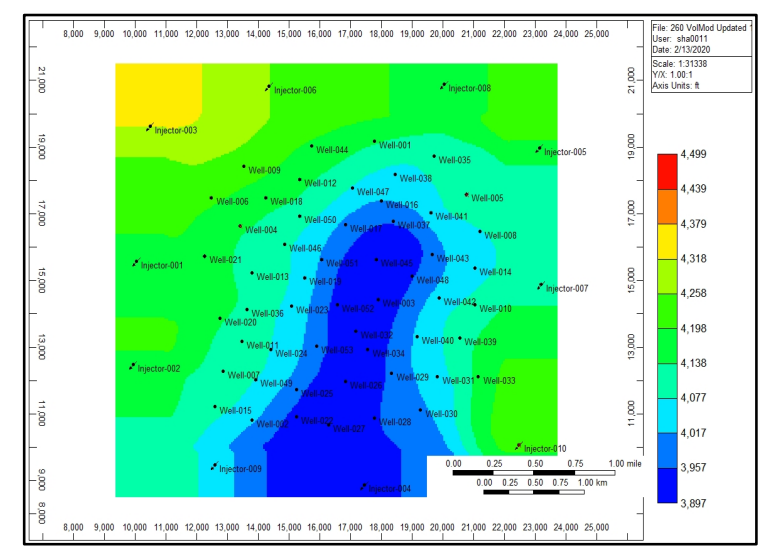

Figure 5: 2D Layer 1 top map 
As layers were $100 \%$ sealed, there is no pressure communication window across; however, pressure variation across layers was created through the anticline structure. Moreover, immense pressure variation was created as a function of the multi-depletion plan per well in terms of production and injection as the first objective is to test the static $\mathrm{KH}$ modeling in picking production patterns per comingled layers as well as testing TDM capabilities in picking these pattern with a simplistic reservoir simulation model of one rock type single porosity model.

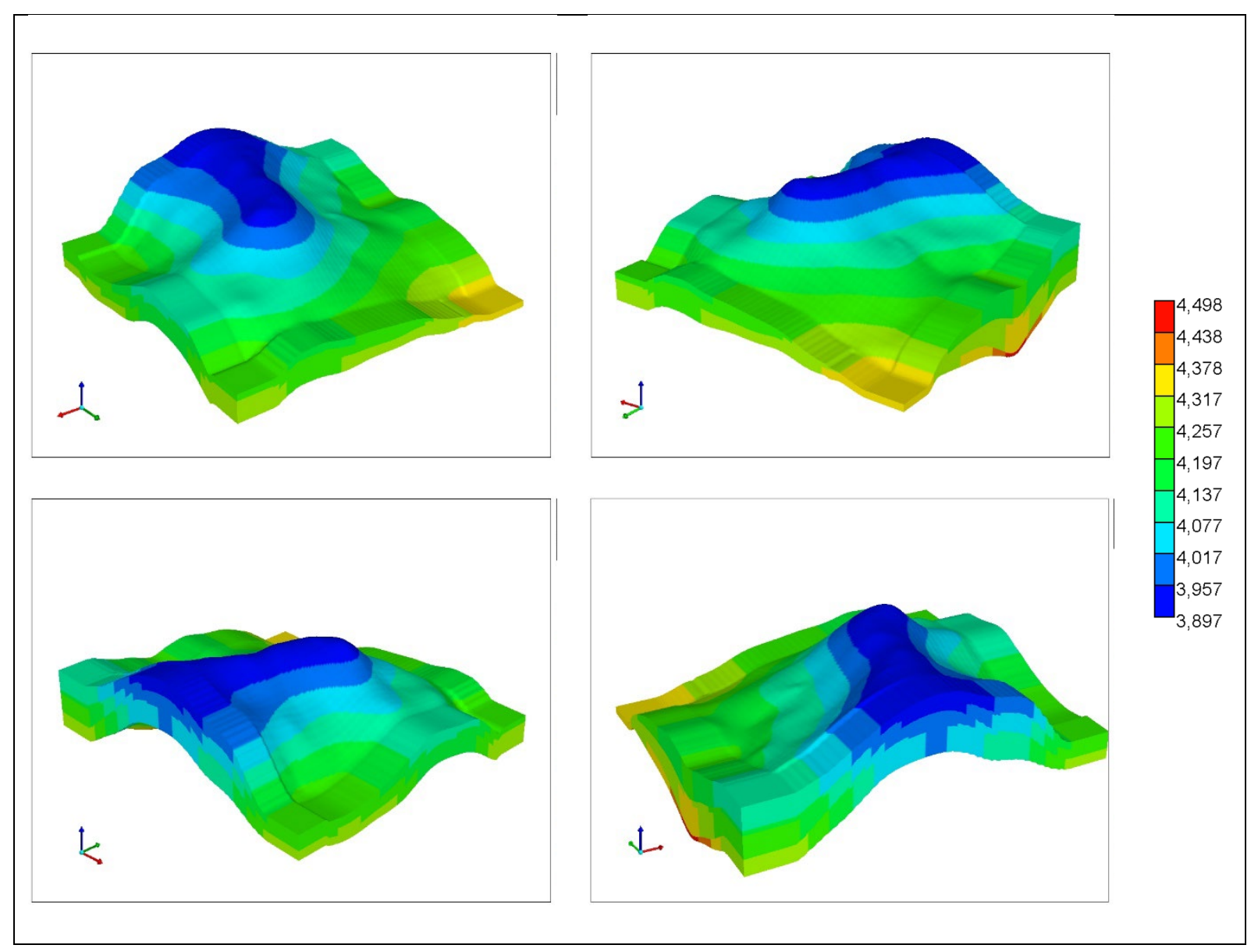

Figure 6: 3D reservoir top map 


\subsubsection{RESERVOIR CHARACTERISTICS}

For mimicking reality, heterogeneity was added among porosity, permeability, and thickness. The reservoir model used a single porosity and permeability model across the grid cell. The model included one rock type across all the layers, Figure 7 shows relative permeability throughout the reservoir layers, while Figure 8 shows porosity and permeability distributions in J direction.

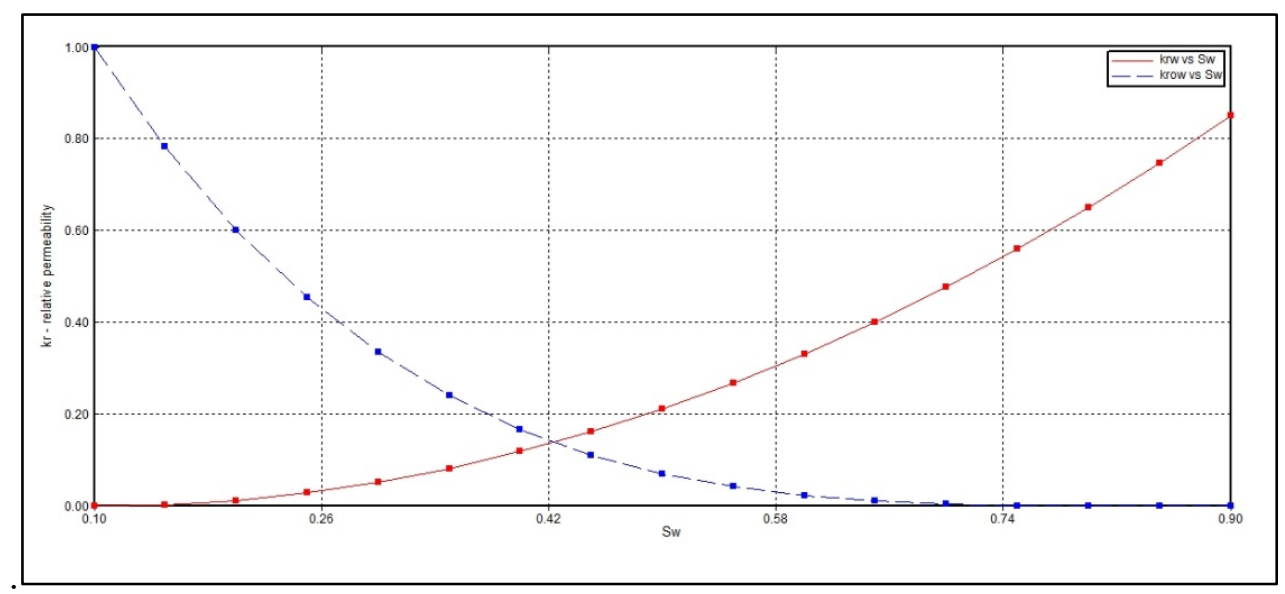

Figure 7: relative permeability versus water saturation

It is essential to understand that the current model is way simplistic as compared to the reality that different layers possess different fluids properties resulting in different mobility across layers as a function of pressure and temperature; however, this model assumes similar fluids properties across the reservoir. On the other hand, heterogeneity added more complexity by limiting pressure communication through channeling, especially in layers 1 and 3, while Layer 6 classified as an amalgamated formation with more pressure communication.

These earlier complexities meant to test the effect of reservoir pressure on the production profile in commingled layers as the depletion surge and swap effect is crucial on commingled layers allocation estimation on the reservoir level individually, adding high uncertainties to the static allocation modeling. 


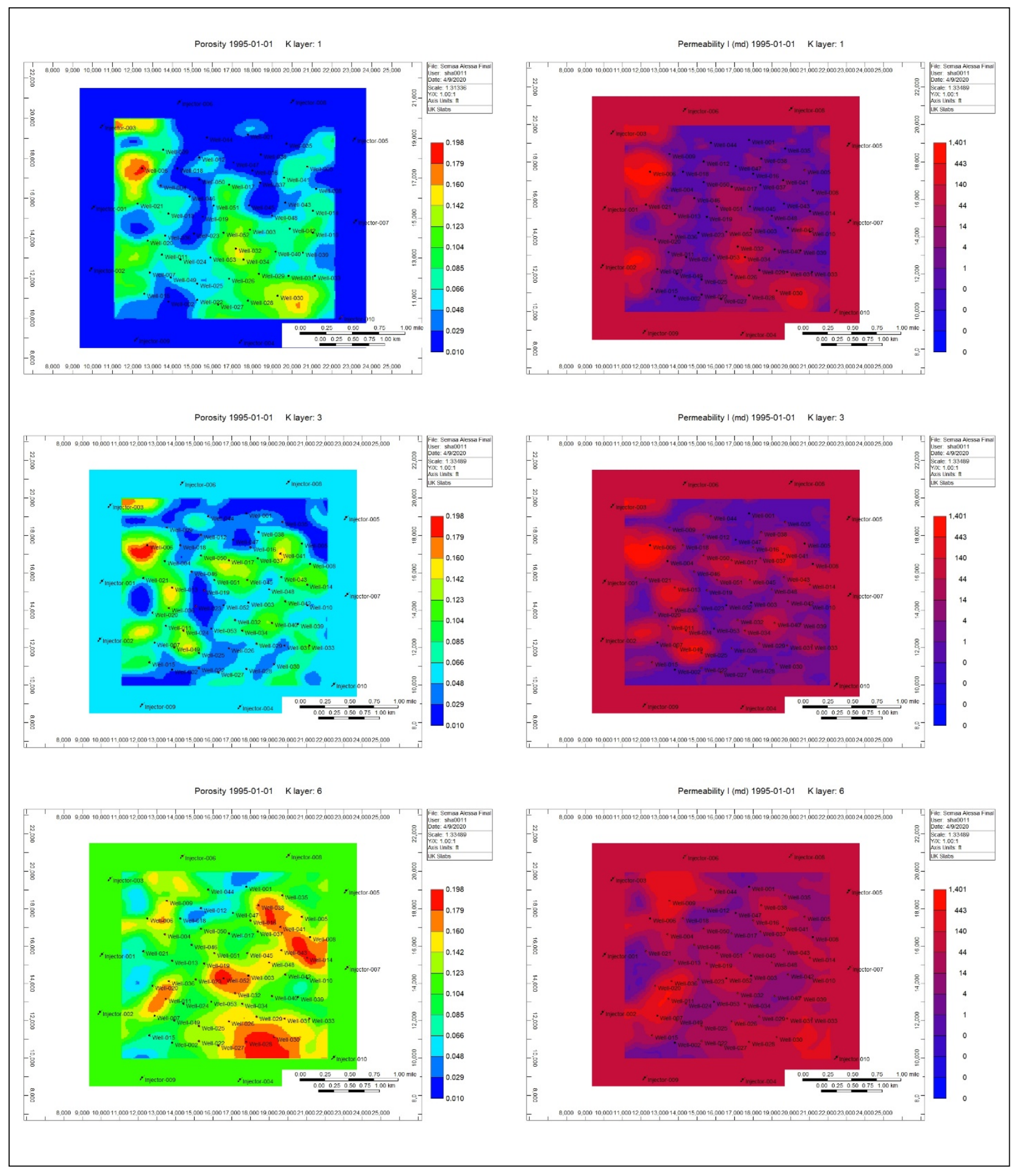

Figure 8: Layers 1, 3, and 6 porosity (left) and permeability (right) respectively 


\subsubsection{DEPLETION PLAN}

The depletion plan mainly objective is to create as much turbulence in the reservoir pressure by adding multi random completion schemes for wells individually. The design was to drill 53 wells on different phases, as shown in Figure 9, furthermore changing completions among layers yearly to create comingled and noncomingled completions.

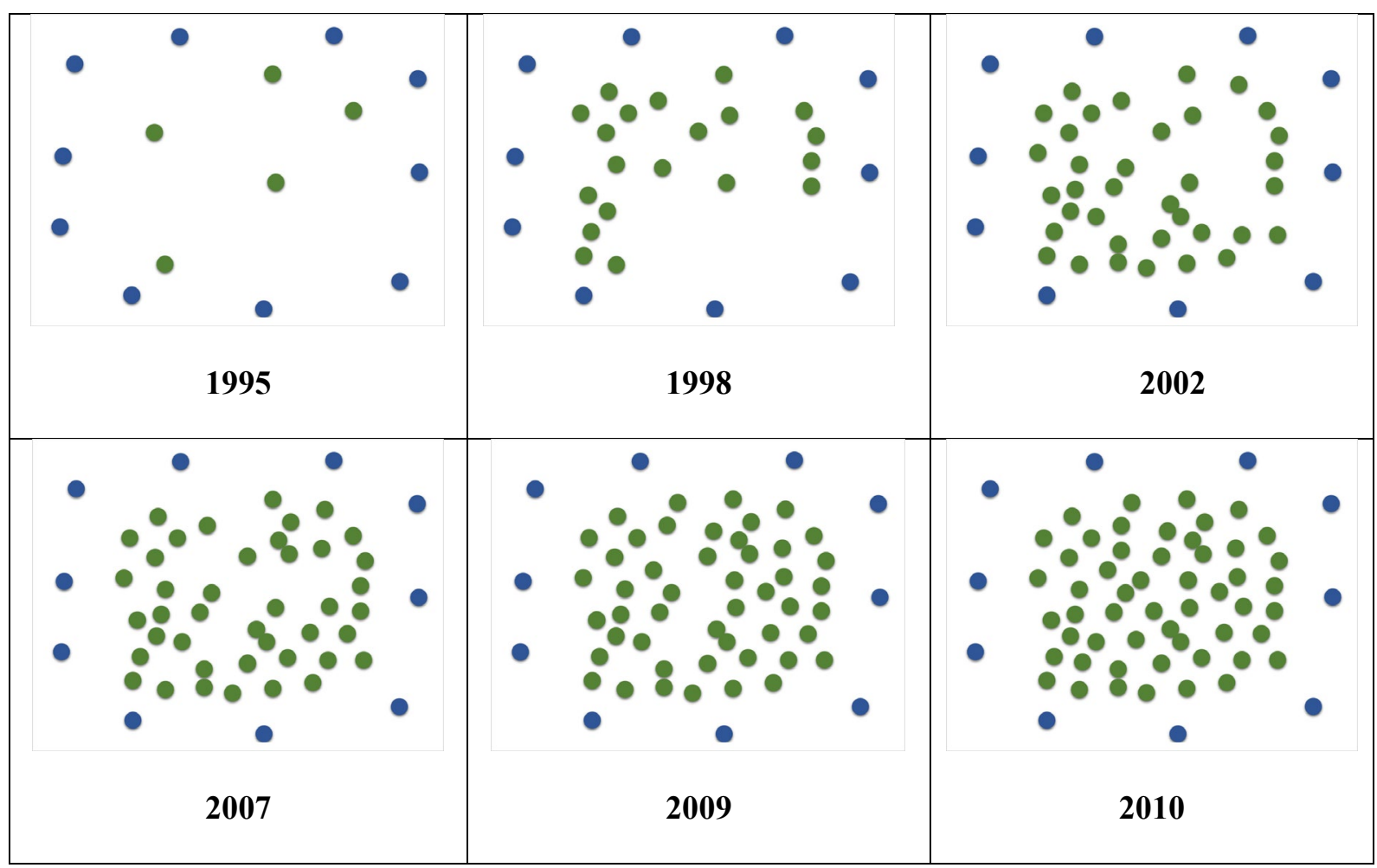

Figure 9: Reservoir development phases

Since aquifer support was not enough, ten injectors added for pressure support and better sweep efficiency. Injector completions divided into two stages; Injector-001-Injector-005 will inject for a longer time in particular layers more than the others to mimic the reality that some wells are not injecting enough in specific segments due to integrity or skin build issues. The other phases of injection through Injector-006-Injector-010 will inject in different layers for shorted time steps. Figures 10 and 11 show yearly production and injection distributions among layers, respectively. 


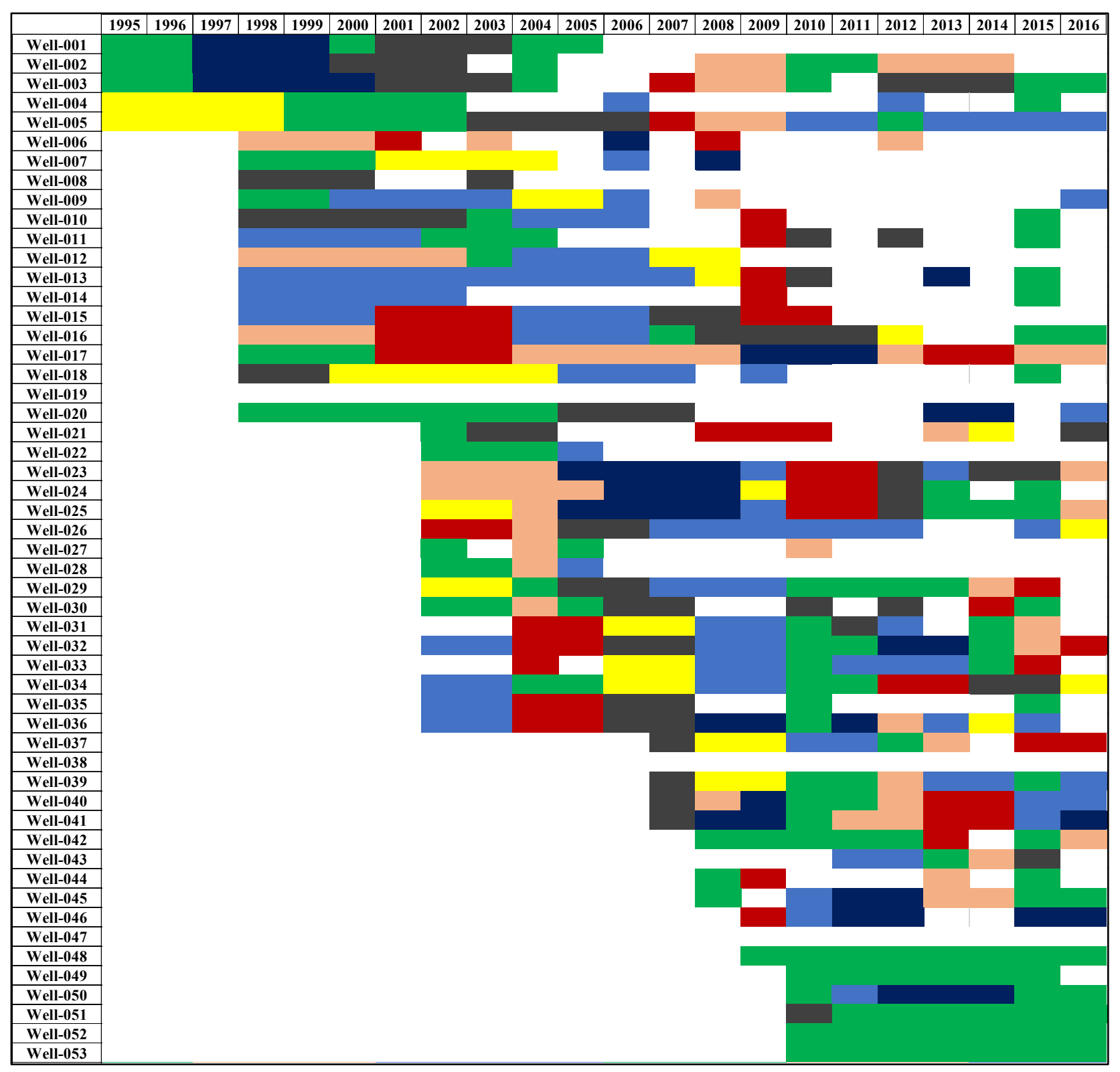

\begin{tabular}{|c|c|}
\hline Opened Layers & Color Code \\
\hline $1,3,6$ & \\
\hline 3,6 & \\
\hline 1,6 & \\
\hline 1,3 & \\
\hline 6 & \\
\hline 3 & \\
\hline 1 & \\
\hline
\end{tabular}

Figure 10: Producers yearly completion schemes 


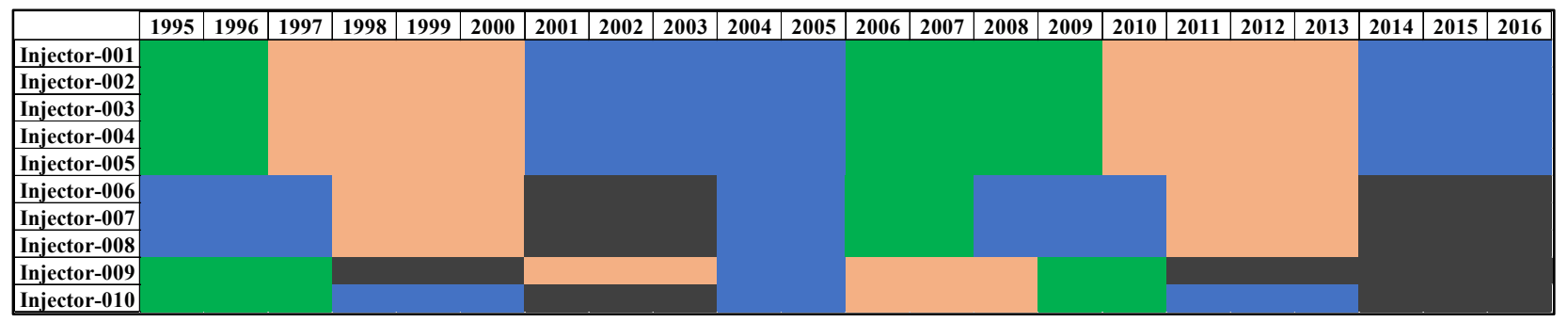

\begin{tabular}{|c|c|}
\hline Opened Layers & Color Code \\
\hline $1,3,6$ & \\
\hline 3,6 & \\
\hline 1,6 & \\
\hline 1,3 & \\
\hline 6 & \\
\hline 3 & \\
\hline 1 & \\
\hline \hline
\end{tabular}

Figure 11: Yearly injection plan

\subsubsection{WELLS CONSTRAINTS}

The modeled constraints involved the following operations:

- Shut-off the layer with higher water break through if total layers water cut $>90 \%$

- Shut-in the well if the total oil rate $<50 \mathrm{bbl} / \mathrm{d}$

- Shut-in the well if the bottom hole flowing pressure (BHFP) $<=1500 \mathrm{psi}$ (bubble point pressure)

Figure 12 shows the total months of production after applying the constraints. It is vital to make sure that data achieve the requirements of data availability in time and space for the next stage in TDM once operation constraints added while polygons highlight the lack of particular completion pattern, which might be useful to study in case of cross-flow between layers was an option. 


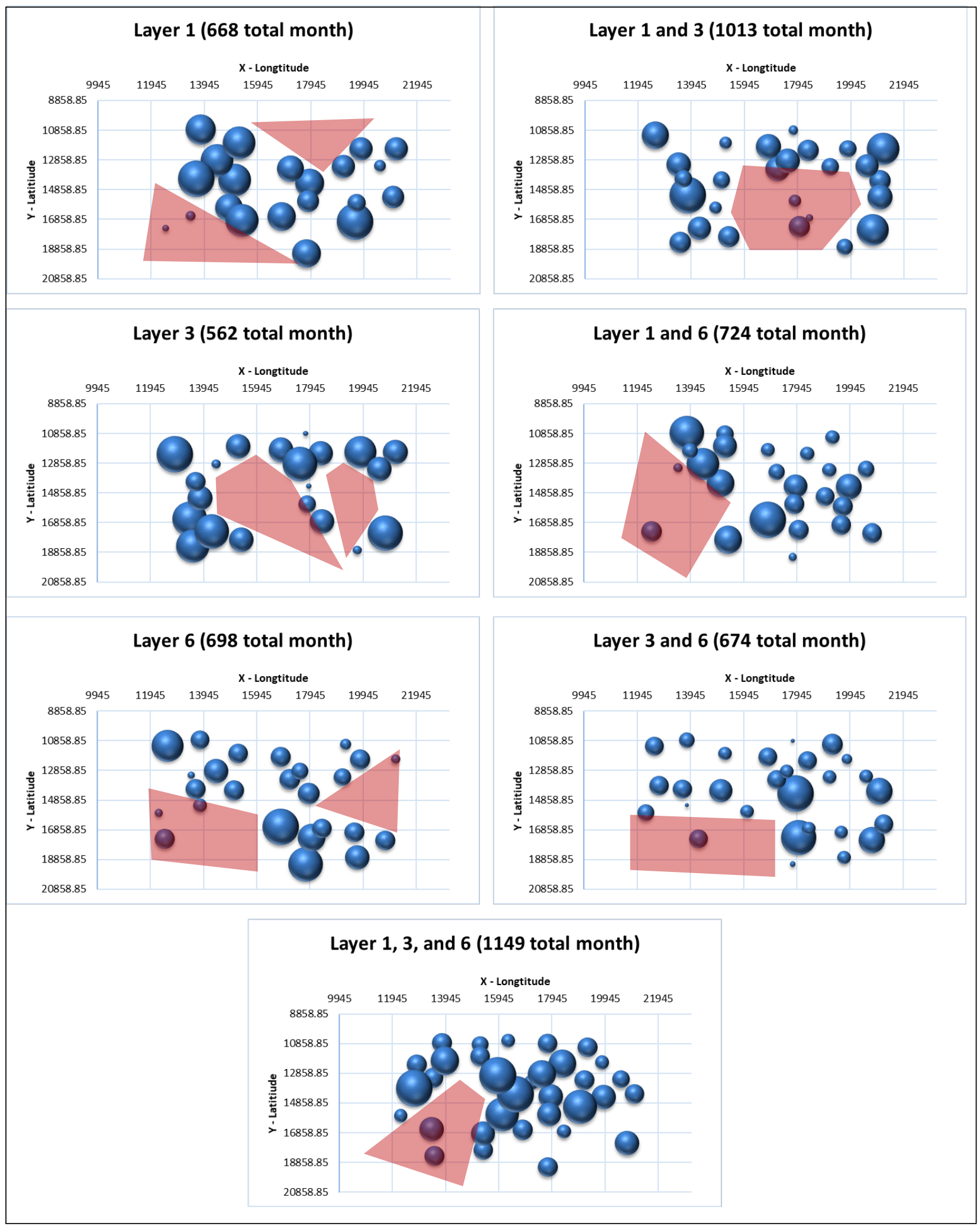

Figure 12: Bubble map of the monthly open layer's distributions among completion schemes 


\subsubsection{DYNAMIC DATA}

As planned to challenge TDM; depletion, and completion schemes were set to simulate the complexity of the reservoir system, and one of these scenarios was the sweep efficiency. Since injection through layers operated with multiple frequencies, a considerable impact exhibited. Figures 13, 14, and 15 show residual oil as a result of the depletion plan and the heterogeneous reservoir characteristics such as permeability. The Figures also show the pressure window of the injectors detected by the high-pressure zones along with the observed water production.

Table 1 gives some information regarding the total production and injection per layer; showing that oil is being depleted in different portions as Layer 6 contributes to $54.6 \%$ of the total oil production, while Layer 1 and 3 contribute to $21.4 \%$ and $23.9 \%$ respectively. On the other hand, the recovery factor (RF) was higher in Layer 6 considering the amalgamated homogeneous structure.

Table 1: Cumulative Production and Injection Rates Per Reservoir Layer

\begin{tabular}{|c|c|c|c|c|c|}
\hline Layer & $\begin{array}{c}\text { Cumulative } \\
\text { Oil } \\
\mathbf{( b b l )}\end{array}$ & $\begin{array}{c}\text { Cumulative Gas } \\
\left.\mathbf{( f t}^{\mathbf{3}}\right)\end{array}$ & $\begin{array}{c}\text { Cumulative } \\
\text { Water } \\
\mathbf{( b b l )}\end{array}$ & $\begin{array}{c}\text { Cumulative } \\
\text { Injection } \\
(\mathbf{b b l})\end{array}$ & $\begin{array}{c}\text { RF } \\
(\mathbf{\%})\end{array}$ \\
\hline $\mathbf{1}$ & $27,493,966$ & $11,476,723,179$ & $13,257,933$ & $45,638,452$ & 55 \\
\hline $\mathbf{3}$ & $30,668,525$ & $12,801,869,114$ & $18,236,068$ & $55,285,248$ & 56 \\
\hline $\mathbf{6}$ & $70,140,044$ & $29,278,345,381$ & $31,345,138$ & $114,403,437$ & 59 \\
\hline
\end{tabular}

Significant vertical pressure variation among the three layers detected in Figure 16 as Layer 6 depleted at a higher rate as compared to Layer 3 and Layer 1. It helps test the efficiency of the static KH modeling in allocating commingled layers with different differential pressures as well as testing TDM capabilities in picking these intricate pressure patterns for history matching. 


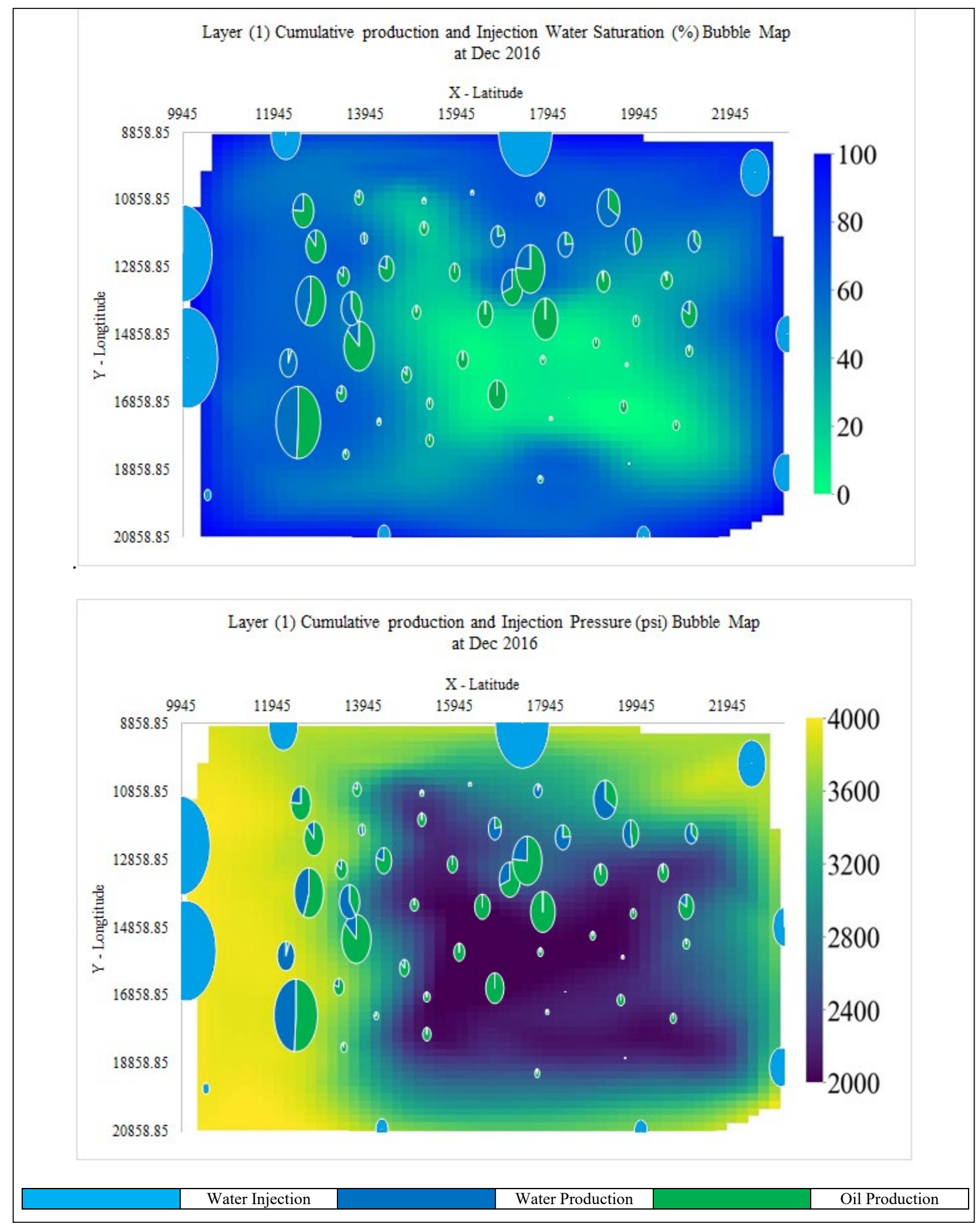

Figure 13: Layer 1 Cumulative Bubble Map across water saturation and reservoir pressure 


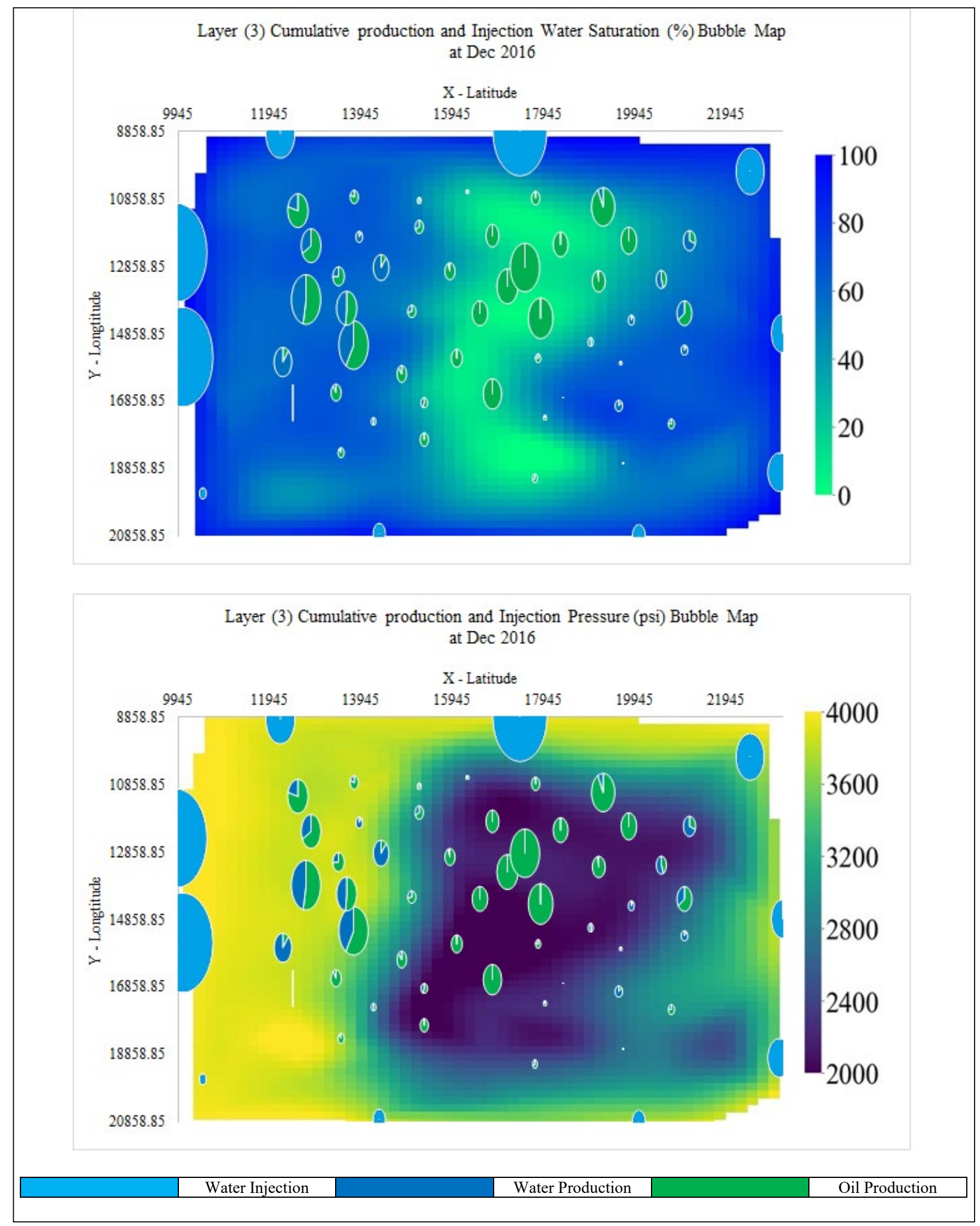

Figure 14: Layer 3 Cumulative Bubble Map across water saturation and reservoir pressure 


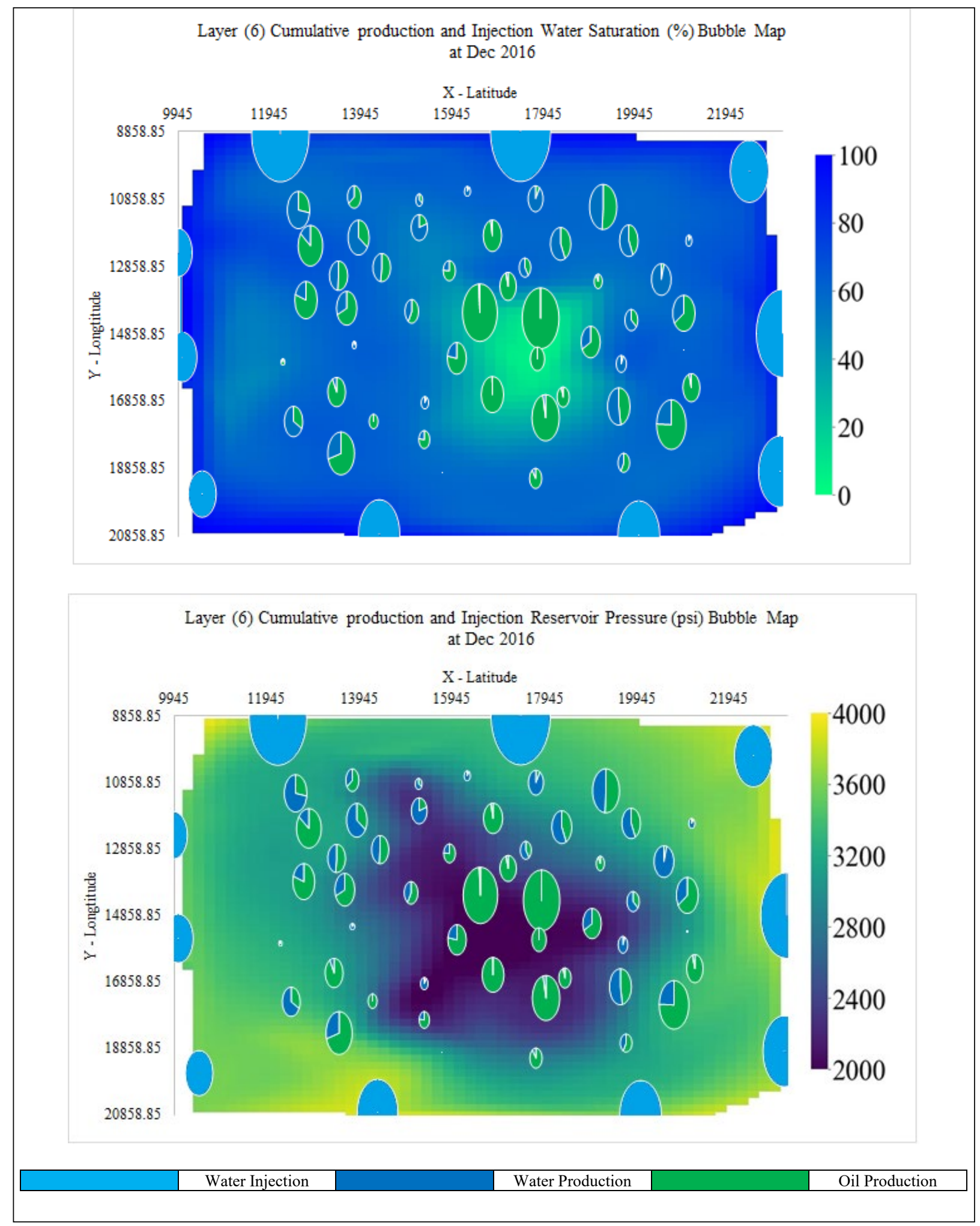

Figure 15: Layer 6 Cumulative Bubble Map across water saturation and reservoir pressure 


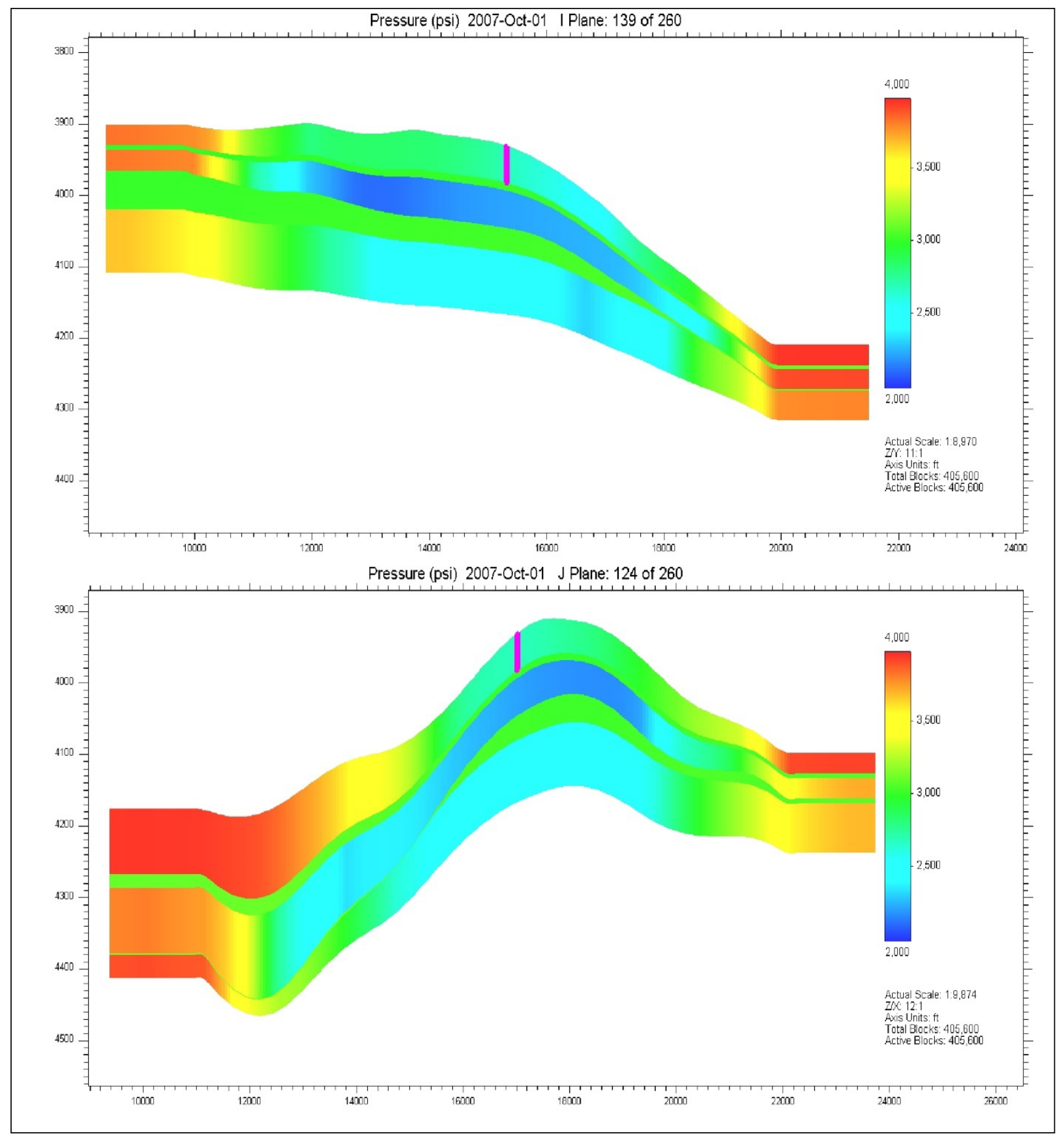

Figure 16: Pressure map in I and J direction showing vertical pressure variation across layers 


\subsubsection{STATIC KH MODELING}

For the purpose of comparing numerical reservoir modeling with the KH static modeling, $\mathrm{KH}$ derived rates were calculated using the following technique:

$$
\mathrm{q}_{\mathrm{i}}=\mathrm{q}_{\mathrm{t}} \frac{\mathrm{k}_{\mathrm{i}} \mathrm{h}_{\mathrm{i}}}{\sum_{\mathrm{i}=1}^{\mathrm{n}} \mathrm{k}_{\mathrm{i}} \mathrm{h}_{\mathrm{i}}}
$$

Where:

$$
\begin{aligned}
& \mathrm{k}_{\mathrm{i}}=\text { horizontal permeability per layer } \mathrm{i} \\
& \mathrm{h}_{\mathrm{i}}=\text { thickness per layer } \mathrm{i} \\
& \mathrm{q}_{\mathrm{t}}=\text { total flow rate of oil and water }
\end{aligned}
$$

While oil and water rates were calculated using the following equations:

$$
\begin{gathered}
\mathrm{q}_{\text {oil }, \mathrm{i}}=\mathrm{q}_{\mathrm{i}}\left(100-W C_{i} \%\right) / 100 \\
\mathrm{q}_{\text {water }, \mathrm{i}}=\mathrm{q}_{\mathrm{i}}\left(W C_{i} \%\right) / 100
\end{gathered}
$$

Where:

$W C_{i} \%=$ Water cut percentage per layer

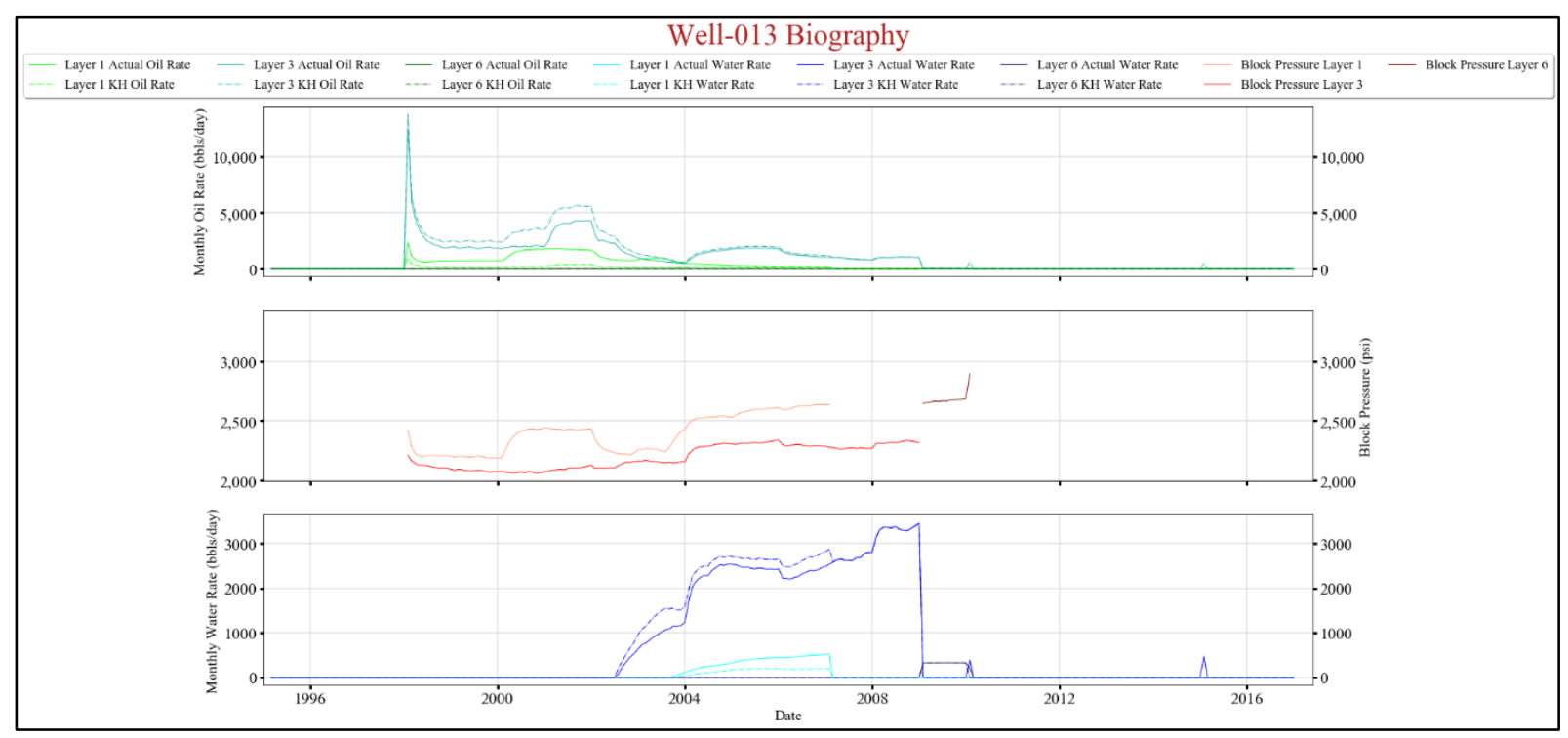

Figure 17: Numerical Reservoir Simulation (Actual Rates) versus KH Modeling (KH Rates) 


\subsection{TOP DOWN MODELING}

TDM is consisted of three main processes: data preparation, static modeling, and top-down modeling.

\subsubsection{DATA PREPARATION}

Data preparation must follow a specific manner and format. In this thesis, the following data was fed into the TDM tool (IMagine ${ }^{\circledR}$ ) for the 63 wells:

Table 2: Summary of Layer input variables to IMagine ${ }^{\circledR}$

\begin{tabular}{l}
\hline \multicolumn{1}{|c|}{ Static Data } \\
\hline - Latitude \\
- Longitude \\
- Top \\
-Pay Thickness \\
-Porosity \\
-Permeability
\end{tabular}

Dynamically Modified Static Data
- Reservoir Pressure
- Bottom-Hole Flowing Pressure
-Water Saturation
-Water Injection

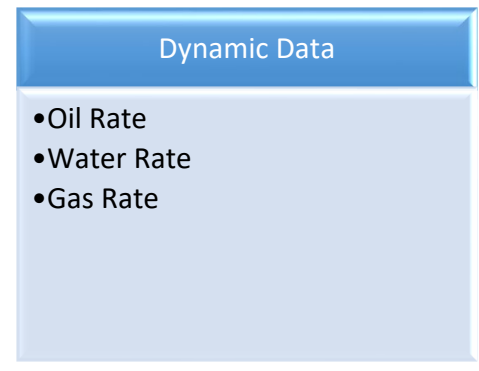

\subsubsection{STATIC DATA}

An Example of static data is shown for Layer 1 in Figure 18.

\begin{tabular}{|c|c|c|c|c|c|c|c|c|c|}
\hline Well Name & Type & $X(f t)$ & $\mathrm{Y}(\mathrm{ft})$ & Top (ft) & Bottom (ft) & Thickness (ft) & Phi (\%) & Swi (\%) & $\mathrm{K}(\mathrm{md})$ \\
\hline Well-001 $\{153,47,1\}$ & $\mathrm{P}$ & 17790.5 & 19169.15 & 4145.21 & 4170.38 & 25.1646 & $3 \%$ & $8 \%$ & 1.11167 \\
\hline Well-002\{81,214,1\} & $P$ & 13812.5 & 10810.8 & 4023.62 & 4076.34 & 52.7234 & $2 \%$ & $5 \%$ & 1.0207 \\
\hline Well-003\{155,142,1\} & $\mathrm{P}$ & 17901 & 14414.4 & 3919.62 & 3967.22 & 47.5914 & $11 \%$ & $4 \%$ & 19.1276 \\
\hline Well-004\{74,98,1\} & $\mathrm{P}$ & 13425.75 & 16616.6 & 4148.82 & 4219.86 & 71.038 & $4 \%$ & $0 \%$ & 3.89959 \\
\hline Well-005\{207,79,1\} & $\mathrm{P}$ & 20774 & 17567.55 & 4095.68 & 4114.95 & 19.2732 & $7 \%$ & $5 \%$ & 1.90208 \\
\hline Well-006\{57,81,1\} & $P$ & 12486.5 & 17467.45 & 4209.26 & 4263.4 & 54.1387 & $18 \%$ & $0 \%$ & 1078.25 \\
\hline Well-007\{64,185,1\} & $P$ & 12873.25 & 12262.25 & 4112.6 & 4202.13 & 89.5265 & $7 \%$ & $0 \%$ & 20.107 \\
\hline Well-008\{215,101,1\} & $P$ & 21216 & 16466.45 & 4075.41 & 4095.51 & 20.0932 & $5 \%$ & $4 \%$ & 1.48777 \\
\hline Well-009\{76,62,1\} & $\mathrm{P}$ & 13536.25 & 18418.4 & 4229.45 & 4253.33 & 23.8899 & $8 \%$ & $0 \%$ & 2.27293 \\
\hline Well-010\{212,145,1\} & $\mathrm{P}$ & 21050.25 & 14264.25 & 4098.49 & 4144.02 & 45.5259 & $11 \%$ & $5 \%$ & 53.073 \\
\hline Well-011 $\{75,167,1\}$ & $P$ & 13481 & 13163.15 & 4104.83 & 4197.13 & 92.296 & $7 \%$ & $0 \%$ & 2.22795 \\
\hline Well-012\{109,70,1\} & $\mathrm{P}$ & 15359.5 & 18018 & 4158.16 & 4213.49 & 55.3276 & $4 \%$ & $0 \%$ & 1.42399 \\
\hline Well-013\{81,126,1\} & $P$ & 13812.5 & 15215.2 & 4109.36 & 4206.1 & 96.7375 & $8 \%$ & $0 \%$ & 14.8659 \\
\hline Well-014\{212,123,1\} & $\mathrm{P}$ & 21050.25 & 15365.35 & 4053.01 & 4083.78 & 30.7683 & $8 \%$ & $4 \%$ & 1.71129 \\
\hline Well-015\{59,206,1\} & $P$ & 12597 & 11211.2 & 4096.94 & 4176.86 & 79.9229 & $7 \%$ & $4 \%$ & 8.69757 \\
\hline
\end{tabular}

Figure 18: A view of Layer 1 static data 


\subsubsection{DYNAMIC DATA}

Dynamic data and statically modified dynamic data are arranged in a similar format for the 66 wells through 22 years (265 months), as explained in Figures 10 and 11. The following Figure shows an example of the oil rate production data preparation format:

\begin{tabular}{|c|c|c|c|c|c|c|c|c|c|c|c|c|c|c|}
\hline Well Name\Date & 1/1/1995 & 2/1/1995 & 3/1/1995 & 4/1/1995 & 5/1/1995 & 6/1/1995 & 7/1/1995 & 8/1/1995 & 9/1/1995 & 10/1/1995 & 11/1/1995 & 12/1/1995 & $1 / 1 / 1996$ & 2/1/1996 \\
\hline Well-001 $\{153,47,1\}$ & 0 & 54.82589 & 47.20112 & 52.08947 & 53.66534 & 54.73097 & 55.58607 & 56.46095 & 57.14637 & 57.709446 & 57.808804 & 57.677082 & 57.70692 & 57.9481 \\
\hline Well-002\{81,214,1\} & 0 & 102.1748 & 90.22081 & 101.8311 & 108.8191 & 113.3939 & 115.9549 & 118.4325 & 120.2247 & 121.56387 & 122.74226 & 122.79047 & 122.9145 & 123.0239 \\
\hline Well-003\{155,142,1\} & 0 & 1390.329 & 915.1402 & 941.852 & 978.8712 & 1023.613 & 1058.872 & 1092.628 & 1124.063 & 1153.0333 & 1172.8734 & 1187.9187 & 1215.232 & 1230.927 \\
\hline Well-004\{74,98,1\} & 0 & 0 & 0 & 0 & 0 & 0 & 0 & 0 & 0 & 0 & 0 & 0 & 0 & 0 \\
\hline Well-005\{207,79,1\} & 0 & 0 & 0 & 0 & 0 & 0 & 0 & 0 & 0 & 0 & 0 & 0 & 0 & 0 \\
\hline Well-006\{57,81,1\} & 0 & 0 & 0 & 0 & 0 & 0 & 0 & 0 & 0 & 0 & 0 & 0 & 0 & 0 \\
\hline Well-007 $664,185,1\}$ & 0 & 0 & 0 & 0 & 0 & 0 & 0 & 0 & 0 & 0 & 0 & 0 & 0 & 0 \\
\hline Well-008\{215,101,1\} & 0 & 0 & 0 & 0 & 0 & 0 & 0 & 0 & 0 & 0 & 0 & 0 & 0 & 0 \\
\hline Well-009\{76,62,1\} & 0 & 0 & 0 & 0 & 0 & 0 & 0 & 0 & 0 & 0 & 0 & 0 & 0 & 0 \\
\hline Well-010 $\{212,145,1\}$ & 0 & 0 & 0 & 0 & 0 & 0 & 0 & 0 & 0 & 0 & 0 & 0 & 0 & 0 \\
\hline Well-011 $\{75,167,1\}$ & 0 & 0 & 0 & 0 & 0 & 0 & 0 & 0 & 0 & 0 & 0 & 0 & 0 & 0 \\
\hline Well-012 $\{109,70,1\}$ & 0 & 0 & 0 & 0 & 0 & 0 & 0 & 0 & 0 & 0 & 0 & 0 & 0 & 0 \\
\hline Well-013 $\{81,126,1\}$ & 0 & 0 & 0 & 0 & 0 & 0 & 0 & 0 & 0 & 0 & 0 & 0 & 0 & 0 \\
\hline Well-014\{212,123,1\} & 0 & 0 & 0 & 0 & 0 & 0 & 0 & 0 & 0 & 0 & 0 & 0 & 0 & 0 \\
\hline Well-015\{59,206,1\} & 0 & 0 & 0 & 0 & 0 & 0 & 0 & 0 & 0 & 0 & 0 & 0 & 0 & 0 \\
\hline Well-016 $\{157,83,1\}$ & 0 & 0 & 0 & 0 & 0 & 0 & 0 & 0 & 0 & 0 & 0 & 0 & 0 & 0 \\
\hline Well-017 $\{136,97,1\}$ & 0 & 0 & 0 & 0 & 0 & 0 & 0 & 0 & 0 & 0 & 0 & 0 & 0 & 0 \\
\hline Well-018\{89,81,1\} & 0 & 0 & 0 & 0 & 0 & 0 & 0 & 0 & 0 & 0 & 0 & 0 & 0 & 0 \\
\hline Well-019\{112,129,1\} & 0 & 0 & 0 & 0 & 0 & 0 & 0 & 0 & 0 & 0 & 0 & 0 & 0 & 0 \\
\hline
\end{tabular}

Figure 19: Example of dynamic data (Oil Rate SC - Monthly (bbl/day))

\subsubsection{STATIC MODELING}

Within this stage, the Spatio-temporal database generates the Cartesian grid system with a grid size of $\approx$ 40 acres. The next step is to determine the distributions of reservoir characteristics and populate the geological model using the geostatistical method "Inverse Distance Weighting".

The last step in static modeling involves assigning the polygon-based grid systems using the Voronoi method (Aurenhammer, 1991) (refer to Figure 20) and calculate the polygon-based volumetrically and the geostatistical properties for the entire reservoir. 


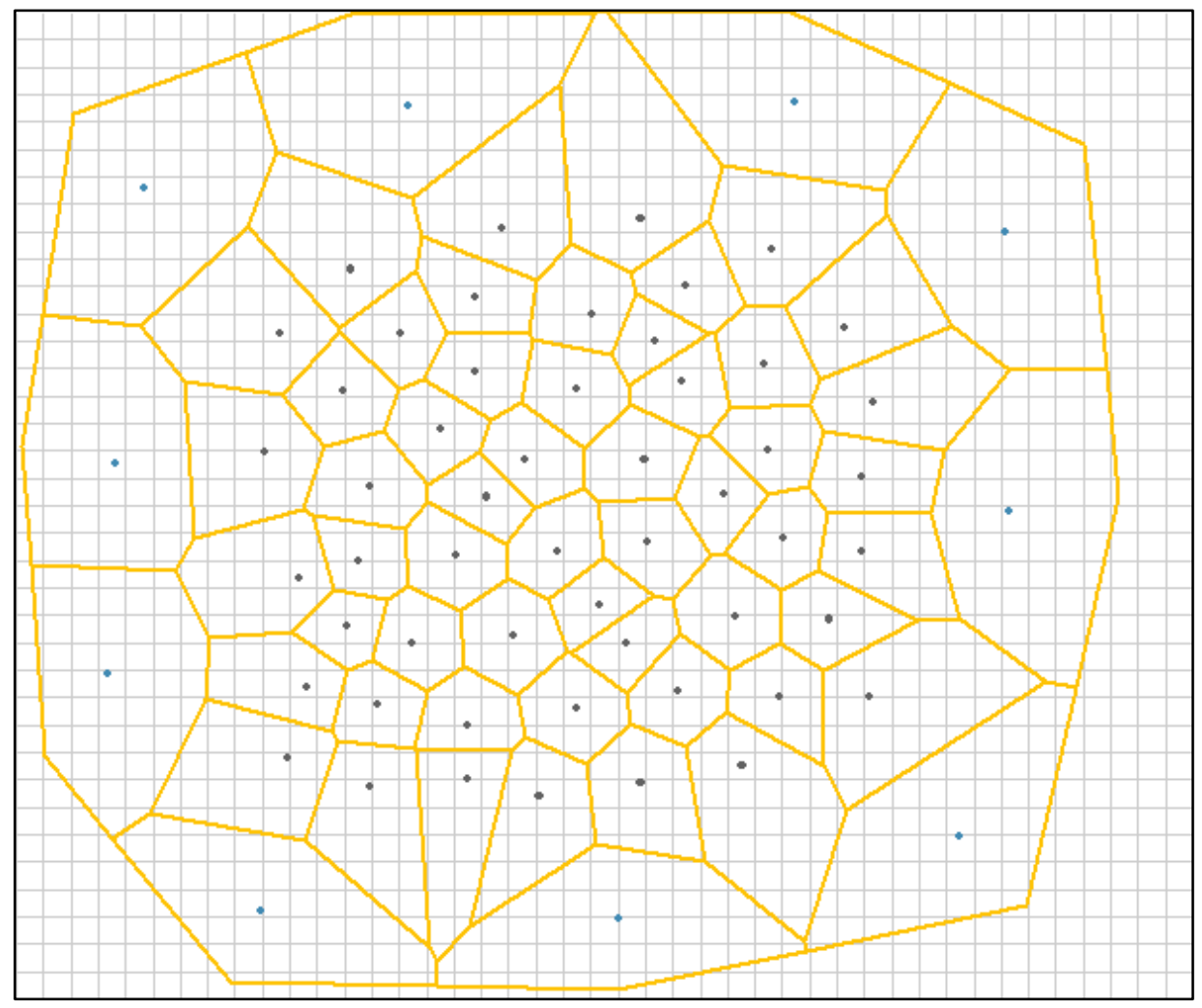

Figure 20: Cartesian and polygon-based grid systems across the reservoir at the final phase

\subsubsection{TOP-DOWN MODELING}

As explained in chapter 2, static and dynamic data must be selected initially for the focal producers and the offset injectors and producers. Once data are prepared for each model, the next stage is to use the IMagine ${ }^{\circledR}$ feature selection option to pick the most influential parameter and training the predictive model, the last step achieved within the build and history match section in IMagine ${ }^{\circledR}$.

The next step is TDM Design that requires designing the TDM model based on the required output sequence, while the sequence decision predetermined in the Build and history match section in IMagine $\mathbb{}$.

The final step is TDM deployment, where TDM evaluates and initiates the execution and implementation of the generated predictive models as well as implying the operational constraints. 


\subsubsection{BUILD AND HISTORY MATCH}

Since we are history matching 3 layers, 3 separate TDMs are required. Each TDM consist of 5 models in the following sequence:

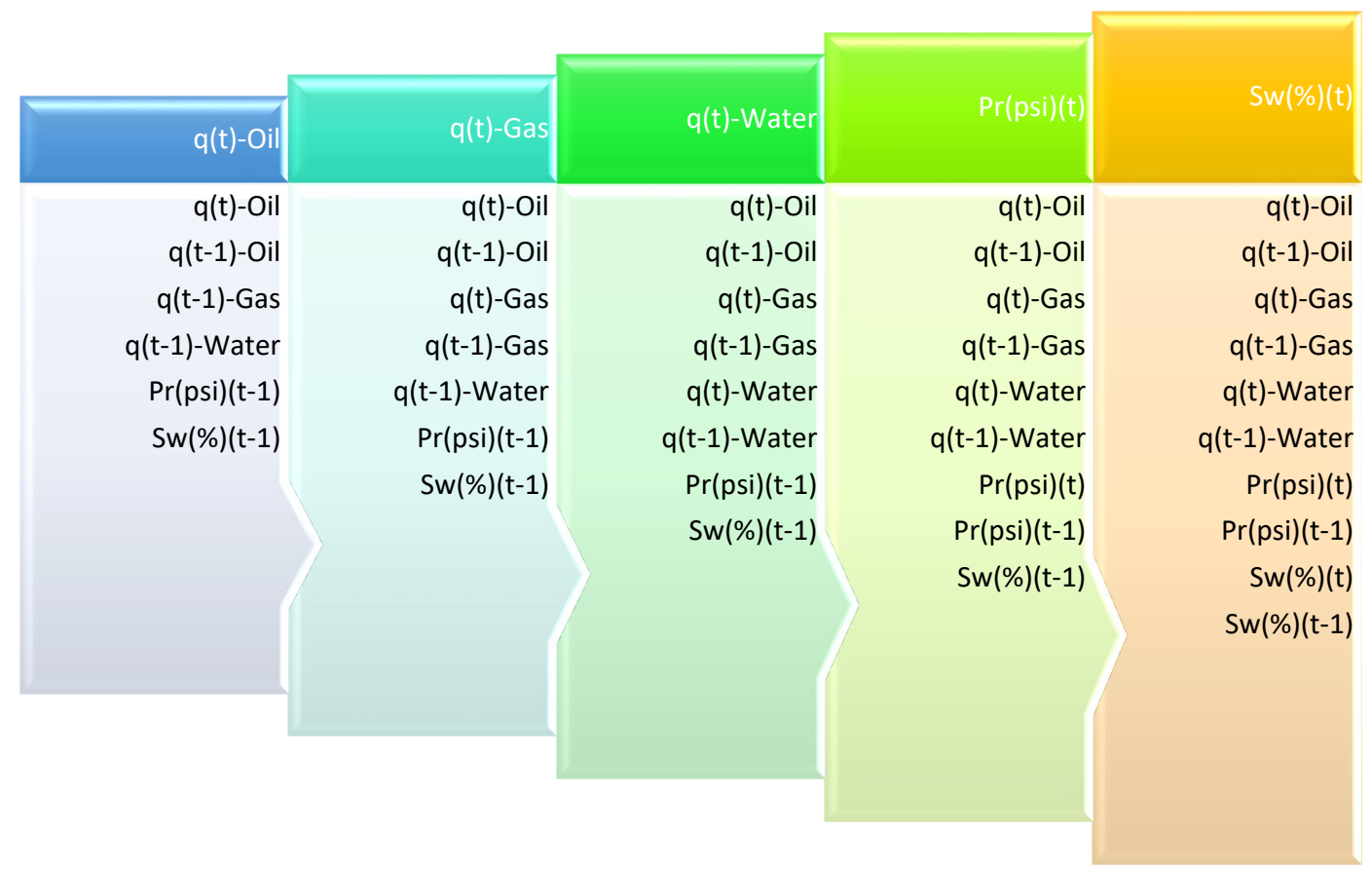

Figure 21: TDM model attributes sequence selections among 5 models

For more information regarding the selection sequence per model, please refer to the TDM design and deployment section in chapter 2. It is also up to the modeler whether to use time step (t-2) in the initial data selection.

The offset wells for each TDM is a function of well communication, so in amalgamated formation such as Layer 6, 3 offsets were excellent but as Layer 1 is more heterogenous, 2 offset achieved better results than 3 offsets.

Table 3 shows the initial attributes selection for Layer $6 \mathrm{q}(\mathrm{t})$-Oil model with 3 offset producers and 1 offset injector, knowing that only attributes located in Figure 21 changes across the five models. 
Table 3: The Initial variable input selection for Layer 6 oil q(t)-Oil model

\begin{tabular}{|c|c|c|}
\hline \multicolumn{3}{|c|}{ Focal Well } \\
\hline Static Data & Dynamic Data & Dynamically Static data \\
\hline $\mathrm{X} /$ Longitude & FBH Pressure $(\mathrm{psi})(\mathrm{t})$ & $\mathrm{q}(\mathrm{t}-1)-\mathrm{Gas}$ \\
\hline Y/Latitude & FBH Pressure $(\mathrm{psi})(\mathrm{t}-1)$ & $\mathrm{q}(\mathrm{t}-2)-\mathrm{Gas}$ \\
\hline Pay thickness (ft) & FBH Pressure (psi)(t-2) & $\mathrm{q}(\mathrm{t}-1)-\mathrm{Oil}$ \\
\hline Permeability (md) & Reservoir Pressure (psi)(t-1) & $\mathrm{q}(\mathrm{t}-2)-\mathrm{Oil}$ \\
\hline Porosity (\%) & Reservoir Pressure (psi)(t-2) & $q(t-1)$-Water \\
\hline Top (ft) & Water Saturation $(\%)(t-1)$ & $q(t-2)$-Water \\
\hline & Water Saturation $(\%)(\mathrm{t}-2)$ & \\
\hline
\end{tabular}

\begin{tabular}{lll} 
& \multicolumn{2}{c}{ Offset Well 1, 2, and 3 } \\
Static Data & Dynamic Data & Dynamically Static data \\
X/Longitude(1P) & FBH Pressure $(\mathrm{psi})(\mathrm{t})(1 \mathrm{P})$ & $\mathrm{q}(\mathrm{t}-1)-\mathrm{Gas}(1 \mathrm{P})$ \\
Y/Latitude(1P) & FBH Pressure $(\mathrm{psi})(\mathrm{t}-1)(1 \mathrm{P})$ & $\mathrm{q}(\mathrm{t}-2)-\mathrm{Gas}(1 \mathrm{P})$ \\
Distance $(\mathrm{t})(1 \mathrm{P})$ & FBH Pressure $(\mathrm{psi})(\mathrm{t}-2)(1 \mathrm{P})$ & $\mathrm{q}(\mathrm{t}-1)-\mathrm{Oil}(1 \mathrm{P})$ \\
Pay thickness $(\mathrm{ft})(1 \mathrm{P})$ & Reservoir Pressure $(\mathrm{psi})(\mathrm{t}-1)(1 \mathrm{P})$ & $\mathrm{q}(\mathrm{t}-2)-\mathrm{Oil}(1 \mathrm{P})$ \\
Permeability $(\mathrm{md})(1 \mathrm{P})$ & Reservoir Pressure $(\mathrm{psi})(\mathrm{t}-2)(1 \mathrm{P})$ & $\mathrm{q}(\mathrm{t}-1)-$ Water(1P) \\
Porosity $(\%)(1 \mathrm{P})$ & Water Saturation $(\%)(\mathrm{t}-1)(1 \mathrm{P})$ & $\mathrm{q}(\mathrm{t}-2)-$ Water $(1 \mathrm{P})$ \\
Top $(\mathrm{ft})(1 \mathrm{P})$ & Water Saturation $(\%)(\mathrm{t}-2)(1 \mathrm{P})$ &
\end{tabular}

\begin{tabular}{lll} 
Static Data & \multicolumn{1}{c}{ Offset Injector 1 } & Dynamically Static data \\
X/Longitude(1I) & Dynamic Data & Injection Rate Layer 6(t)(1I) \\
Y/Latitude(1I) & FBH Pressure $(\mathrm{psi})(\mathrm{t})(1 \mathrm{I})$ & Injection Rate Layer 6(t-1)(1I) \\
Distance(t)(1I) & FBH Pressure $(\mathrm{psi})(\mathrm{t}-1)(1 \mathrm{I})$ & Injection Rate Layer 6(t-2)(1I) \\
Pay thickness $(\mathrm{ft})(1 \mathrm{I})$ & FBH Pressure $(\mathrm{psi})(\mathrm{t}-2)(1 \mathrm{I})$ & \\
Permeability $(\mathrm{md})(1 \mathrm{I})$ & Reservoir Pressure $(\mathrm{psi})(\mathrm{t}-1)(1 \mathrm{I})$ & \\
Porosity $(\%)(1 \mathrm{I})$ & Reservoir Pressure $(\mathrm{psi})(\mathrm{t}-2)(1 \mathrm{I})$ & \\
Top $(\mathrm{ft})(1 \mathrm{I})$ & Water Saturation $(\%)(\mathrm{t}-1)(1 \mathrm{I})$ &
\end{tabular}

After the initial selection of the attributes, TDM allow determining the most influential parameters to be included in the training process, since it is not preferred to use all the first selected attributes. The key performance indicator per attribute presented for Layer $6 \mathrm{q}(\mathrm{t})$-Oil model, shows that FBHP and Pr have a high impact on oil production for the focal well. 
Table 4: Key Performance Indicator for Layer 6 q(t)-Oil model

\begin{tabular}{|c|c|c|}
\hline & Attribute & KPI(\%) \\
\hline 1 & $\mathrm{q}(\mathrm{t}-1)-\mathrm{Gas}$ & 100 \\
\hline 2 & $\mathrm{q}(\mathrm{t}-1)-\mathrm{Oil}$ & 100 \\
\hline 3 & $\mathrm{q}(\mathrm{t}-2)-\mathrm{Gas}$ & 82 \\
\hline 4 & $\mathrm{q}(\mathrm{t}-2)-\mathrm{Oil}$ & 82 \\
\hline 5 & Permeability (md) & 79 \\
\hline 6 & FBH Pressure (psi)(t-2) & 73 \\
\hline 7 & Reservoir Pressure (psi)(t-2) & 63 \\
\hline 8 & FBH Pressure $(\mathrm{psi})(\mathrm{t}-1)$ & 54 \\
\hline 9 & Time & 45 \\
\hline 10 & Reservoir Pressure (psi)(t-1) & 43 \\
\hline 11 & FBH Pressure $(p s i)(t-2)(2 P)$ & 41 \\
\hline 12 & FBH Pressure $(\mathrm{psi})(\mathrm{t}-2)(1 \mathrm{P})$ & 39 \\
\hline 13 & Reservoir Pressure (psi)(t-2)(3P) & 39 \\
\hline 14 & Reservoir Pressure (psi)(t-2)(1P) & 38 \\
\hline 15 & Water Saturation $(\%)(\mathrm{t}-2)$ & 38 \\
\hline 16 & Pay thickness $(\mathrm{ft})(3 \mathrm{P})$ & 37 \\
\hline 17 & Water Saturation $(\%)(t-1)$ & 37 \\
\hline 18 & Pay thickness $(\mathrm{ft})(2 \mathrm{P})$ & 34 \\
\hline 19 & Porosity $(\%)$ & 34 \\
\hline 20 & Reservoir Pressure (psi)(t-2)(2P) & 33 \\
\hline 21 & Top (ft)(3P) & 27 \\
\hline 22 & FBH Pressure (psi)(t-2)(3P) & 27 \\
\hline 23 & Reservoir Pressure (psi)(t-1)(3P) & 27 \\
\hline 24 & FBH Pressure $(\mathrm{psi})(\mathrm{t}-1)(1 \mathrm{P})$ & 26 \\
\hline 25 & Pay thickness (ft) & 26 \\
\hline 26 & Pay thickness (ft)(1P) & 26 \\
\hline 27 & Water Saturation $(\%)(\mathrm{t}-1)(2 \mathrm{P})$ & 26 \\
\hline 28 & FBH Pressure $(\mathrm{psi})(\mathrm{t}-1)(2 \mathrm{P})$ & 26 \\
\hline 29 & Top (ft) & 26 \\
\hline 30 & Water Saturation $(\%)(\mathrm{t}-2)(2 \mathrm{P})$ & 25 \\
\hline 31 & Reservoir Pressure (psi)(t-1)(1P) & 25 \\
\hline 32 & Reservoir Pressure (psi)(t-1)(2P) & 25 \\
\hline 33 & Top $(\mathrm{ft})(2 \mathrm{P})$ & 25 \\
\hline 34 & Permeability $(\mathrm{md})(2 \mathrm{P})$ & 25 \\
\hline 35 & $\mathrm{X} /$ Longitude & 25 \\
\hline 36 & $\mathrm{X} /$ Longitude(3P) & 24 \\
\hline
\end{tabular}

\begin{tabular}{|c|c|c|}
\hline & Attribute & KPI(\%) \\
\hline 47 & Injection Rate Layer 6(t-1)(1I) & 21 \\
\hline 48 & FBH Pressure $(\mathrm{psi})(\mathrm{t}-1)(3 \mathrm{P})$ & 21 \\
\hline 49 & Y/Latitude(1P) & 21 \\
\hline 50 & Porosity $(\%)(2 \mathrm{P})$ & 20 \\
\hline 51 & Porosity $(\%)(1 \mathrm{P})$ & 20 \\
\hline 52 & $\mathrm{q}(\mathrm{t}-2)-\mathrm{Gas}(1 \mathrm{P})$ & 20 \\
\hline 53 & $\mathrm{q}(\mathrm{t}-2)-\mathrm{Oil}(1 \mathrm{P})$ & 20 \\
\hline 54 & Porosity $(\%)(3 \mathrm{P})$ & 19 \\
\hline 55 & Water Saturation $(\%)(\mathrm{t}-1)(3 \mathrm{P})$ & 19 \\
\hline 56 & Top $(\mathrm{ft})(1 \mathrm{I})$ & 19 \\
\hline 57 & Water Saturation $(\%)(\mathrm{t}-1)(1 \mathrm{P})$ & 19 \\
\hline 58 & $\mathrm{q}(\mathrm{t}-1)-\mathrm{Gas}(1 \mathrm{P})$ & 19 \\
\hline 59 & $\mathrm{q}(\mathrm{t}-1)-\mathrm{Oil}(1 \mathrm{P})$ & 19 \\
\hline 60 & Y/Latitude(2P) & 19 \\
\hline 61 & $\mathrm{q}(\mathrm{t}-1)-$ Water(3P) & 19 \\
\hline 62 & Permeability $(\mathrm{md})(3 \mathrm{P})$ & 19 \\
\hline 63 & $\mathrm{q}(\mathrm{t}-2)-$ Water(3P) & 19 \\
\hline 64 & FBH Pressure $(\mathrm{psi})(\mathrm{t})(2 \mathrm{P})$ & 18 \\
\hline 65 & FBH Pressure (psi)(t) & 18 \\
\hline 66 & $\mathrm{X} /$ Longitude(2P) & 18 \\
\hline 67 & $\mathrm{q}(\mathrm{t}-2)-\mathrm{Water}(2 \mathrm{P})$ & 18 \\
\hline 68 & FBH Pressure $(\mathrm{psi})(\mathrm{t}-2)(1 \mathrm{I})$ & 18 \\
\hline 69 & $\mathrm{q}(\mathrm{t}-1)-$ Water(2P) & 18 \\
\hline 70 & Y/Latitude(1I) & 18 \\
\hline 71 & FBH Pressure $(p s i)(t)(3 P)$ & 18 \\
\hline 72 & Distance(t)(1P) & 17 \\
\hline 73 & $\mathrm{q}(\mathrm{t}-2)-\mathrm{Oil}(3 \mathrm{P})$ & 17 \\
\hline 74 & $\mathrm{q}(\mathrm{t}-2)-\mathrm{Gas}(3 \mathrm{P})$ & 17 \\
\hline 75 & $\mathrm{q}(\mathrm{t}-2)-\mathrm{Water}(1 \mathrm{P})$ & 17 \\
\hline 76 & $\mathrm{q}(\mathrm{t}-1)-$ Water(1P) & 17 \\
\hline 77 & FBH Pressure $(\mathrm{psi})(\mathrm{t}-1)(1 \mathrm{I})$ & 17 \\
\hline 78 & $\mathrm{q}(\mathrm{t}-1)-\mathrm{Oil}(3 \mathrm{P})$ & 17 \\
\hline 79 & $\mathrm{q}(\mathrm{t}-1)-\mathrm{Gas}(3 \mathrm{P})$ & 17 \\
\hline 80 & Permeability (md)(1P) & 16 \\
\hline 81 & Injection Rate Layer 6(t)(1I) & 16 \\
\hline 82 & FBH Pressure $(p s i)(t)(1 P)$ & 15 \\
\hline
\end{tabular}




\begin{tabular}{|c|l|c|}
\hline 37 & Pay thickness (ft)(1I) & 24 \\
\hline 38 & FBH Pressure (psi)(t)(1I) & 23 \\
\hline 39 & Reservoir Pressure (psi)(t-2)(1I) & 23 \\
\hline 40 & Water Saturation (\%)(t-2)(3P) & 22 \\
\hline 41 & Distance(t)(1I) & 22 \\
\hline 42 & Water Saturation $(\%)(\mathrm{t}-2)(1 \mathrm{P})$ & 22 \\
\hline 43 & Reservoir Pressure $(\mathrm{psi})(\mathrm{t}-1)(1 \mathrm{I})$ & 22 \\
\hline 44 & Injection Rate Layer 6(t-2)(1I) & 21 \\
\hline 45 & Distance(t)(3P) & 21 \\
\hline 46 & Top $(\mathrm{ft})(1 \mathrm{P})$ & 21 \\
\hline
\end{tabular}

\begin{tabular}{|c|l|c|}
\hline 83 & $\mathrm{q}(\mathrm{t}-1)-\operatorname{Gas}(2 \mathrm{P})$ & 15 \\
\hline 84 & $\mathrm{q}(\mathrm{t}-1)-O i l(2 \mathrm{P})$ & 15 \\
\hline 85 & $\mathrm{Y} /$ Latitude(3P) & 14 \\
\hline 86 & $\mathrm{q}(\mathrm{t}-2)-\operatorname{Gas}(2 \mathrm{P})$ & 14 \\
\hline 87 & $\mathrm{q}(\mathrm{t}-2)-O i l(2 \mathrm{P})$ & 14 \\
\hline 88 & $\mathrm{X} /$ Longitude(1P) & 13 \\
\hline 89 & Y/Latitude & 13 \\
\hline 90 & Distance(t)(2P) & 12 \\
\hline 91 & $\mathrm{X} /$ Longitude(1I) & 12 \\
\hline 92 & $\mathrm{q}(\mathrm{t}-1)$-Water & 1 \\
\hline 93 & $\mathrm{q}(\mathrm{t}-2)$-Water & \\
\hline
\end{tabular}

Once the feature selection accomplished, data partitioning is next. As explained in the chapter 2 data partitioning section, a partitioning sequence must be identified. Among the three partitioning methods, random partitioning selected for Layer $6 \mathrm{q}(\mathrm{t})$-Oil model with 20\% Calibration, $8 \%$ verification, and $72 \%$ training.

Models are trained for as many numbers of epochs till the best convergence occurs. Figure 22 shows an example of a good convergence for Layer $6 \mathrm{q}(\mathrm{t})$-Oil model at epoch number 3812, where R2 is $0.98,0.91,0.94$ for training, calibration, and verification, respectively.
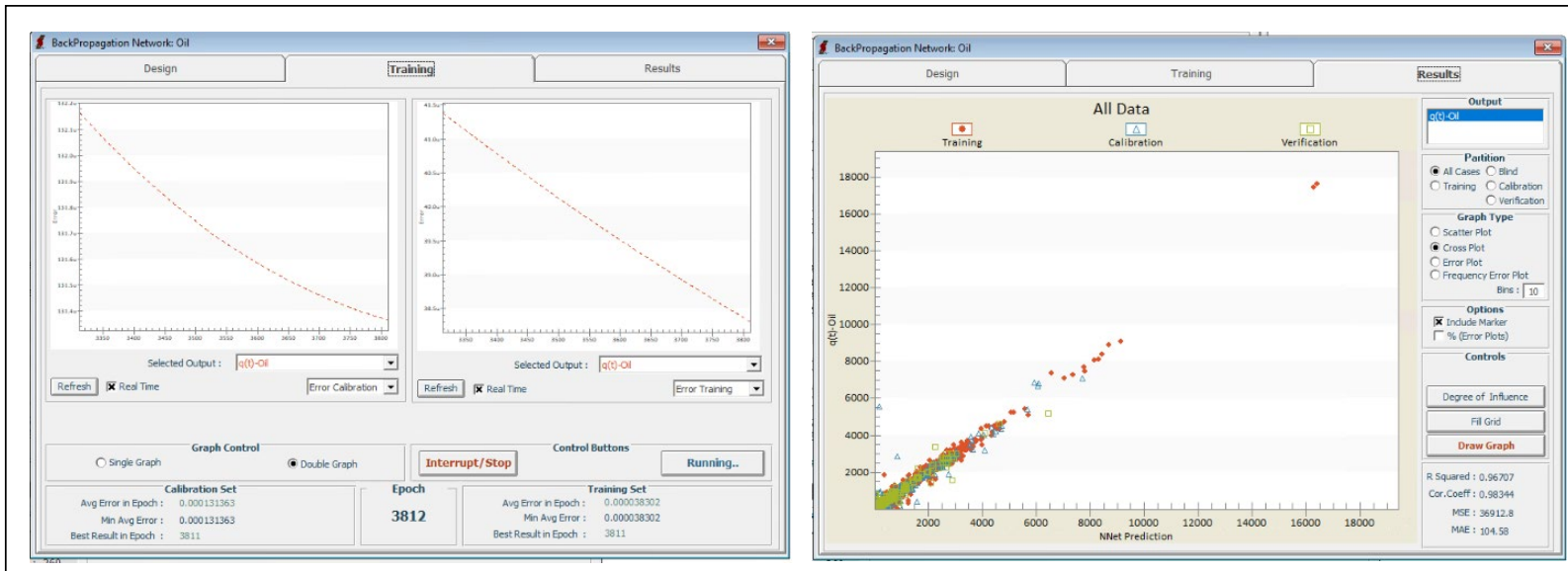

Figure 22: Layer $6 \mathrm{q}(\mathrm{t})-$ Oil model training, verification and calibration 


\subsubsection{DESIGN AND DEPLOY TDM}

Same for $\mathrm{q}(\mathrm{t})$-Oil predictive model, all the other 4 predictive models presented in Figure 16 are generated and set in the same sequence. IMagine ${ }^{\circledR}$ offers the options for history matching and forecasting; however, the objectives of the thesis is to test TDM capabilities in history matching commingled layers.

At the end of the deployment, history match data prepared for oil, water, and gas production, as well as history matching of reservoir pressure and water saturation. Figure 23 shows history matching results for Layer 6 production for the entire reservoir.

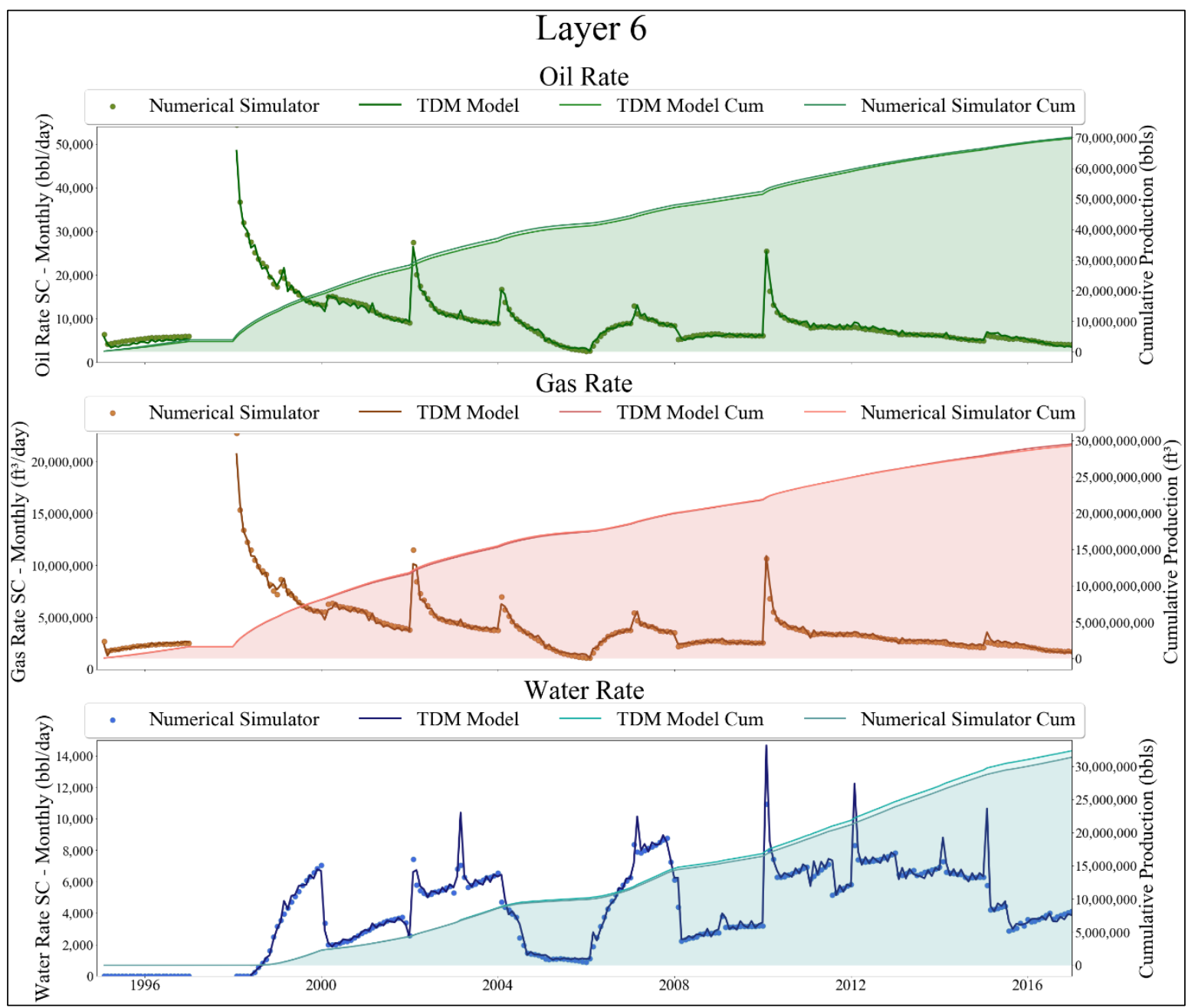

Figure 23: Entire Reservoir Layer 6 areal oil, gas, and water production (TDM versus Numerical Simulation) 
While Figure 24 and 25 show an example of the 4 generated TDM's results for Layer 1, Layer 3, Layer 6, and total layers for well-030.

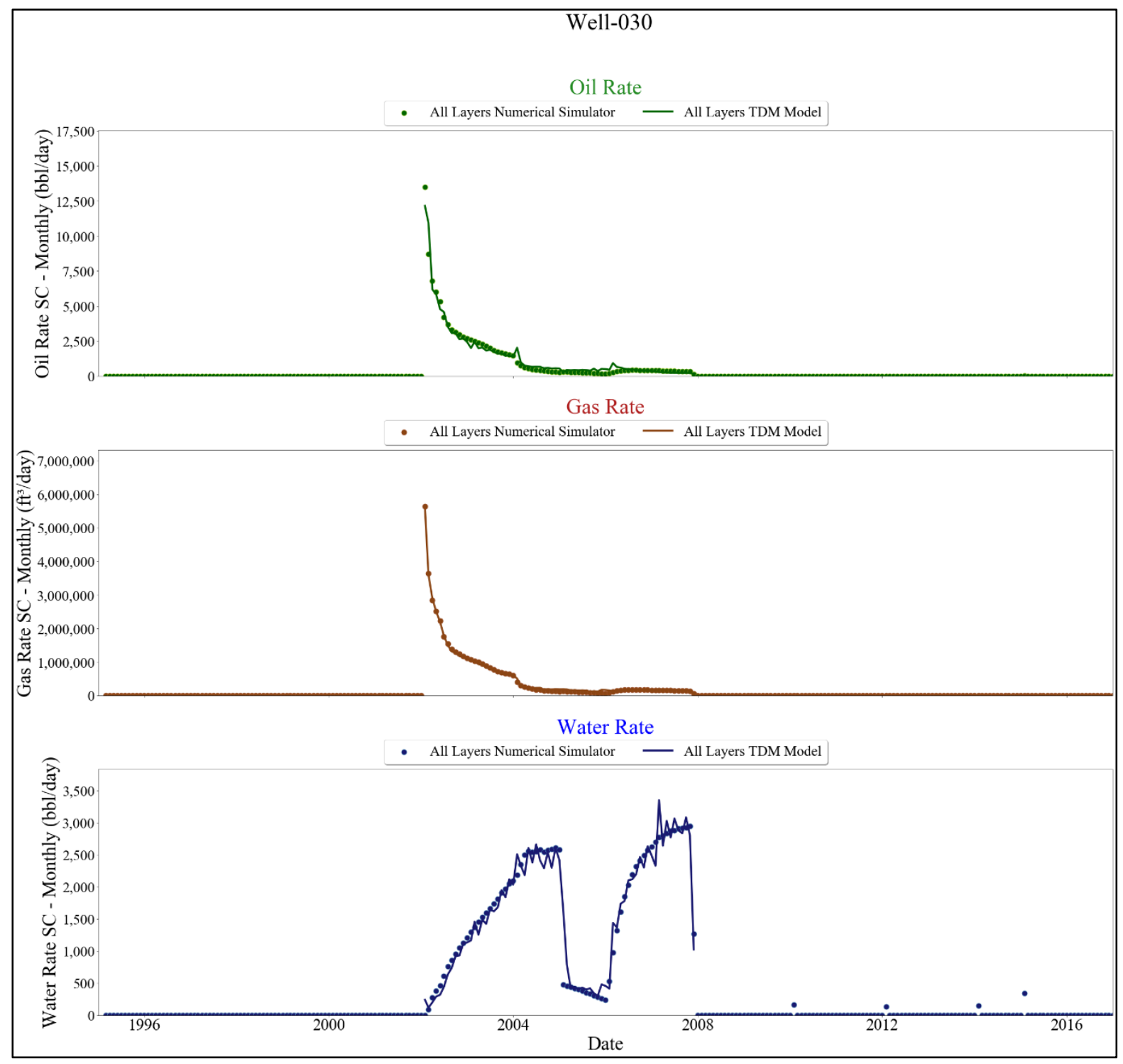

Figure 24: Well 30 total vertical production (TDM versus Numerical Simulation) 


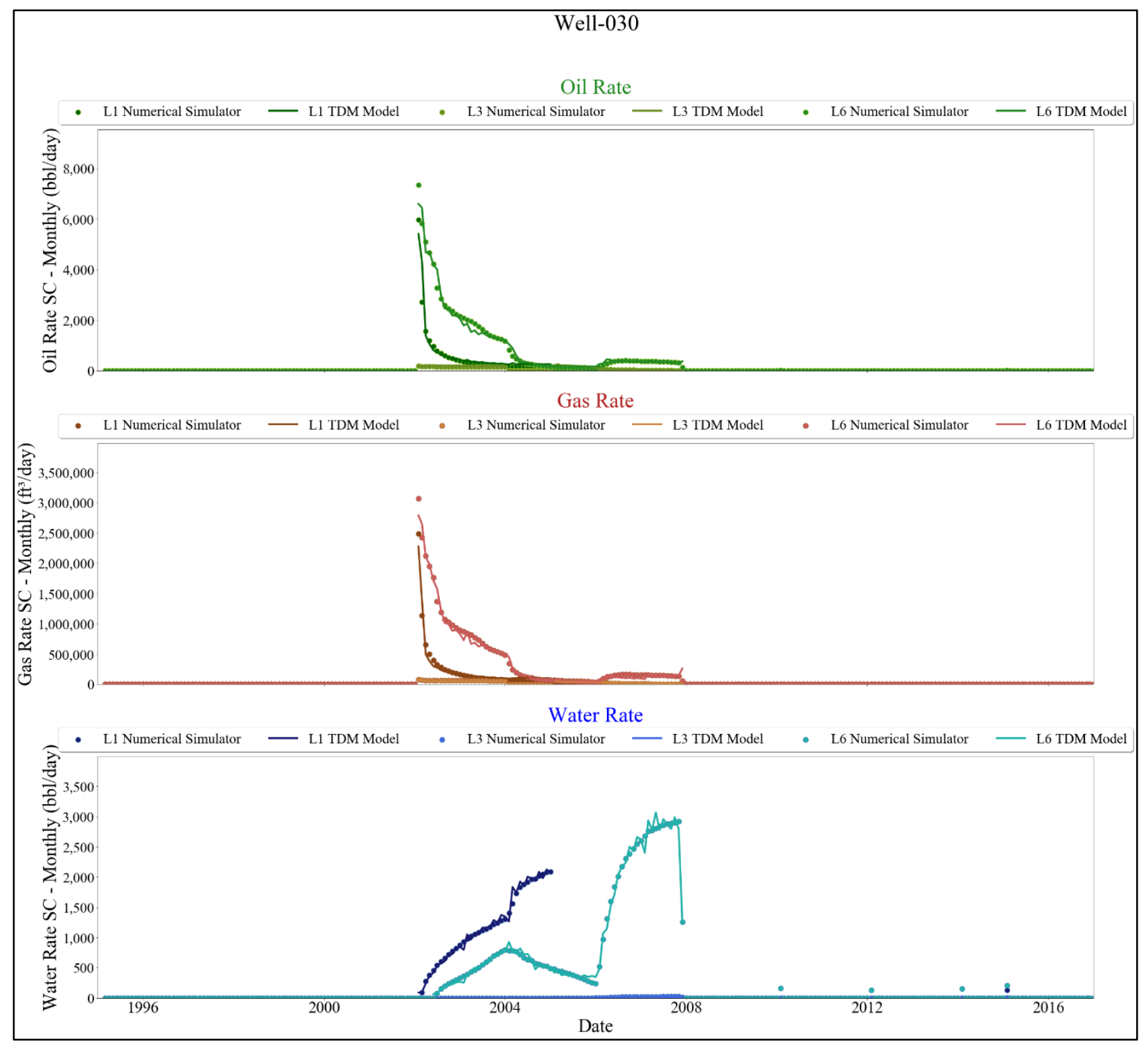

Figure 25: Well-030 oil, gas, and water production per Layer (L1, L3, and L6) (TDM versus Numerical Simulation) 


\section{CHAPTER IV}

\section{RESULTS AND DISCUSSION}

As the $\mathrm{KH}$ modeling shown high discrepancies as compared to the numerical reservoir simulation, the behavior was investigated based on water cut and formation pressure, since the designed depletion plan anticipated high-pressure fluctuation within the reservoir.

4 TDM models were generated and tested against numerical reservoir simulation and later compared to $\mathrm{KH}$ allocation modeling. TDM resolution in time and space tested for wells with data shortage as well as, the TDM key performance indicator tool was evaluated.

\subsection{KH STATIC MODELING DISCREPANCIES}

The $\mathrm{KH}$ allocation model generated for the 53 wells with results showing a high mismatch as a function of reservoir pressure and water cut per Layer. This behavior makes sense since fluids mobility is also pressuredependent; however, the only case KH is applicable is associated with similar deferential pressure across each comingled Layer. KH validity might only be presented in layers with a pressure window considering single-phase flow.

Figure 26 represents the effect of reservoir pressure (block pressure) on Layer allocation. While an overestimation and underestimation of the flow rate per Layer as a function of block pressure. 


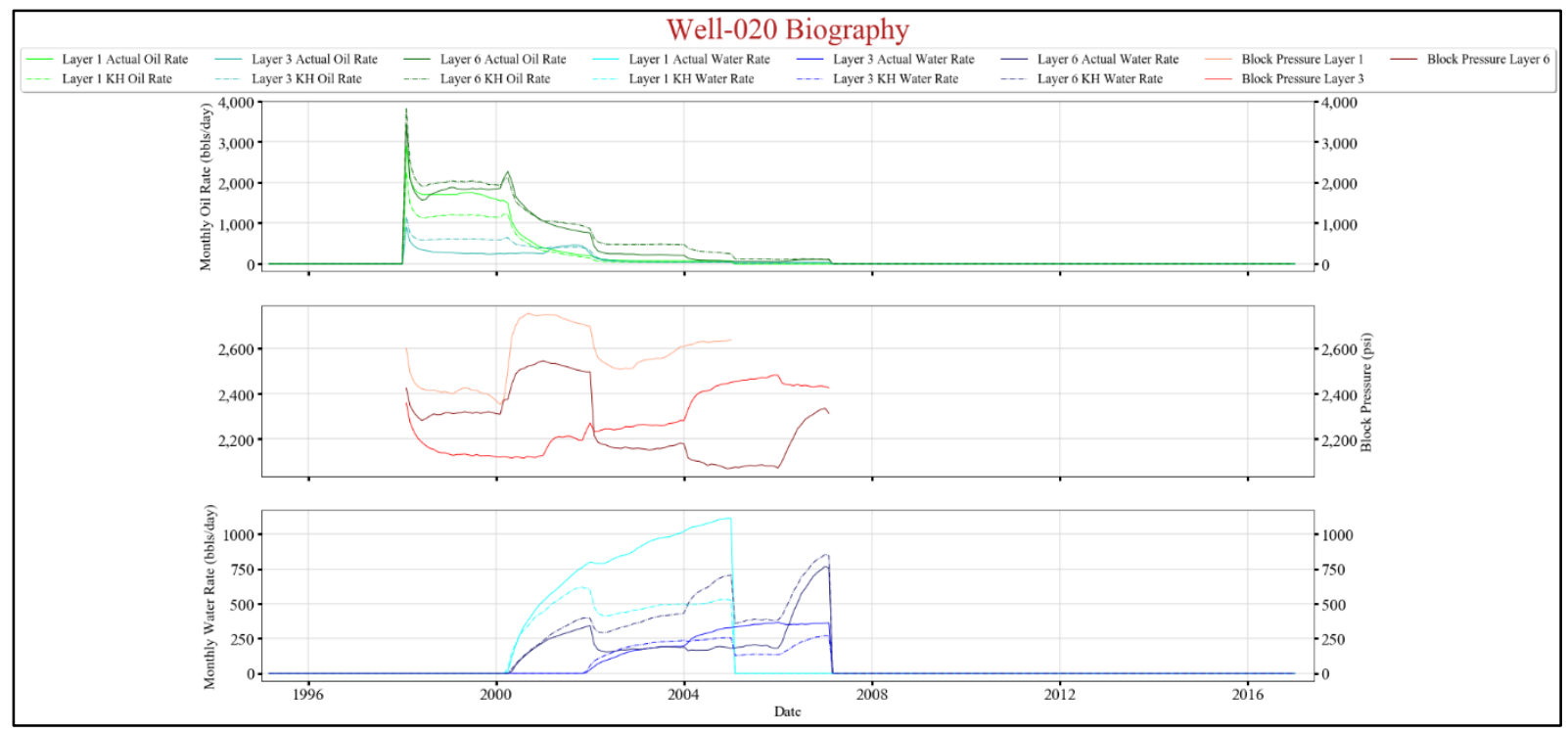

Figure 26: Well-020 biography showing the effect of block pressure on allocating flow rate

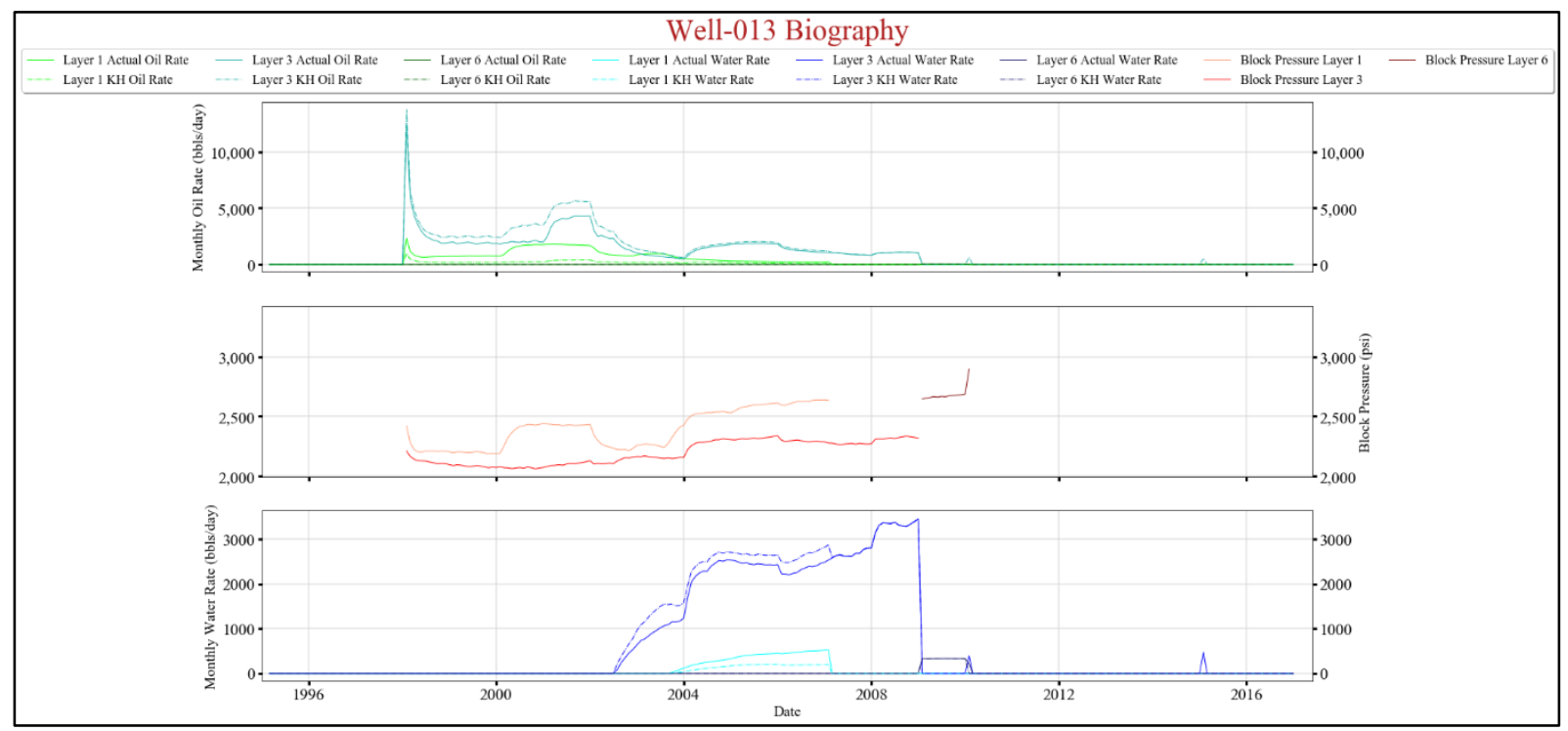

Figure 27: Well-013 biography showing the effect of block pressure on allocating flow rate

Well-013 biography indicates a clear impact of the block pressure at the year 2000 as Layer one witnessed pressure increase, the flow rate discrepancies increased, which give the impression that KH can be misleading even if the produced fluid was single phase. 


\subsection{TDM MODELING VERSUS KH MODELING}

One of the significant KH modeling challenges is that it fails in predicting layers allocation as water-cut increase since it is a single-phase modeling tool. TDM could solve this challenge through the accurate estimation of water cut distributions among layers, as presented in Figure 28 TDM modeling and Figure 29 KH modeling:

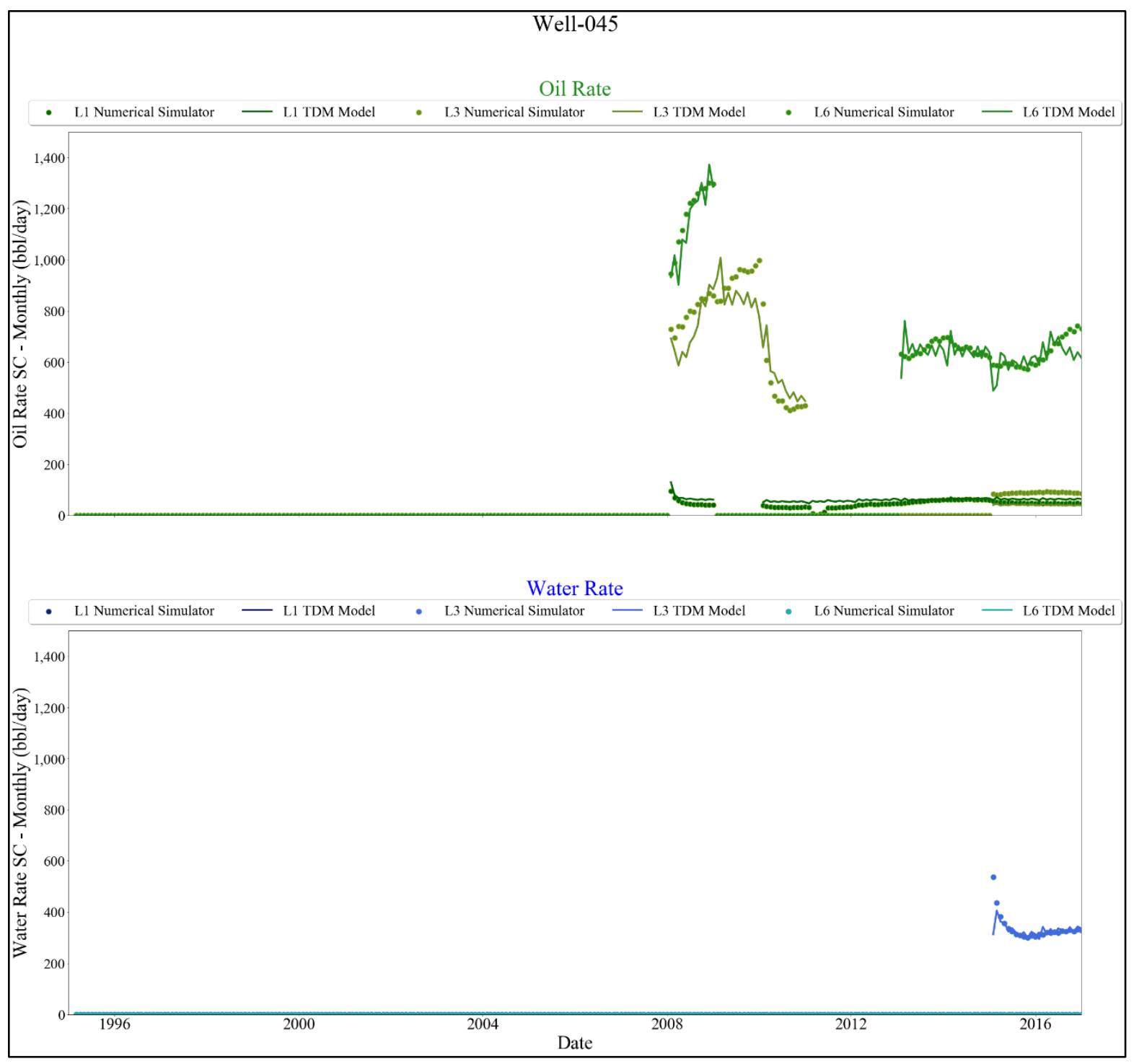

Figure 28: TDM water and oil rate versus numerical reservoir simulation 


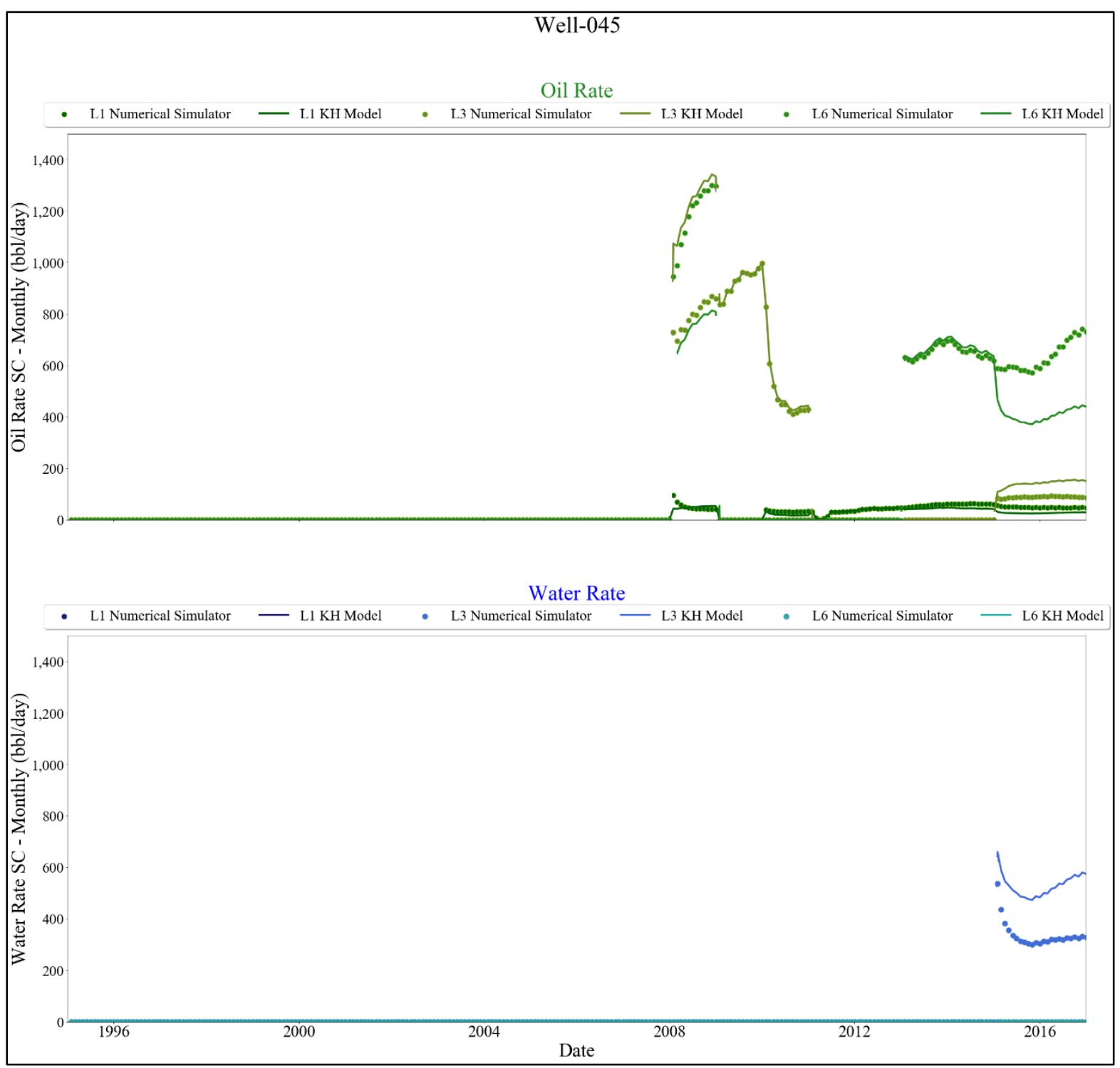

Figure 29: KH water and oil rate versus numerical reservoir simulation

Results also assessed on the full field level. Discrepancies associated with the static KH modeling shown in Table 5 that an underestimation of oil production within layers 1 and 6 observed. The last could be critical in term of oil storage design since the field will produce an extra $1.4 \mathrm{MMbbl}$; moreover, water production overestimated, which might impact reservoir pressure response as the depletion plans suggest enough water injection. 
Table 5: Cumulative production per numerical reservoir simulation and static KH modeling

\begin{tabular}{|c|c|c|c|}
\cline { 2 - 4 } \multicolumn{1}{c|}{} & $\begin{array}{c}\text { Numerical Reservoir } \\
\text { Simulation } \\
\text { (bbl) }\end{array}$ & $\begin{array}{c}\text { Static KH } \\
\text { Modeling } \\
\text { (bbl) }\end{array}$ & Gap \\
\hline Layer 1 Cumulative Oil Rate & 27493966.8 & 22849289.36 & 4644678 \\
\hline Layer 3 Cumulative Oil Rate & 30668525.04 & 34651270.11 & -3982740 \\
\hline Layer 6 Cumulative Oil Rate & 70140044.07 & 69370129.41 & 769914.6 \\
\hline Layer 1 Cumulative Water Rate & 13257933.67 & 11850000 & 1404255.3 \\
\hline Layer 3 Cumulative Water Rate & 18236068.07 & 20940000 & -2701494 \\
\hline Layer 6 Cumulative Water Rate & 31345138.83 & 31479745.77 & -134607 \\
\hline
\end{tabular}

Figure 30-35 represents the static KH modeling and TDM modeling versus the numerical reservoir simulation. TDM was better in picking reservoir properties' effect on allocation profile, especially in the early field life where high-pressure turbulence anticipated. $\mathrm{KH}$ failed in modeling layers 1 and 3 because they are more heterogeneous than Layer six, having to know that skin was assumed zero across all layers, alongside with single rock type. As more the reservoir properties vary among layers, the more uncertainty expected.

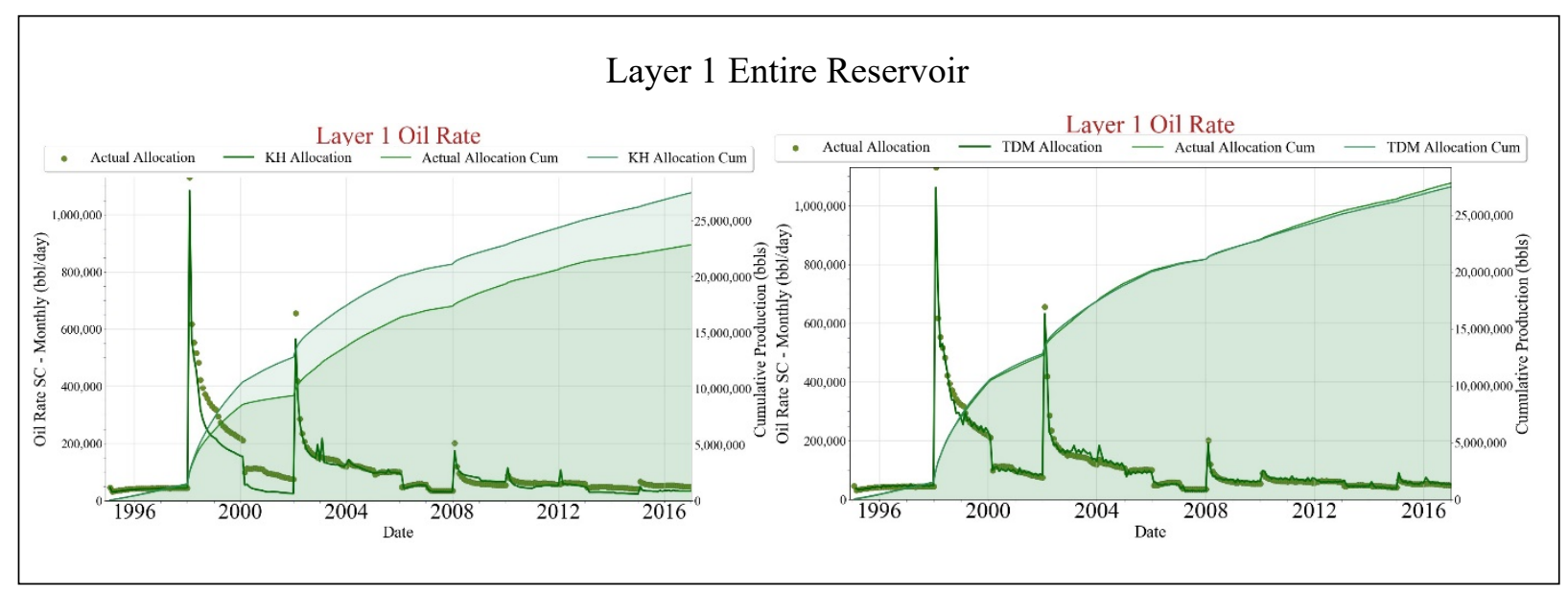

Figure 30: Layer 1 areal oil KH modeling (left) versus TDM modeling (Right) 


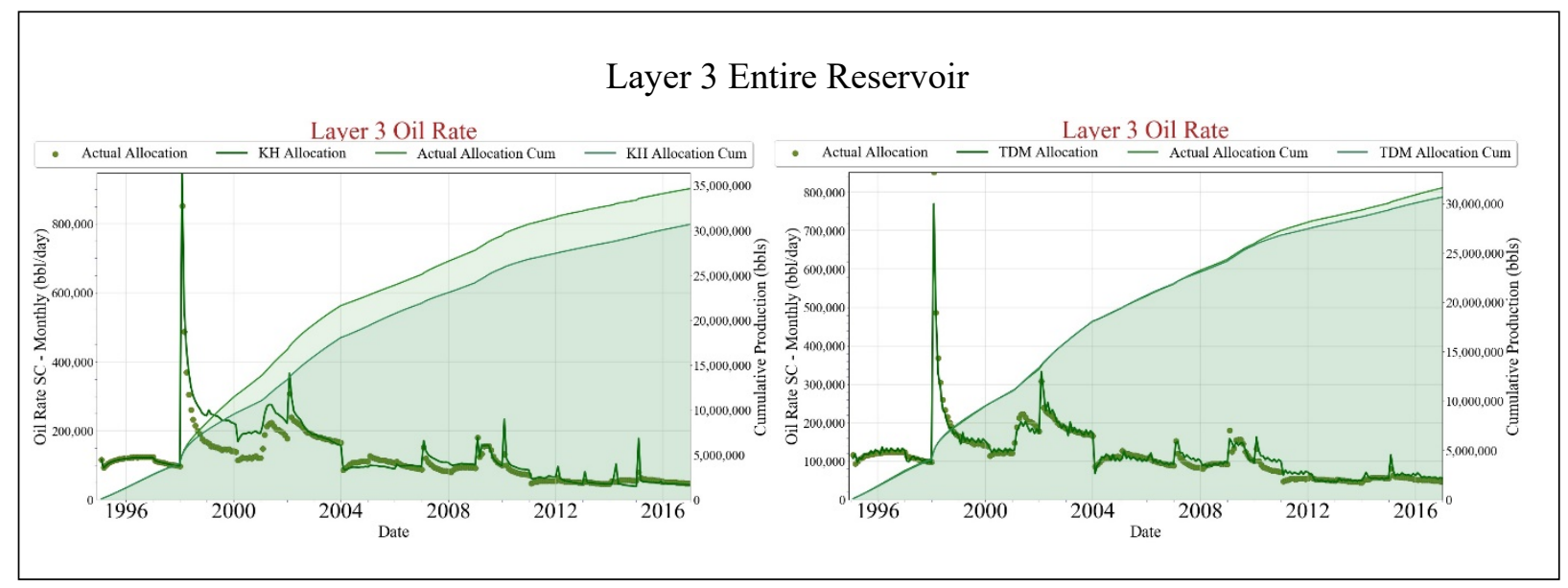

Figure 31: Layer 3 areal oil KH modeling (left) versus TDM modeling (Right)

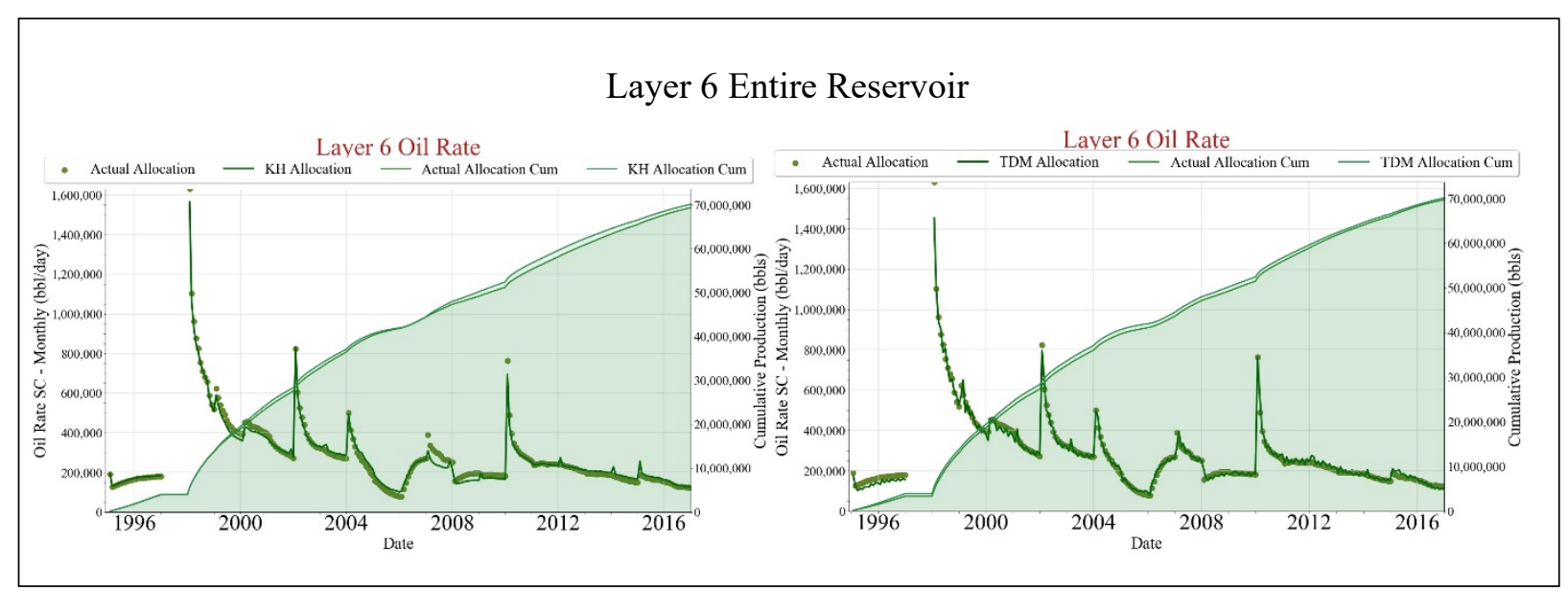

Figure 32: Layer 6 areal oil KH modeling (left) versus TDM modeling (Right) 


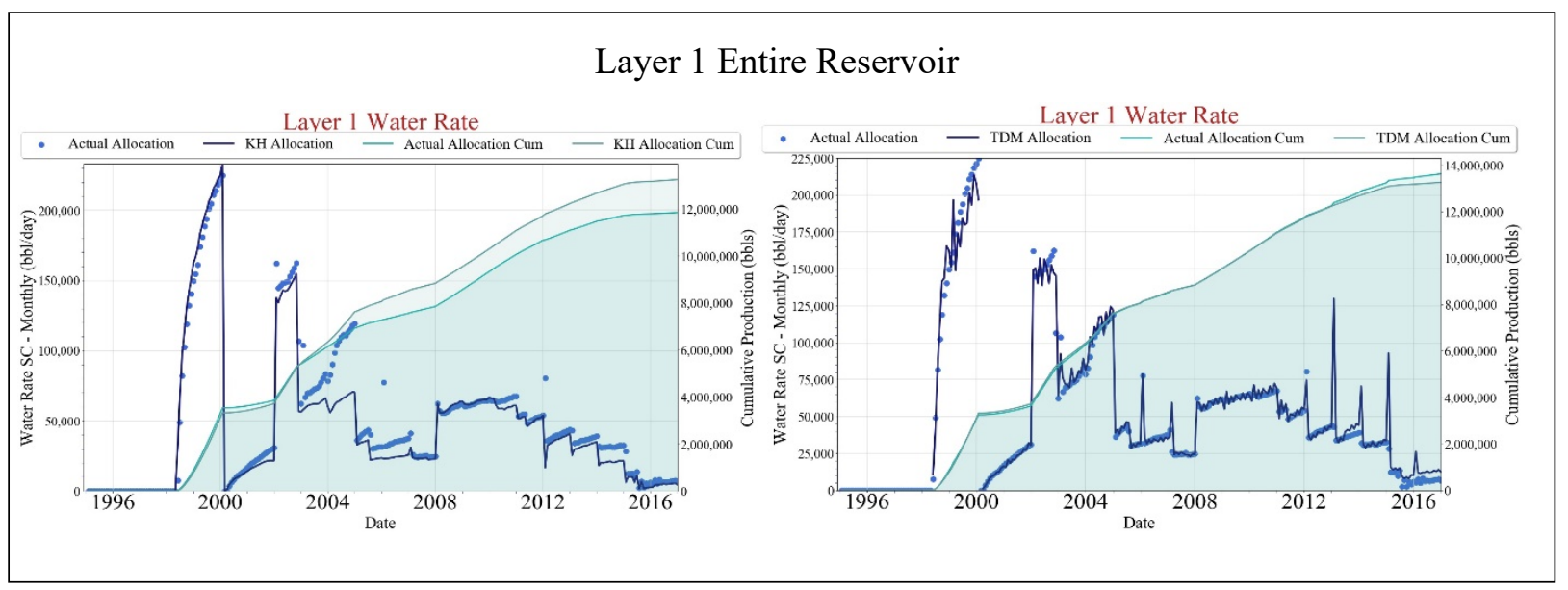

Figure 33: Layer 1 areal water KH modeling (left) versus TDM modeling (Right)

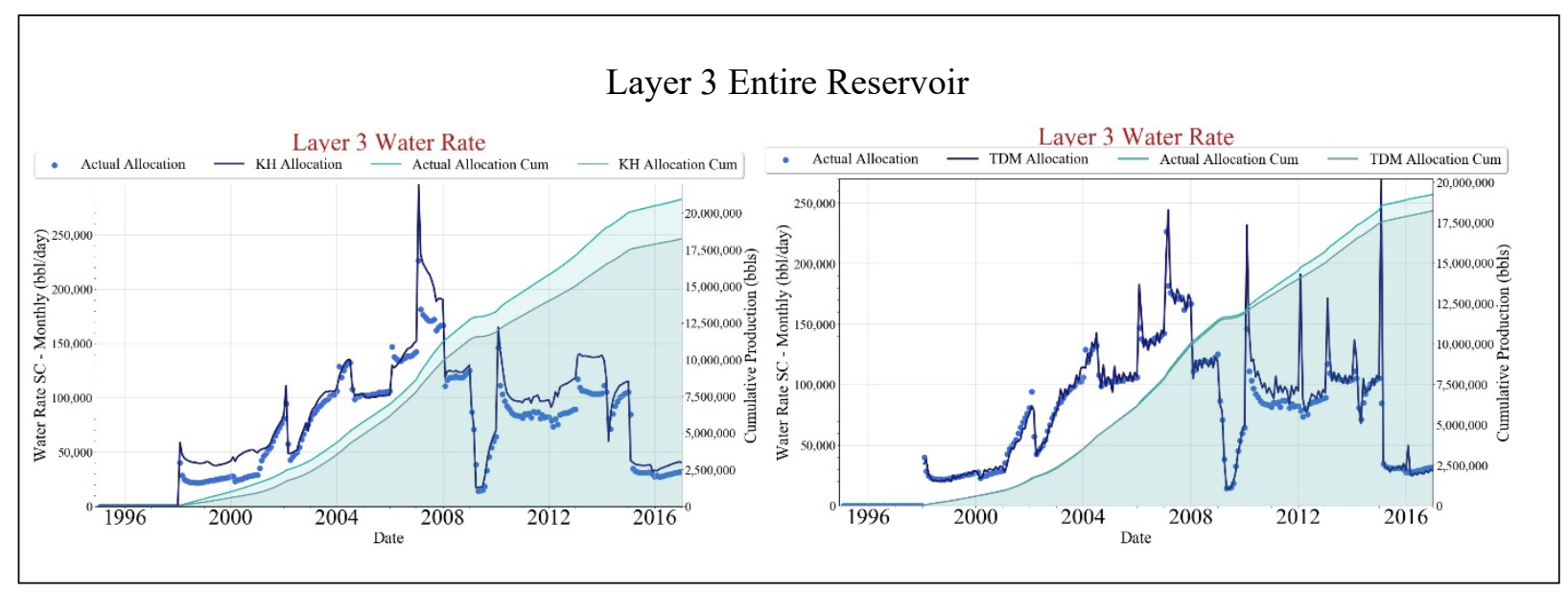

Figure 34: Layer 3 areal water KH modeling (left) versus TDM modeling (Right) 


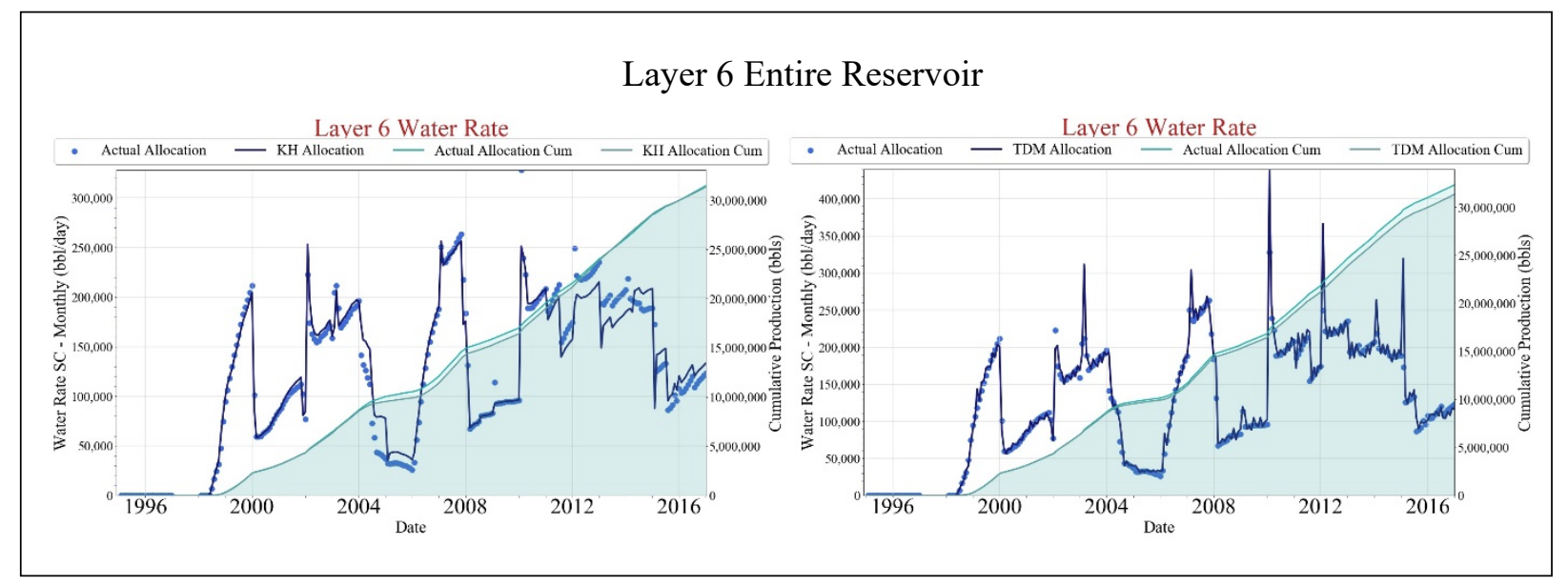

Figure 35: Layer 6 areal water KH modeling (left) versus TDM modeling (Right)

\subsection{TDM AREAL AND VERTICAL MODELING}

Layers were evaluated individually for history matching which resulted in 4 TDMs. The generated synthetic model ignored the hydrostatic friction among layers, resulting in no crossflow; however, as the flow gets more complex, the topology and structure of TDM can be adjusted to compensate for that effect. The current challenges presented to TDM is only understanding the dynamic block pressure effect on the production profile.

The list of results shown in Figures 36-45, proven TDM capability in picking pressure effect patterns that KH was incapable of. 


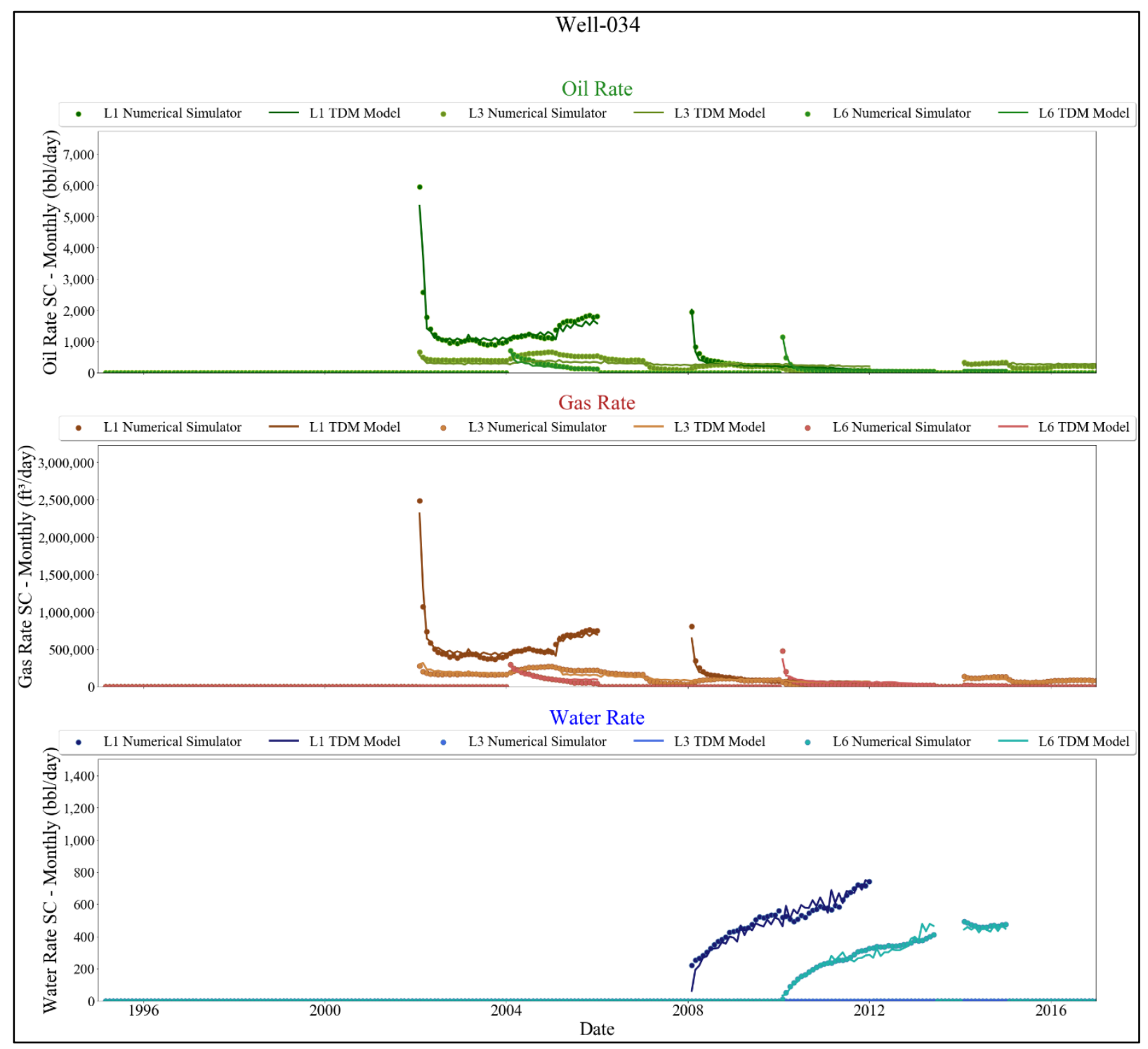

Figure 36: Well-034 production profile per Layer 


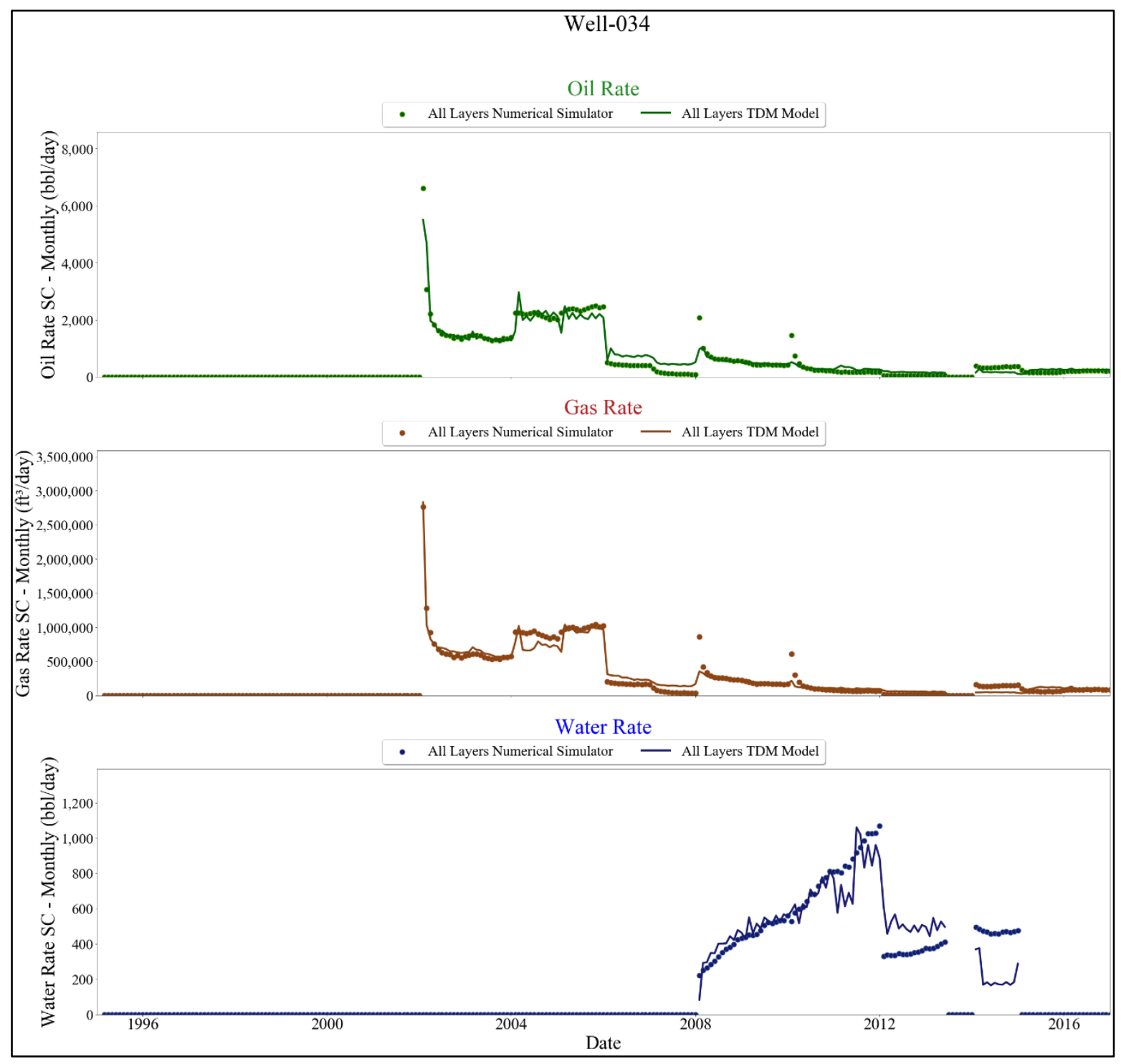

Figure 37: Well-034 vertical production profile 


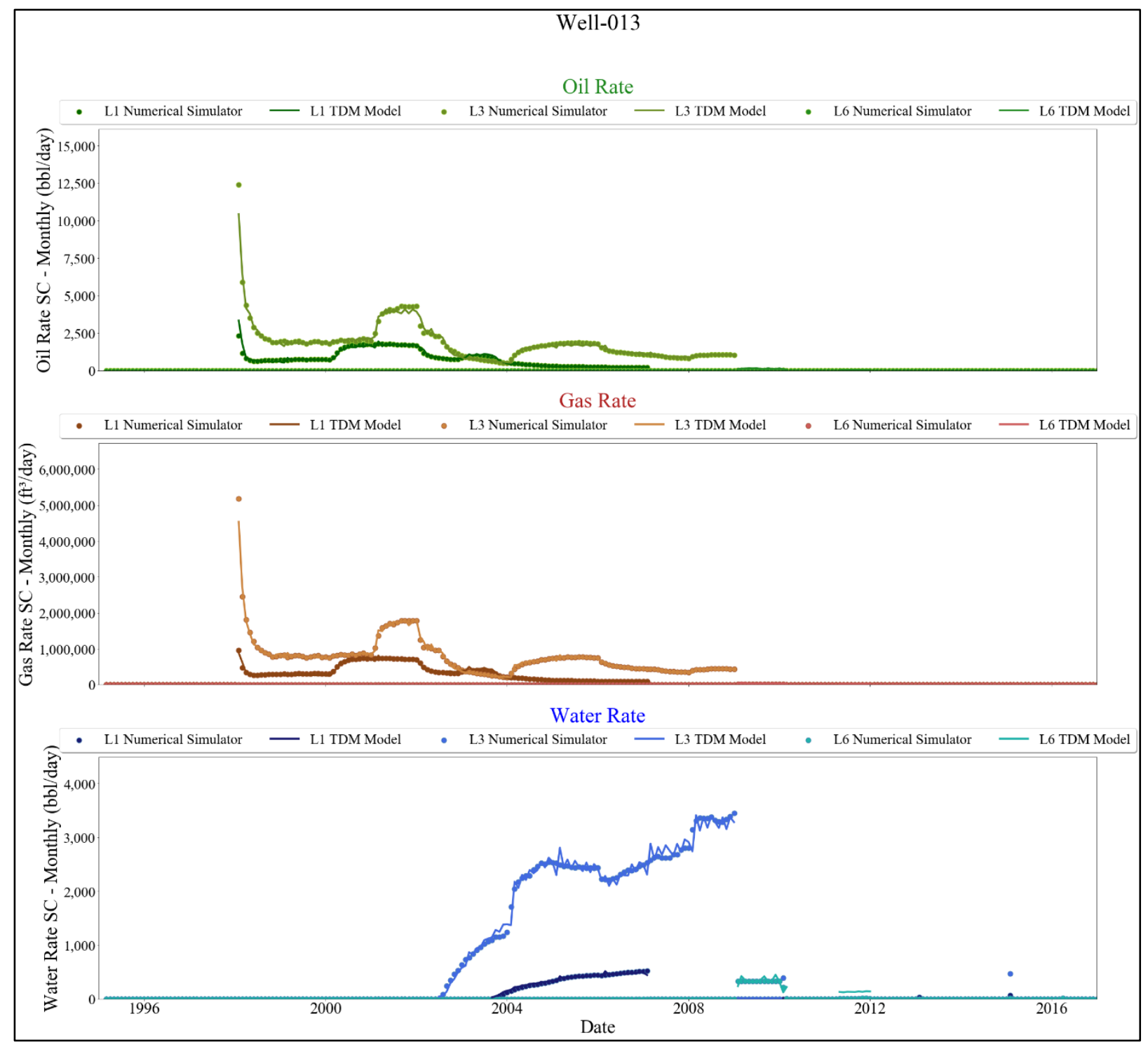

Figure 38: Well-013 production profile per Layer 


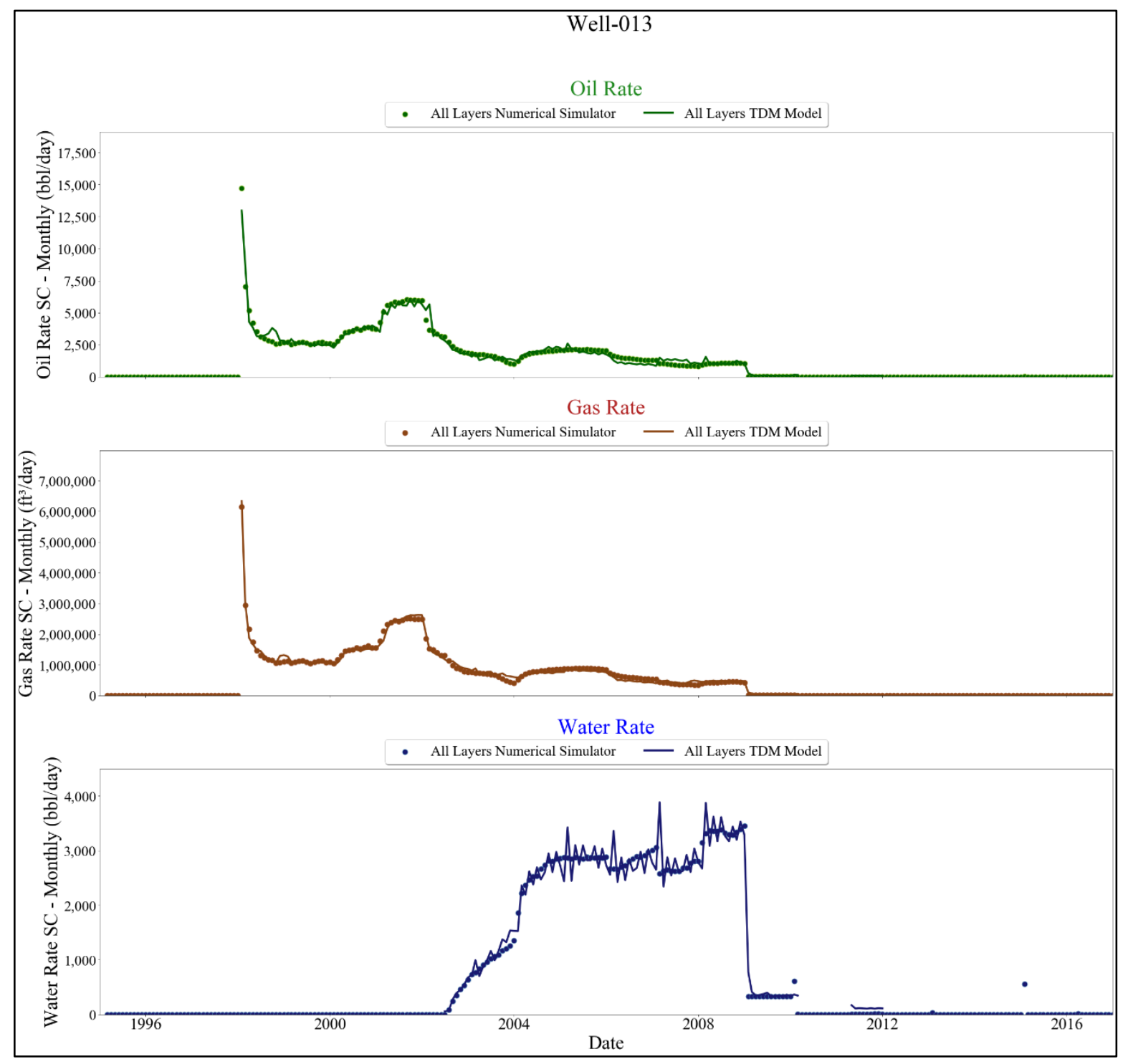

Figure 39: Well-013 vertical production profile 


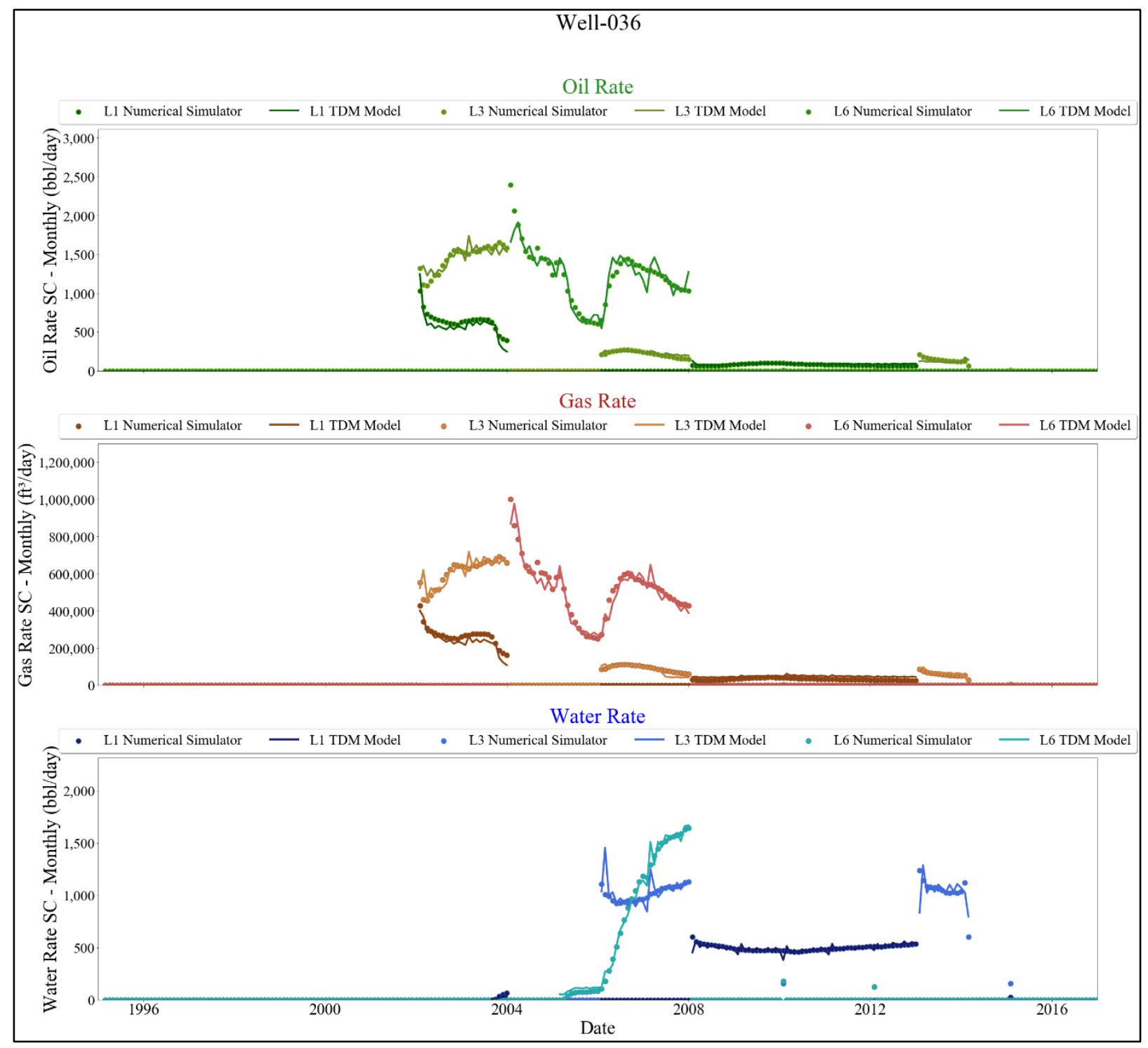

Figure 40: Well-036 production profile per Layer 


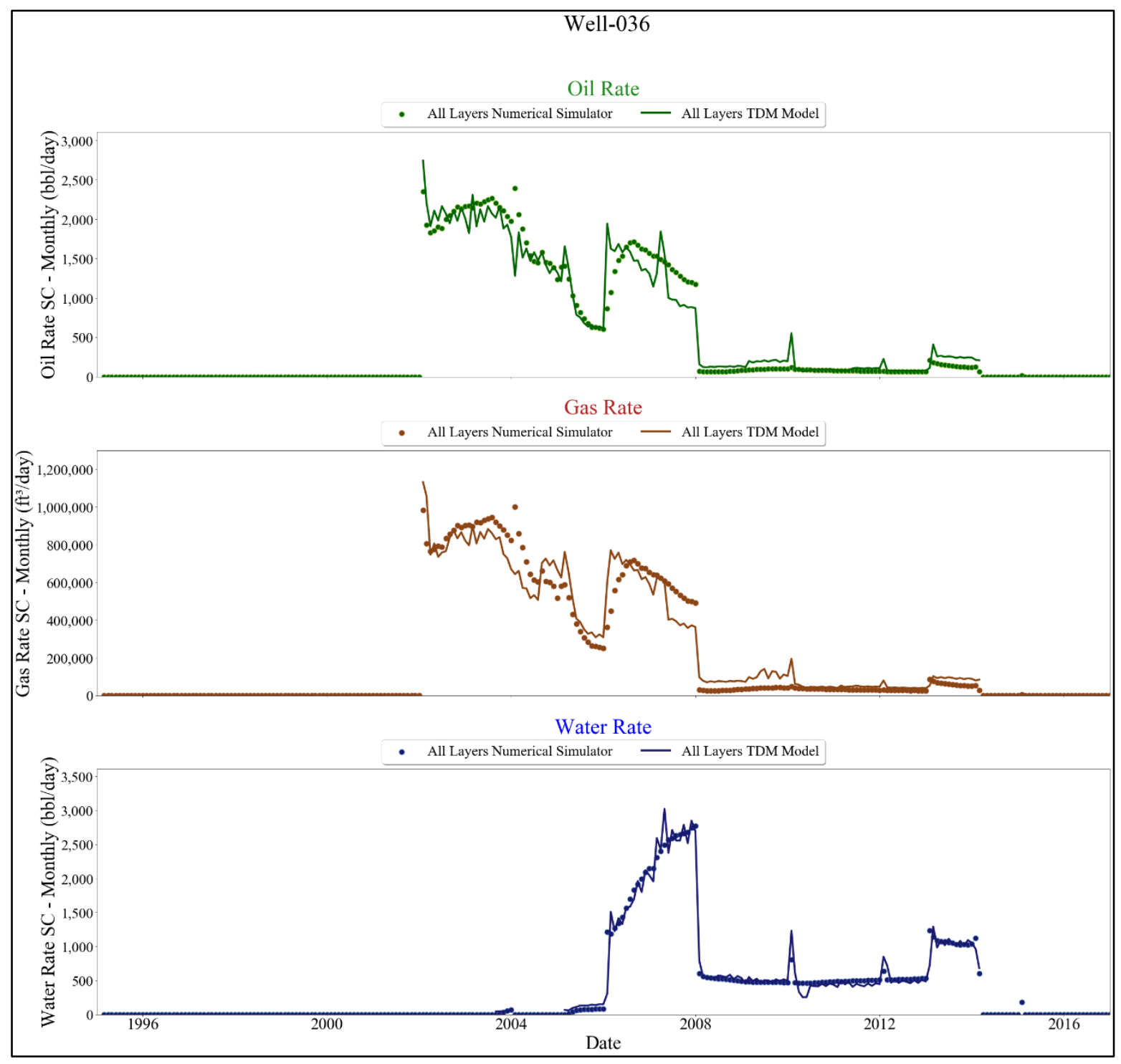

Figure 41: Well-036 vertical production profile 


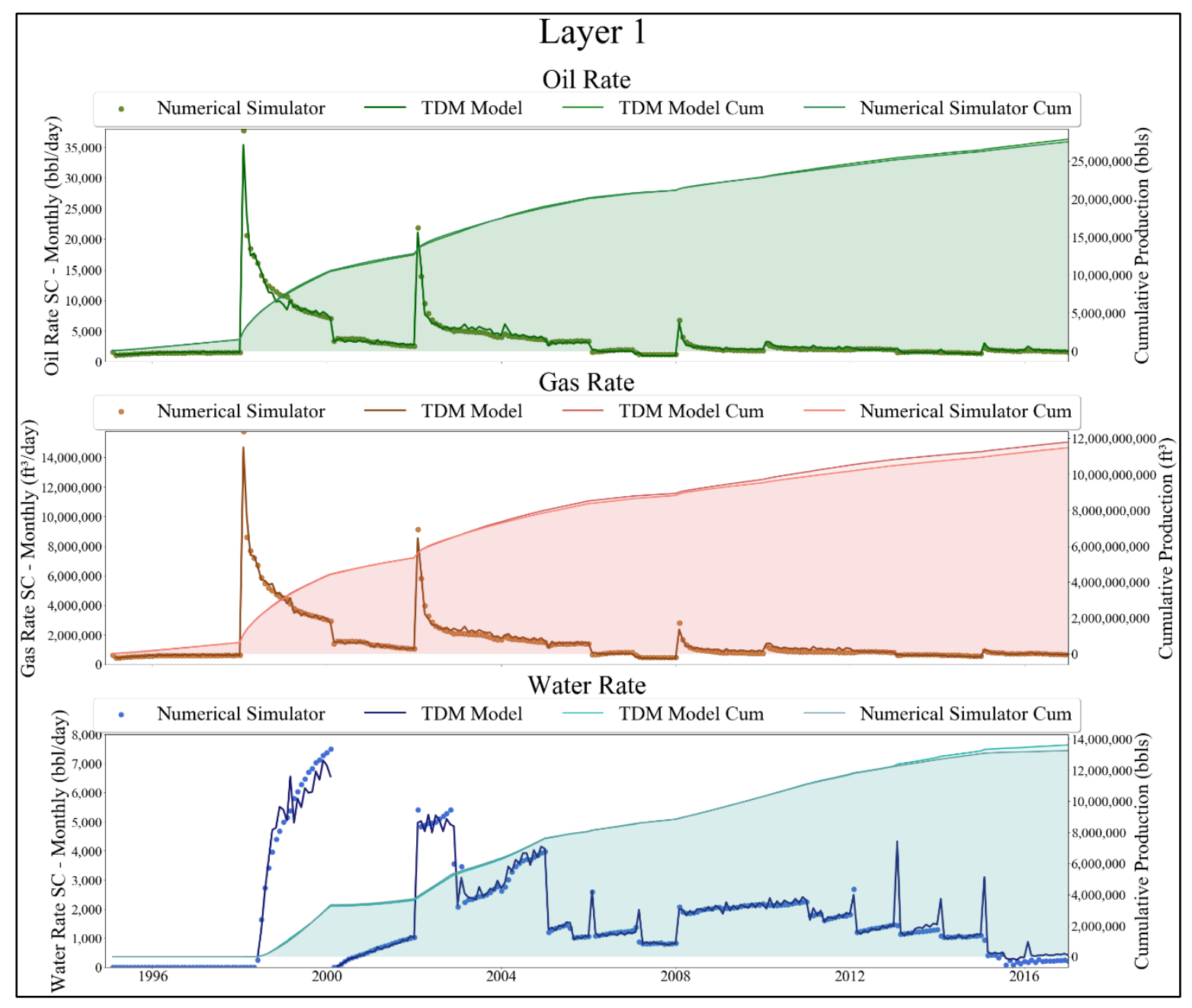

Figure 42: Areal Layer 1 production profile 


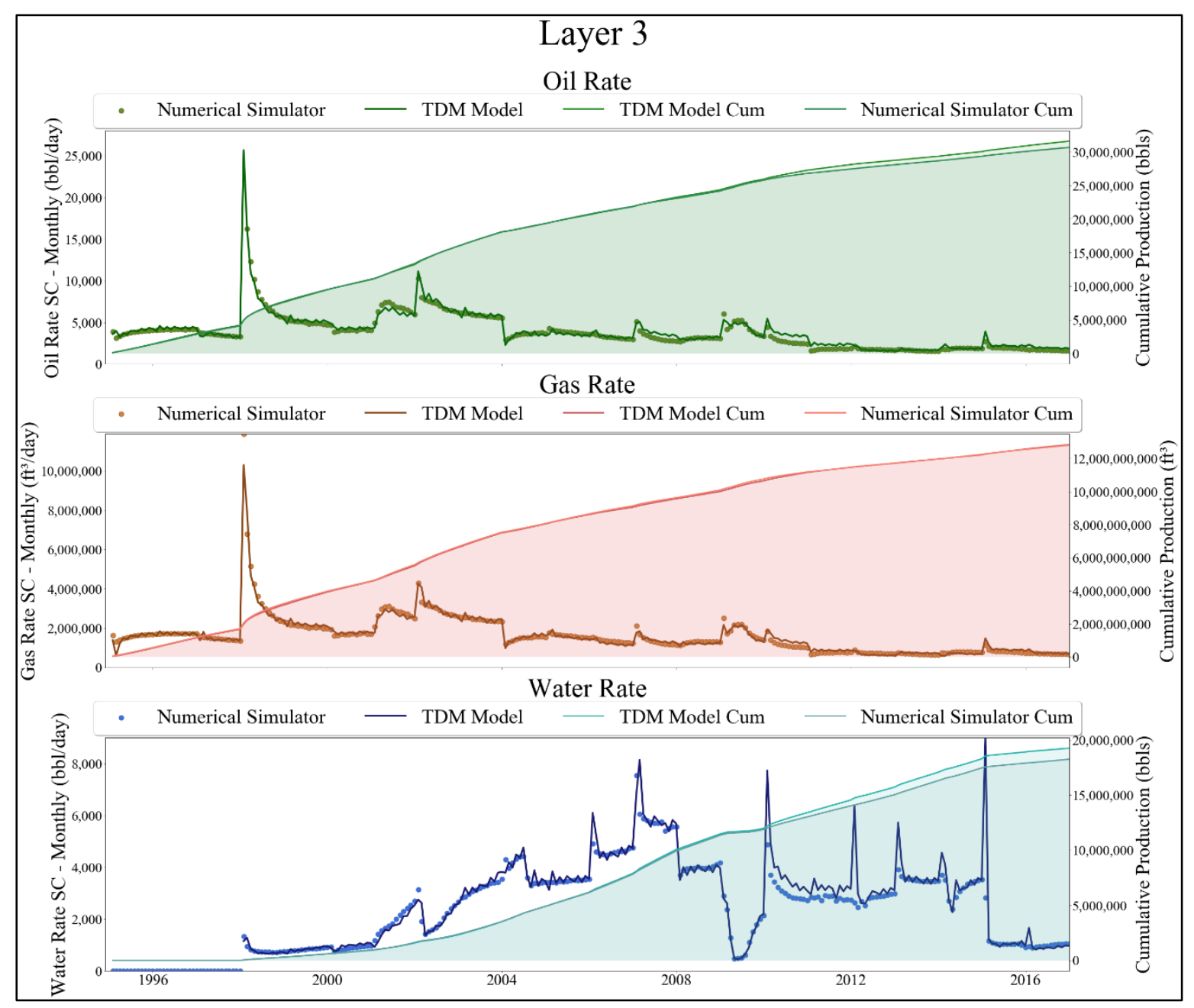

Figure 43: Areal Layer 3 production profile 


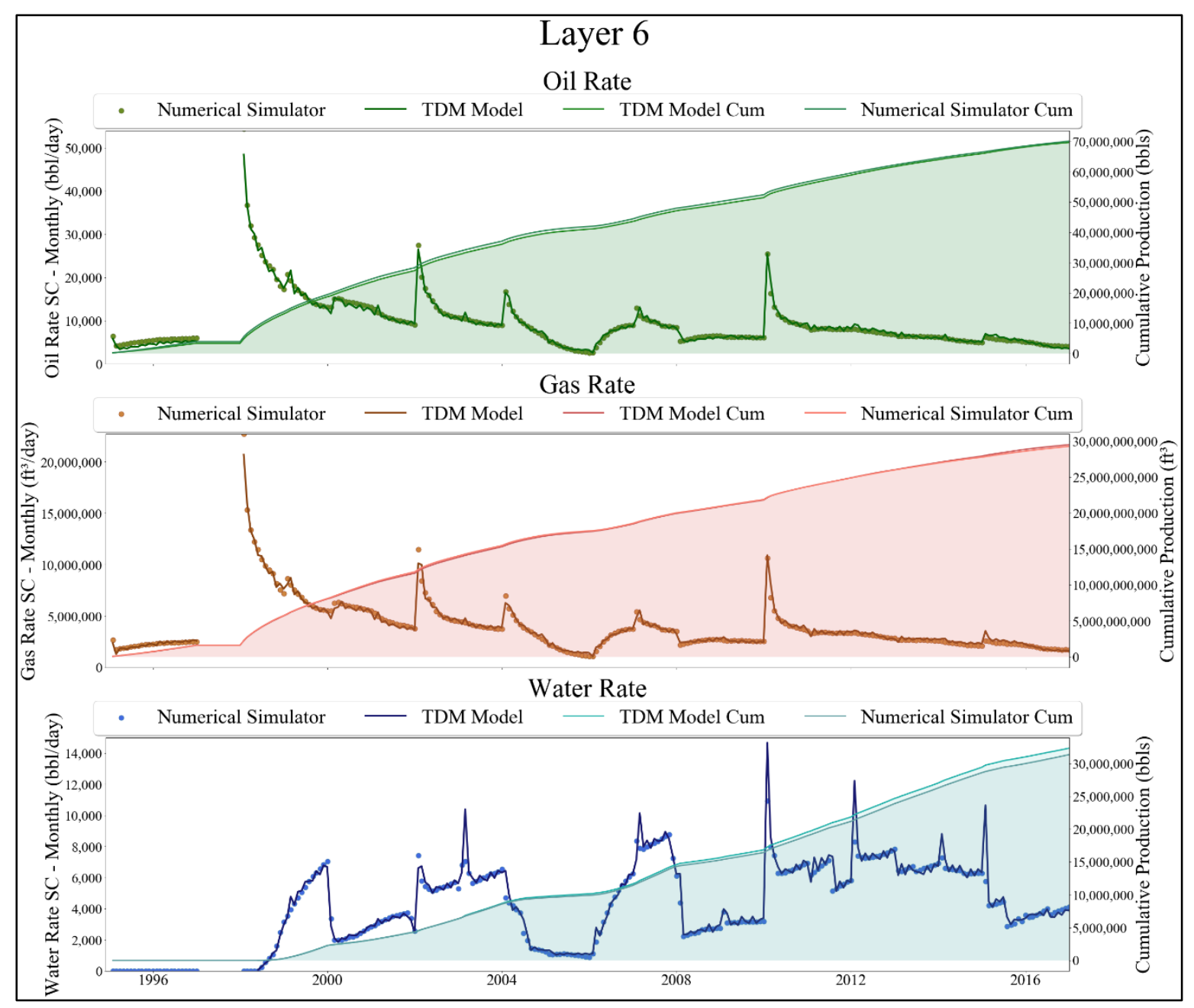

Figure 44: Areal Layer 6 production profile 


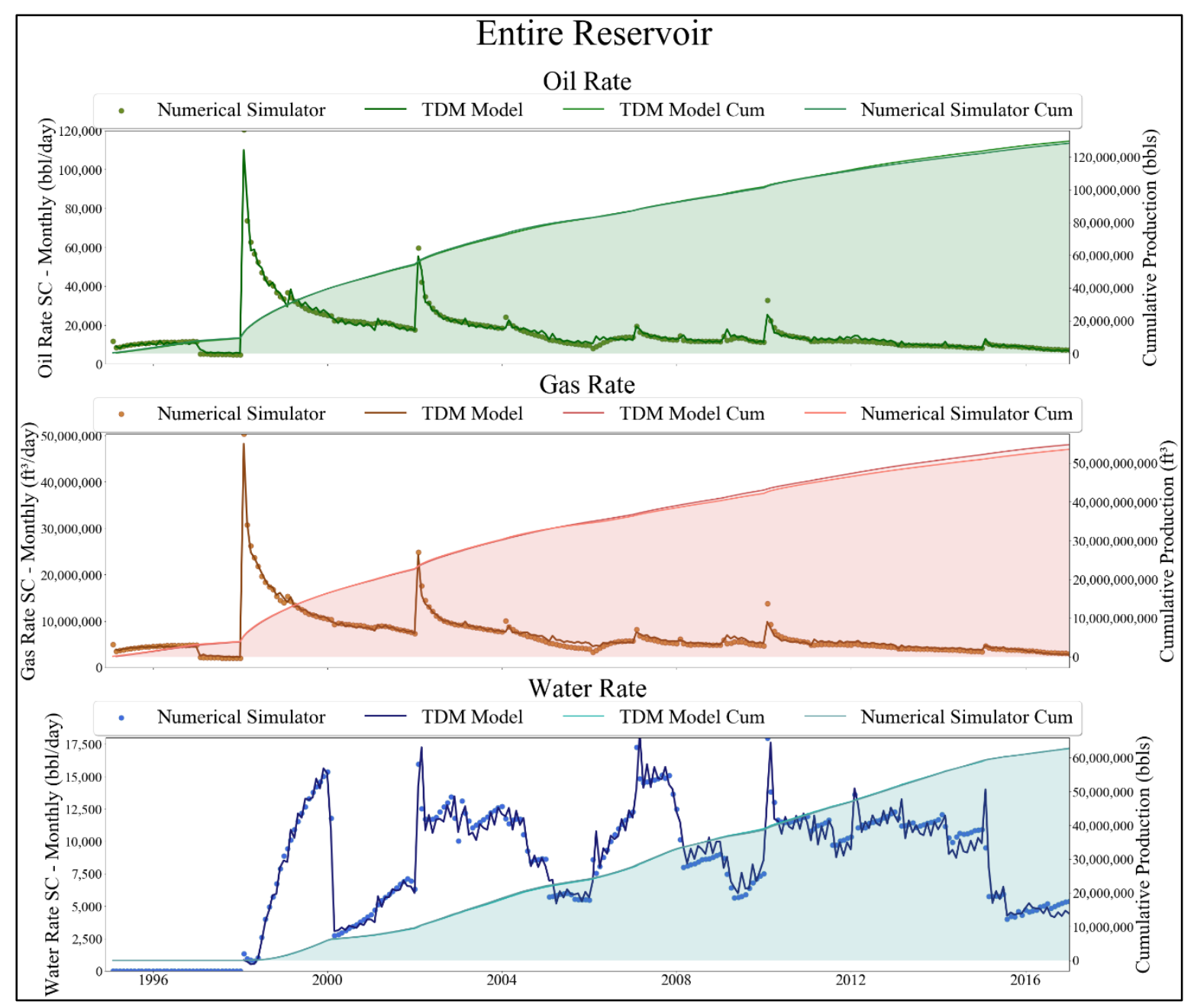

Figure 45: Areal entire reservoir production profile 


\subsection{RESOLUTION IN TIME AND SPACE INVESTIGATION}

As mentioned in chapter 2, the resolution in time and space is a function of the total number of wells, and the length of their production is critical in TDM. So, to perform better quality control, it is essential to investigate layers' behavior in the lack of offsets production. Figure 46 suggests areal production gaps highlighted by the polygons that require a further check for decreasing uncertainties.

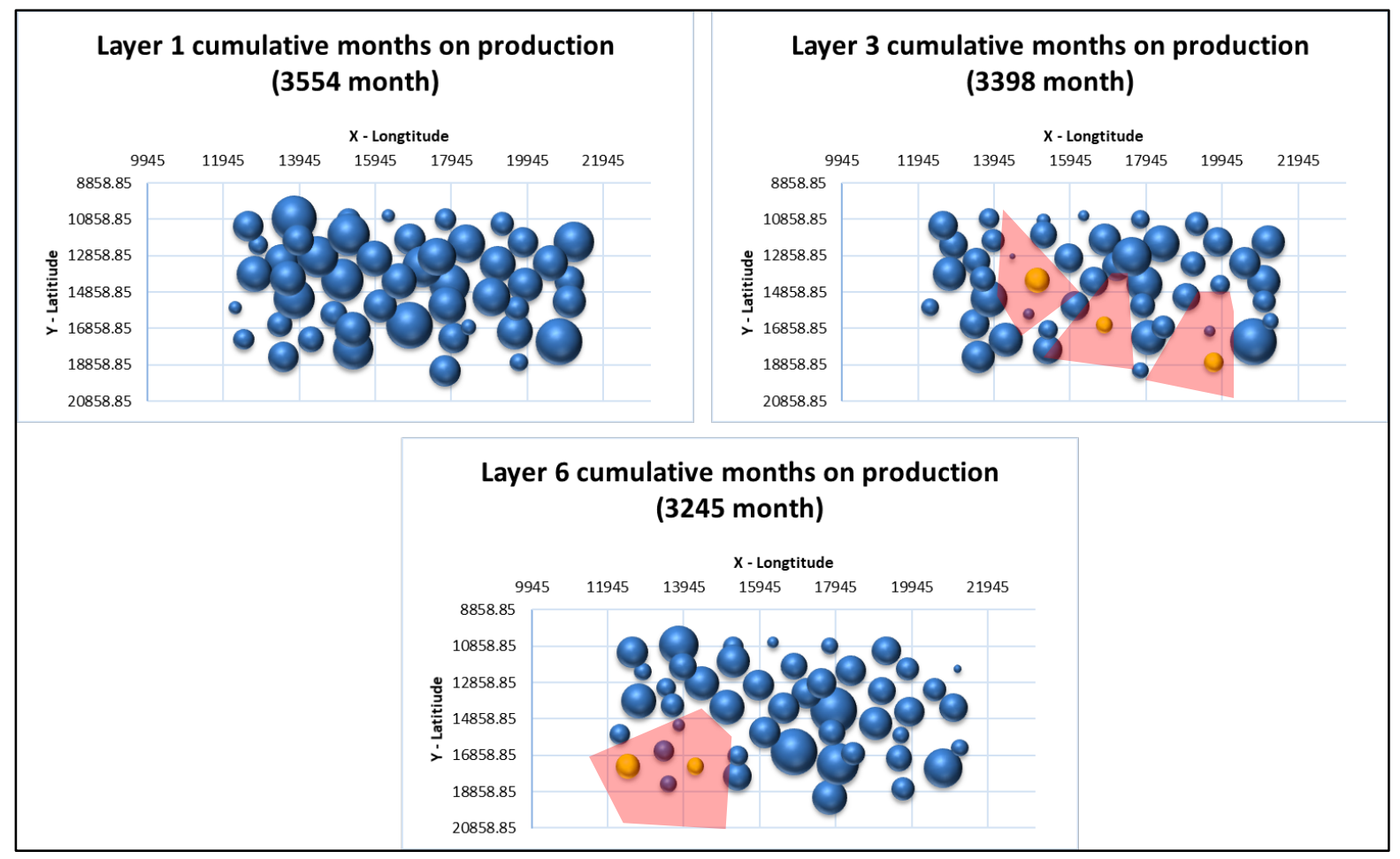

Figure 46: Layer 1, 3, and 6 cumulative months on production

So, Layer three behavior investigation held within well-023, well-026, and well-035, yellow dots on on Figure 46 respectively, as well as Layer six behavior in well-006 and well-018, yellow dots on Figure 46 respectively. The results are shown in Figure 47-51, suggesting proper history matching in allocating production. Despite some discrepancies within Layer six at the well-023 oil and well-035 water profile, the difference is less than $150 \mathrm{bbl} / \mathrm{d}$ suggesting that TDM is capable of approximate reasoning within the current synthetic. 


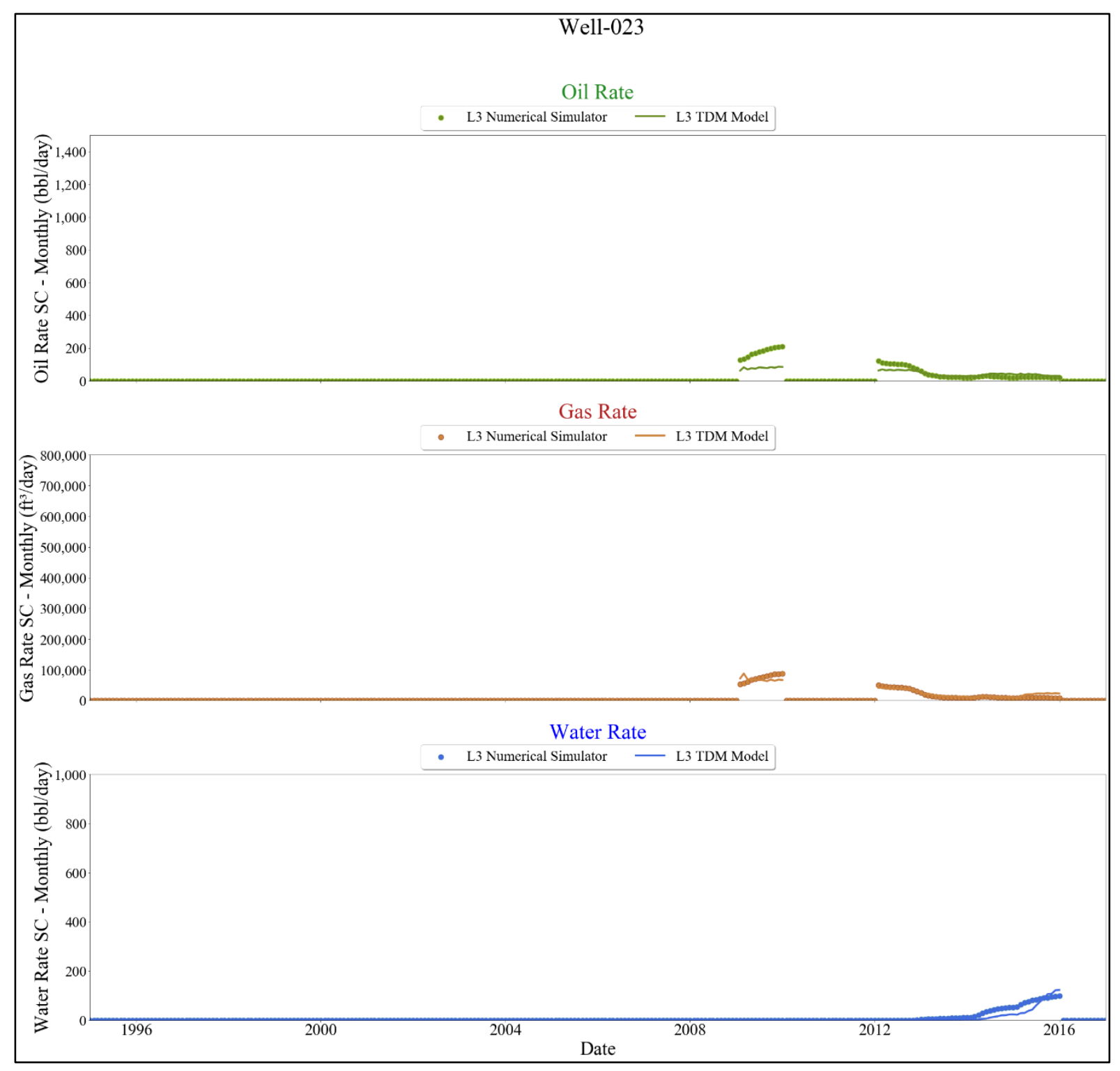

Figure 47: Well-023 Layer 3 allocation profile 


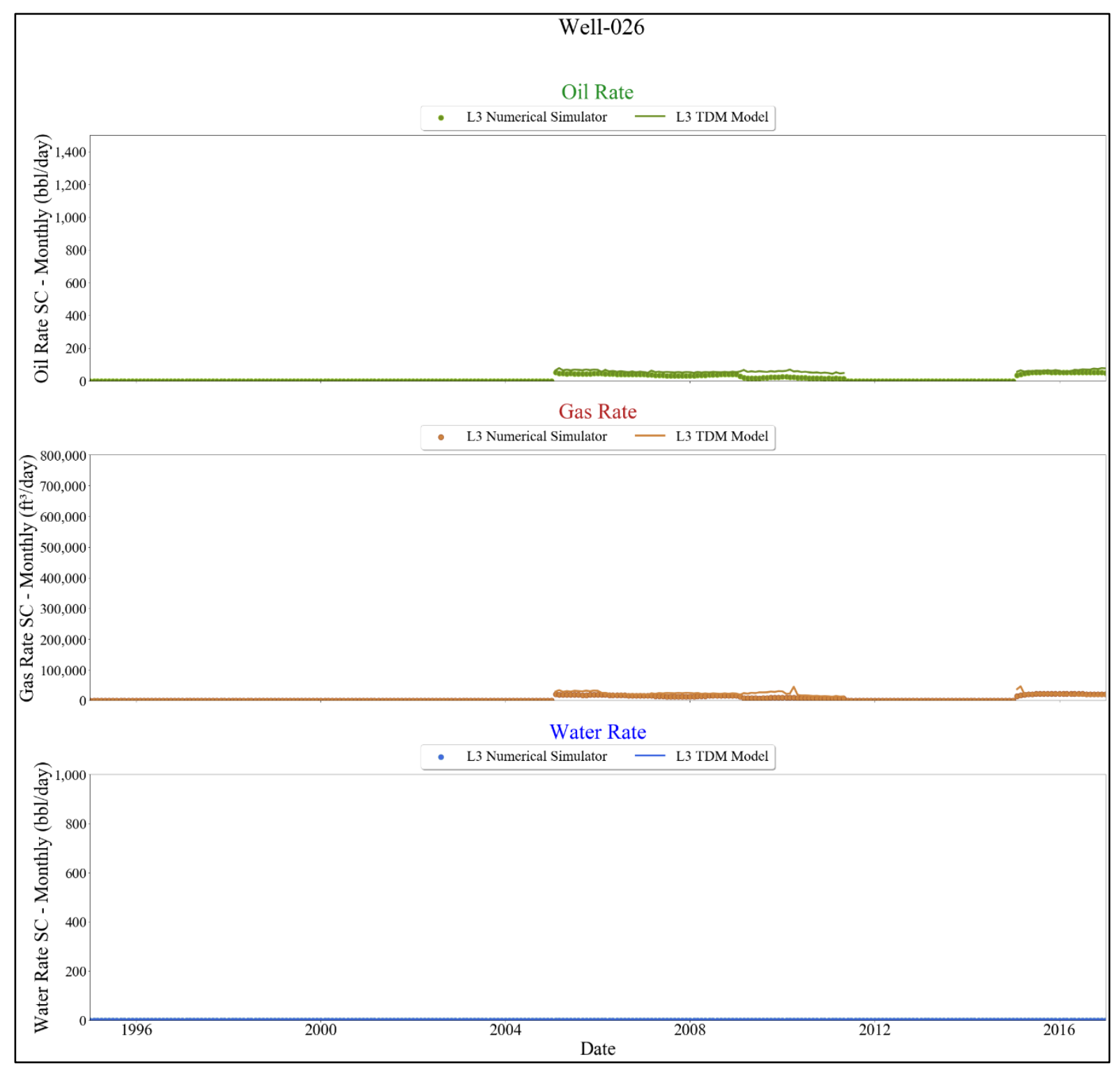

Figure 48: Well-026 Layer 3 allocation profile 


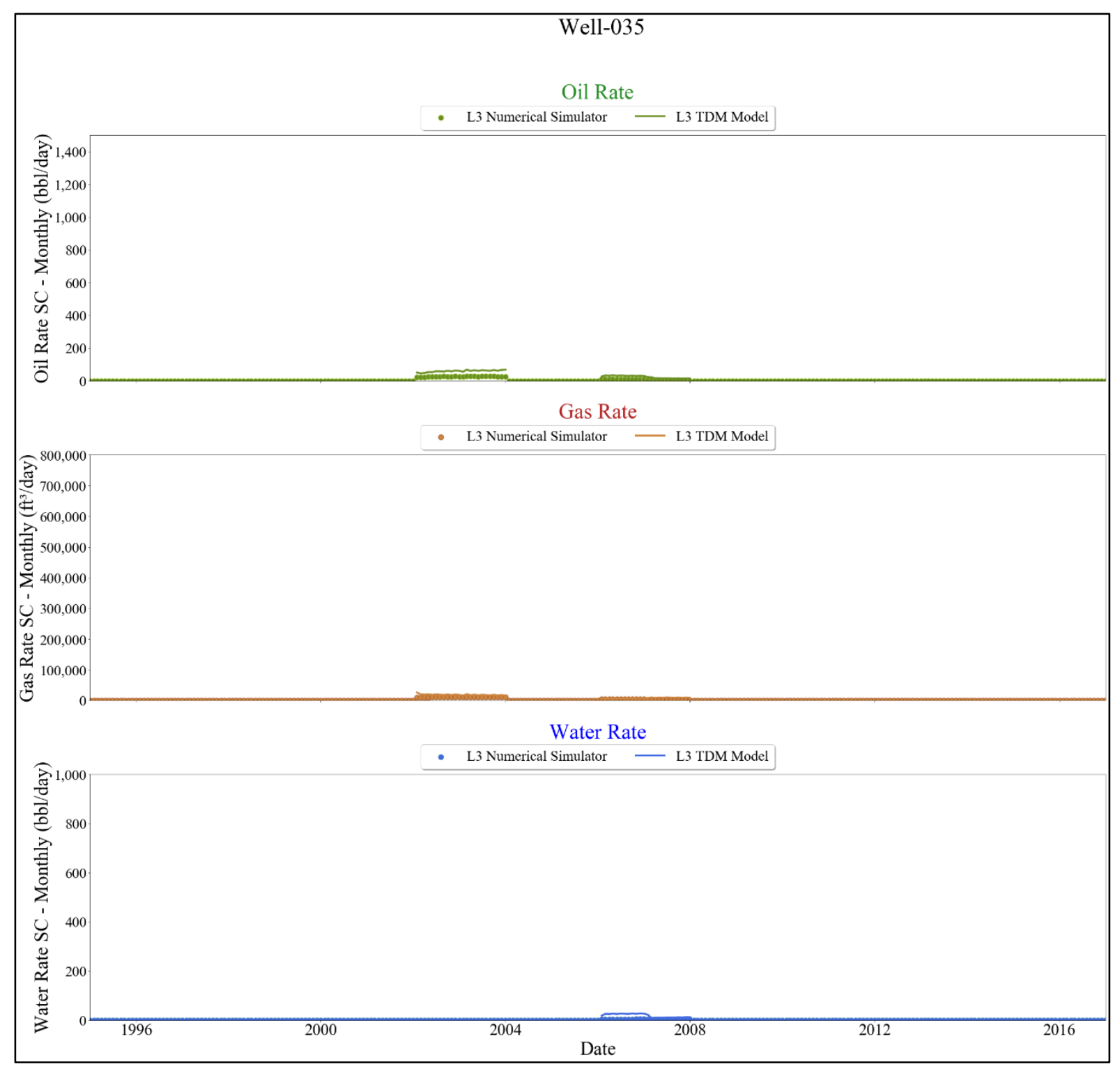

Figure 49: Well-035 Layer 3 allocation profile 


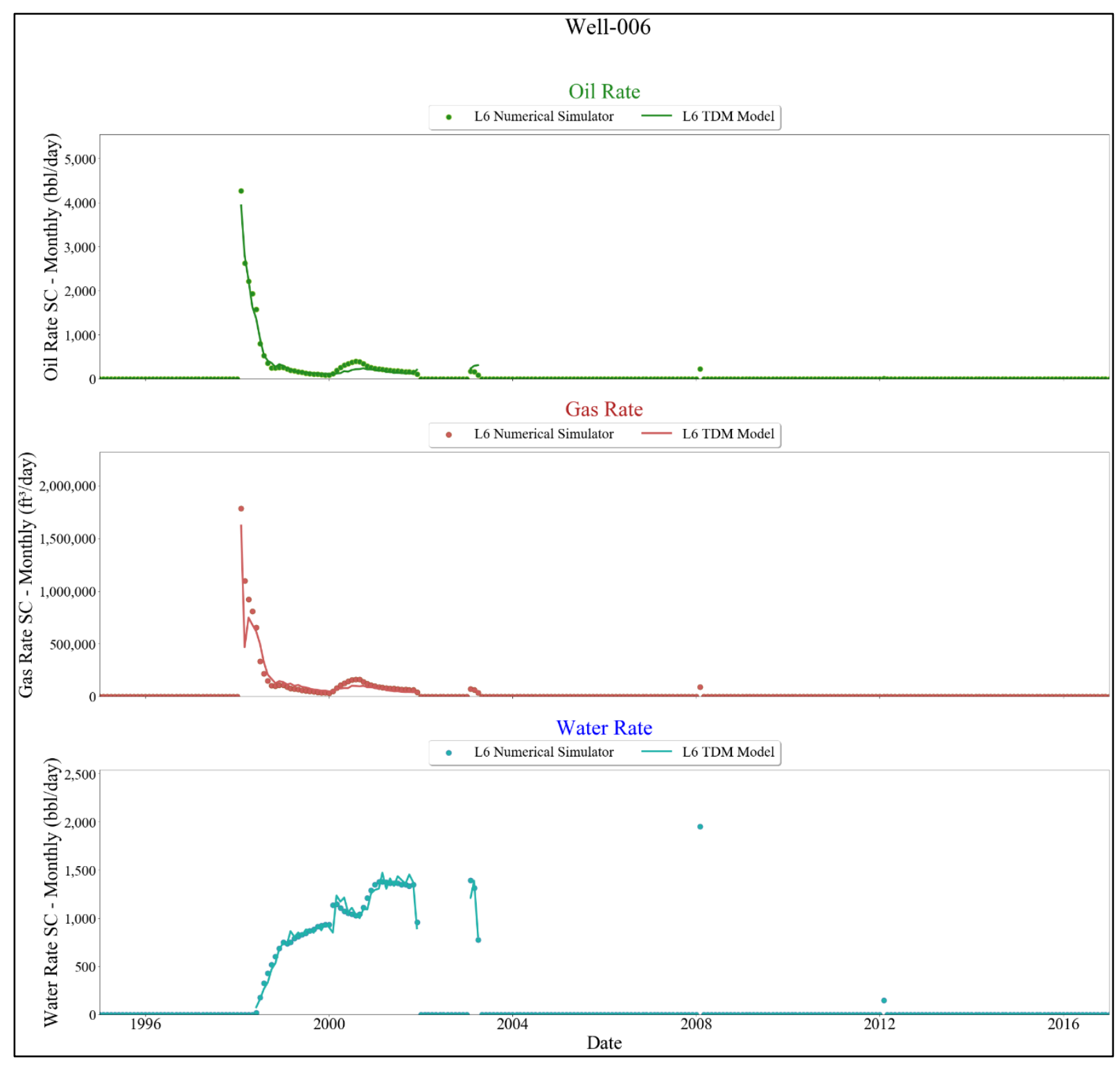

Figure 50: Well-006 Layer 6 allocation profile 


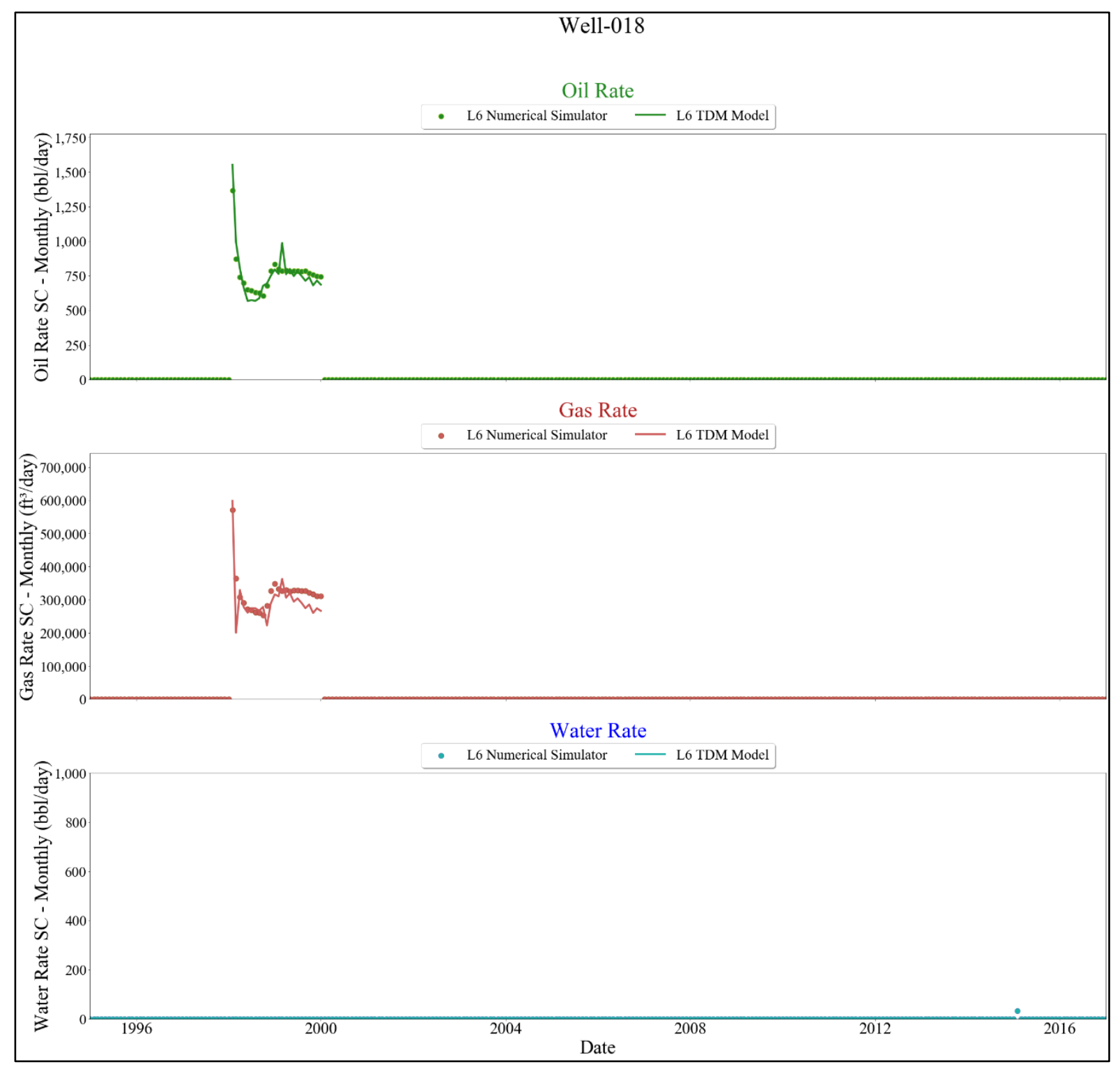

Figure 51: Well-018 Layer 6 allocation profile

\subsection{KEY PERFORMANCE INDICATOR}

TDM offers KPI behavior analysis using Fuzzy cluster analysis that provides understanding of reservoir behavior through finding patterns within vague data. The KPI behavior patterns can be used as a reference tool for completion recommendations such as new completions location, stimulation, and recommended operation constraints. 


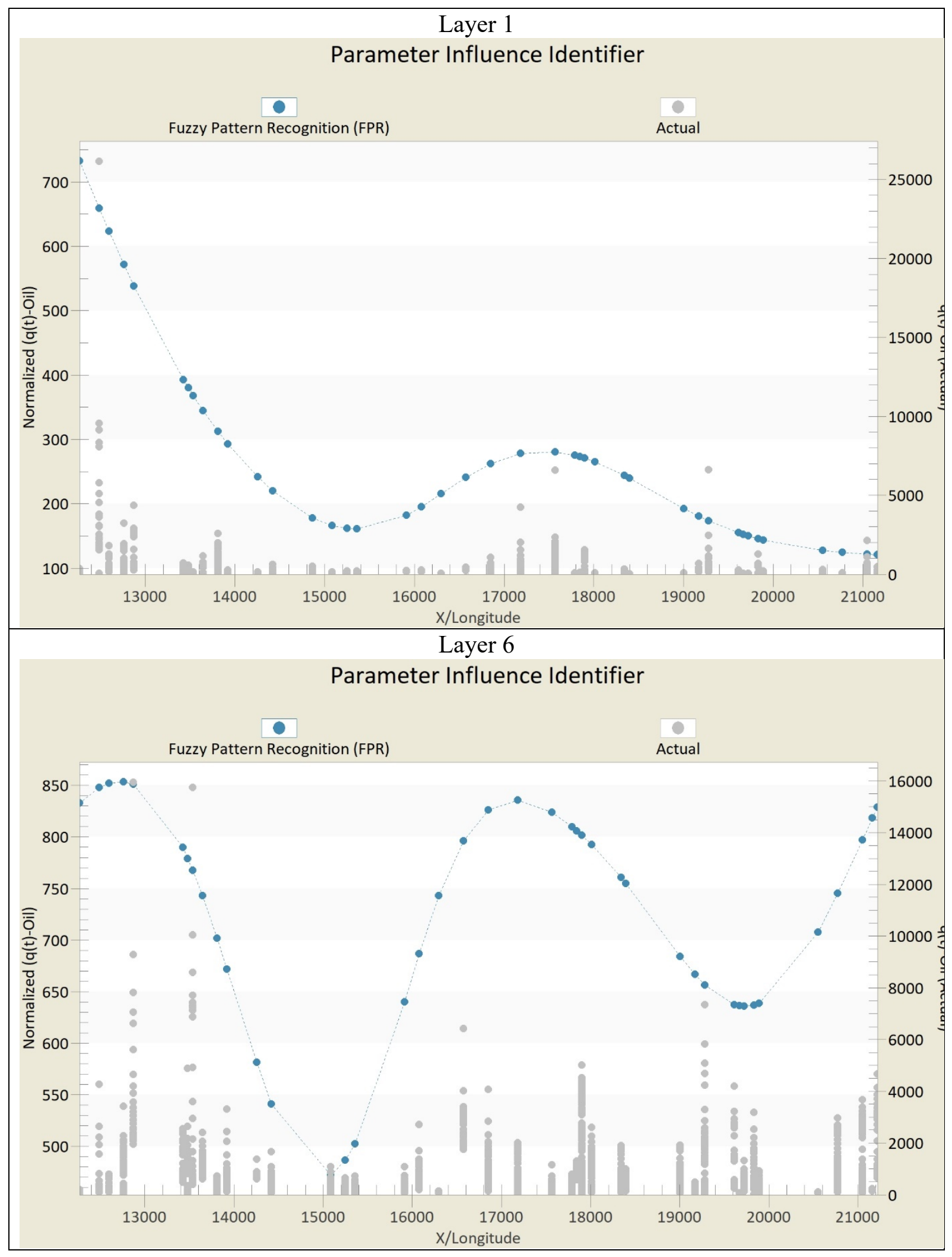

Figure 52: Key Performance behavior for X/Longitude of Layer 1 and Layer 6 


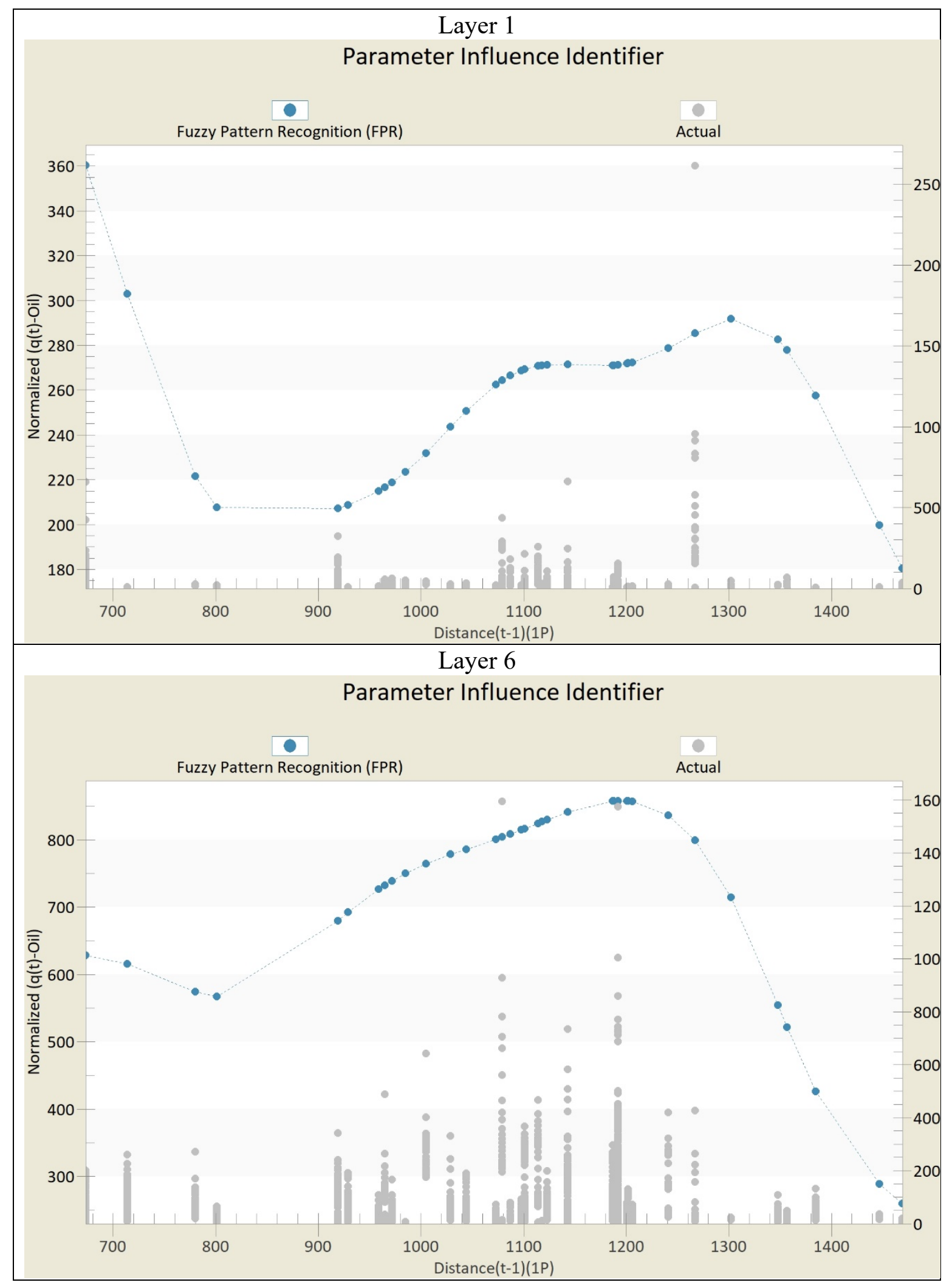

Figure 53: Key Performance for offsets distance of Layer 1 and Layer 6 


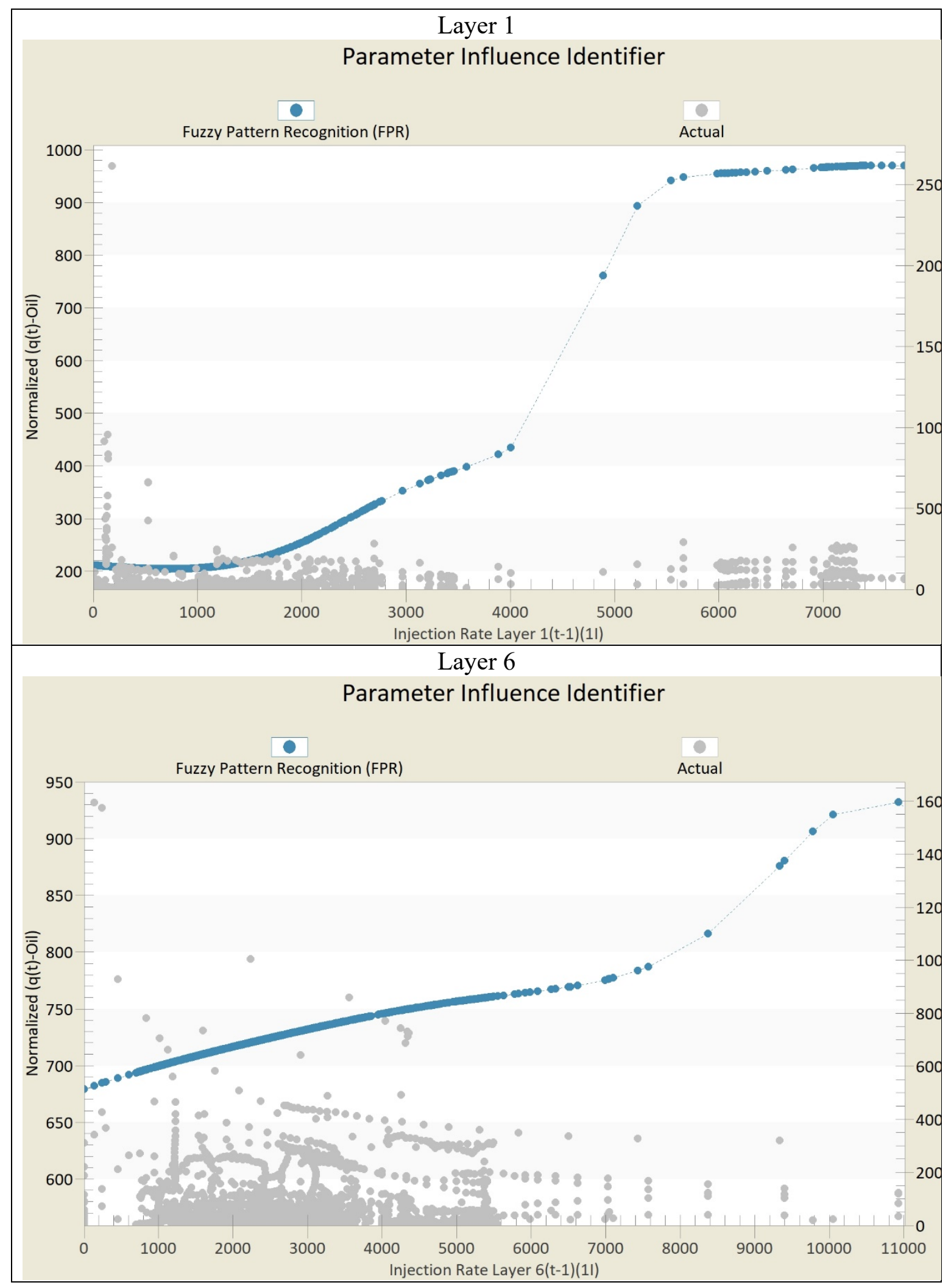

Figure 54: Key Performance for water injection of Layer 1 and Layer 6 
Figure 52 represents an understanding of reservoir heterogeneity, showing considerable flexibility in Layer six as a function of well location production since Layer 6 is homogenous. However, Layer one heterogeneity has a significant influence on production since most of the locations have low production as compared to Layer 6. This KPI behavior gives an impression regarding the new well's location.

Another understanding of the reservoir behavior seen throughout Figure 53; that the distance of offset wells has a higher impact on Layer six as compared to Layer one because of the high-pressure communication in Layer 6.

Lastly, Figure 54 represents the injection effect on oil production, and because Layer 1 is heterogeneous, the injection effect on production has a lower impact than in Layer 6.

\subsection{TDM'S TRAINING, VALIDATION, AND CALIBRATION}

The earlier discussed results passed the TDM training, calibration, and verification briefly explained in the literature review section. 4 TDM models were deployed after five levels individually (refer to Figure 21) to obtain the results presented above. The error metric $\mathrm{R}^{2}$ for the entire TDM models was more than 0.95 for training, validation, and calibration, as shown in Table 6 suggest which validate and verify TDM capabilities in history matching commingled layers. 


\begin{tabular}{|c|c|c|c|c|c|}
\hline Layer & Model & Training & Calibration & $\begin{array}{c}\text { History } \\
\text { Matching }\end{array}$ & Epoch \\
\hline \multirow{5}{*}{ Layer 1 TDM } & $q(t)-O i l$ & 0.99079 & 0.96201 & 0.95598 & 14521 \\
\hline & $q(\mathrm{t})-\mathrm{Gas}$ & 0.99206 & 0.95121 & 0.98779 & 12549 \\
\hline & $q(\mathrm{t})$-Water & 0.99514 & 0.99544 & 0.99662 & 7166 \\
\hline & $\operatorname{Pr}(\mathrm{psi})(\mathrm{t})$ & 0.99315 & 0.98467 & 0.99032 & 6236 \\
\hline & $\mathrm{Sw}(\%)(\mathrm{t})$ & 0.99759 & 0.99501 & 0.99578 & 6168 \\
\hline \multirow{5}{*}{ Layer 3 TDM } & $q(t)-$ Oil & 0.98528 & 0.98278 & 0.9834 & 5203 \\
\hline & $q(\mathrm{t})-\mathrm{Gas}$ & 0.99253 & 0.97743 & 0.97189 & 8152 \\
\hline & $q(t)$-Water & 0.99663 & 0.99471 & 0.99542 & 6176 \\
\hline & $\operatorname{Pr}(p s i)(t)$ & 0.98701 & 0.9764 & 0.9808 & 6825 \\
\hline & $\mathrm{Sw}(\%)(\mathrm{t})$ & 0.99842 & 0.99695 & 0.99647 & 9464 \\
\hline \multirow{5}{*}{ Layer 6 TDM } & $q(t)-O i l$ & 0.99115 & 0.97087 & 0.98422 & 6795 \\
\hline & $q(\mathrm{t})-\mathrm{Gas}$ & 0.99103 & 0.9549 & 0.97166 & 5128 \\
\hline & $q(t)$-Water & 0.99575 & 0.99117 & 0.98883 & 4510 \\
\hline & $\operatorname{Pr}(\mathrm{psi})(\mathrm{t})$ & 0.99373 & 0.97164 & 0.9804 & 5172 \\
\hline & $\operatorname{Sw}(\%)(t)$ & 0.99767 & 0.99381 & 0.9928 & 5413 \\
\hline \multirow{5}{*}{$\begin{array}{c}\text { Total Layers } \\
\text { TDM }\end{array}$} & $q(t)-O i l$ & 0.96462 & 0.9584 & 0.94647 & 5183 \\
\hline & $q(\mathrm{t})-\mathrm{Gas}$ & 0.97403 & 0.96508 & 0.96612 & 4840 \\
\hline & $q(t)-$ Water & 0.9662 & 0.96017 & 0.97133 & 2312 \\
\hline & $\operatorname{Pr}(p s i)(t)$ & 0.96932 & 0.95888 & 0.96816 & 5129 \\
\hline & $\mathrm{Sw}(\%)(\mathrm{t})$ & 0.99142 & 0.98698 & 0.98723 & 2275 \\
\hline
\end{tabular}

On the other hand, it is important to mention that $10 \%$ of the wells records was used for history matching while at least 70\% of the data was used for training the TDM's with more details within Table 10. 
Table 7: partitioning across TDM models

\begin{tabular}{|c|c|c|c|c|}
\hline Layer & Model & $\begin{array}{c}\text { Training } \\
\%\end{array}$ & $\begin{array}{c}\text { Calibration } \\
\%\end{array}$ & $\begin{array}{c}\text { History } \\
\text { Matching } \\
\%\end{array}$ \\
\hline \multirow{3}{*}{ Layer 1} & $\mathrm{q}(\mathrm{t})-\mathrm{Oil}$ & 80 & 10 & 10 \\
\hline & $q(\mathrm{t})$-Water & 70 & 20 & 10 \\
\hline & $\mathrm{q}(\mathrm{t})-\mathrm{Gas}$ & 80 & 10 & 10 \\
\hline \multirow{3}{*}{ Layer 3} & $\mathrm{q}(\mathrm{t})-\mathrm{Oil}$ & 70 & 20 & 10 \\
\hline & $\mathrm{q}(\mathrm{t})$-Water & 70 & 20 & 10 \\
\hline & $q(t)$-Gas & 70 & 20 & 10 \\
\hline \multirow{3}{*}{ Layer 6} & $\mathrm{q}(\mathrm{t})-\mathrm{Oil}$ & 70 & 20 & 10 \\
\hline & $\mathrm{q}(\mathrm{t})$-Water & 70 & 20 & 10 \\
\hline & $q(t)$-Gas & 70 & 20 & 10 \\
\hline \multirow{3}{*}{$\begin{array}{c}\text { Total } \\
\text { Layers }\end{array}$} & $\mathrm{q}(\mathrm{t})$-Oil & 80 & 10 & 10 \\
\hline & $q(t)$-Water & 80 & 10 & 10 \\
\hline & $q(t)-G a s$ & 80 & 10 & 10 \\
\hline
\end{tabular}

Figures 55-58 tells more about TDM efficiency in history matching results shown by the green symbol approving excellent history matching for $10 \%$ of the total data per model. While having more than $0.97 \mathrm{R}^{2}$ for pressure and water saturation predictive models gives certainty that TDM is also a tool for forecasting reservoir pressure and water saturation. 


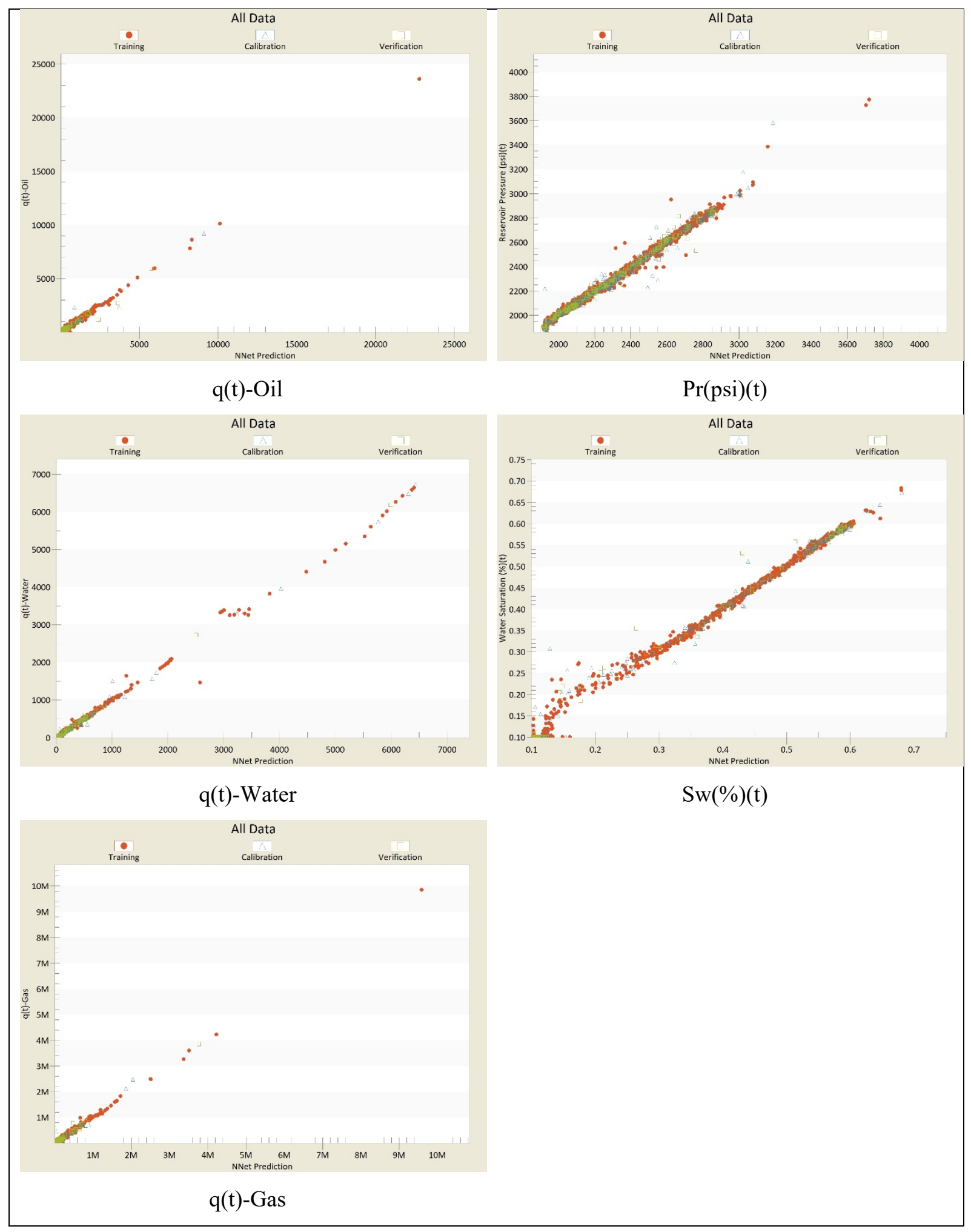

Figure 55: Layer 1 TDM numerical reservoir simulation versus neural networks perdition cross plot

68 

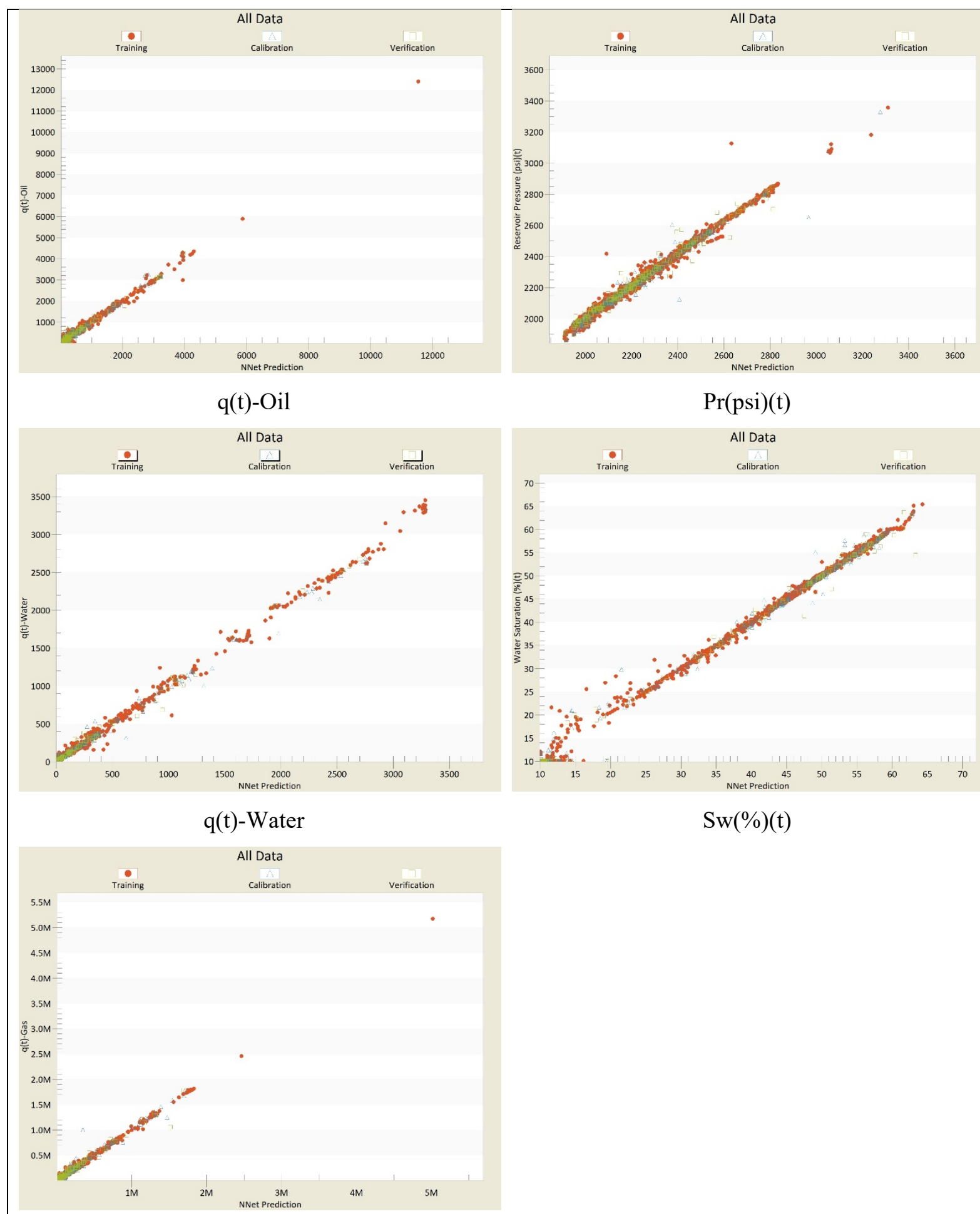

$\operatorname{Sw}(\%)(\mathrm{t})$

$\mathrm{q}(\mathrm{t})-\mathrm{Gas}$

Figure 56: Layer 3 TDM numerical reservoir simulation versus neural networks perdition cross plot 


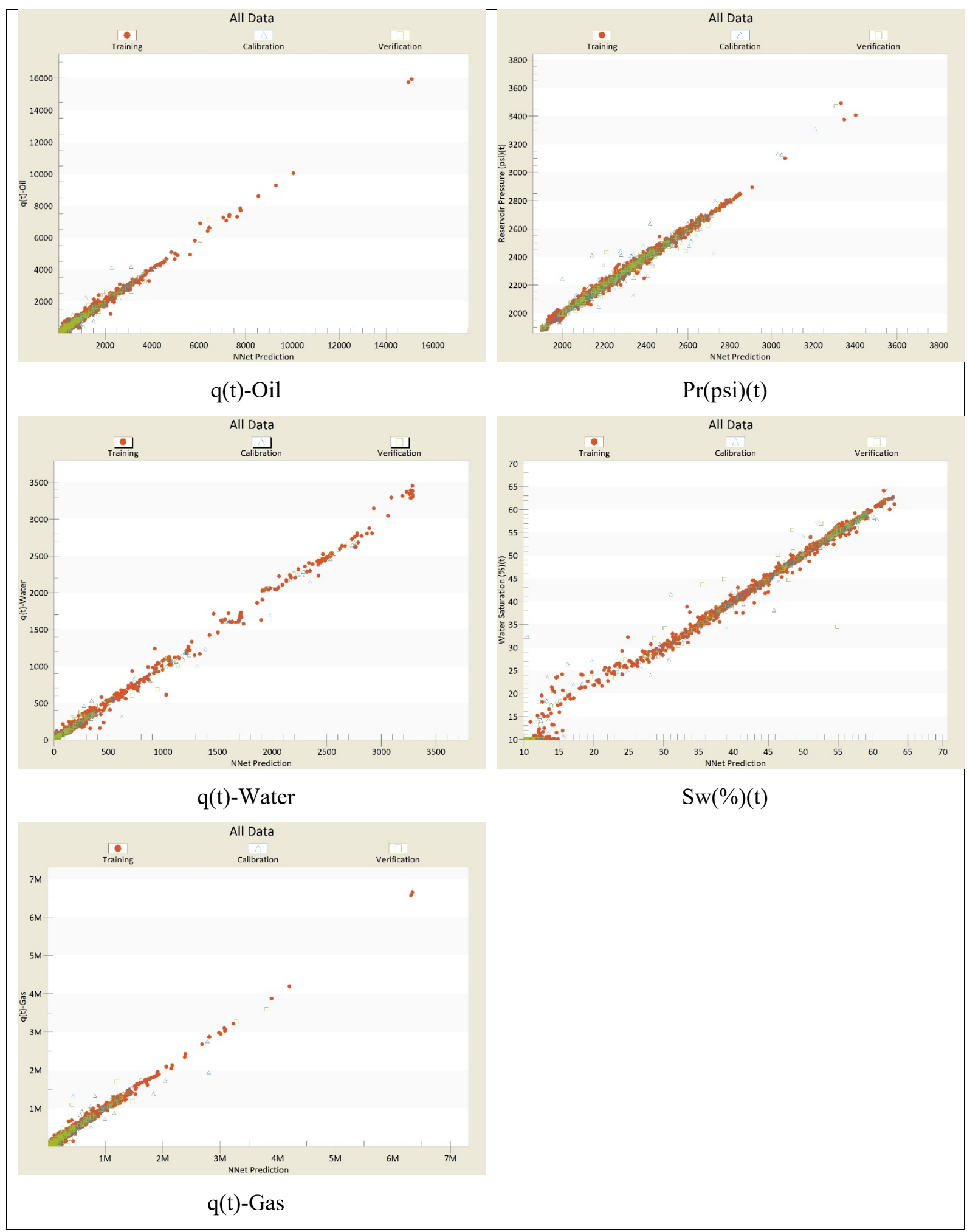

Figure 57: Layer 6 TDM numerical reservoir simulation versus neural networks perdition cross plot 

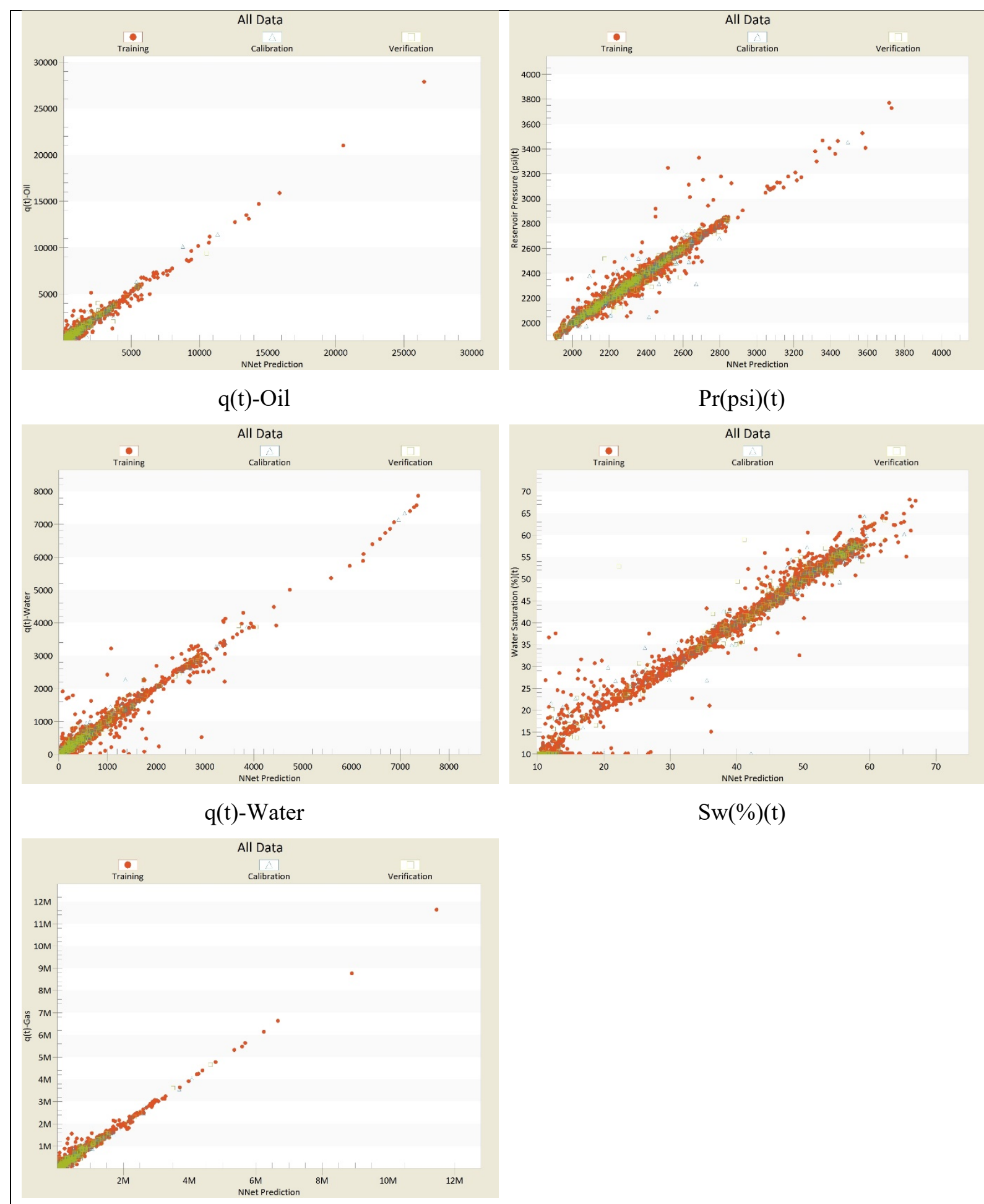

$\mathrm{q}(\mathrm{t})-\mathrm{Gas}$

Figure 58: Total layers TDM numerical reservoir simulation versus neural networks perdition cross plot 


\section{CHAPTER V}

\section{CONCLUSION AND RECOMMENDATIONS}

A study held comparing Top-Down modeling (TDM) with the commonly static KH modeling (KH) in allocating production from commingled layers. The research performed on a heterogeneous reservoir consisting of three producing layers commingled differently with a single rock type.

$\mathrm{KH}$ was not capable of adjusting the effect of reservoir pressure among layers within one rock type reservoir, while TDM was excellent in picking pressure/production patterns. This finding drives the conclusion that $\mathrm{KH}$ expected to have high uncertainty with different rock types as the reservoir pressure affects fluids mobility.

The results have shown that TDM is an excellent history matching tool both vertically and horizontally in commingled layers with high certainty. TDM has proven better in allocating water cut since KH is a singlephase modeling tool and usually associated with high ambiguities as water-cut increases.

TDM requires domain expert rather than a computer scientist because the use of the software requires understandings of the flow dynamics as a function of heterogeneity in order to perform space and time calibrations since trial and error practices shown that the more heterogenous the reservoir the less offset wells correlations required.

The key performance indicator can be used as a decision tool for completion recommendation since it offers understanding of reservoir behavior and can be considered as a tool for lesson learning since the KPI behavior can provide understanding of what can impact the production. 
TDM can be used as a tool for pressure and saturation forecasting since the history matching of pressure and water saturation models recorded more than 0.97 on the error metrics.

If TDM is capable of picking reservoir rock and fluids patters, it might be a complemental tool in the lack of data such as well testing which solves most of the brown oil fields surveillance challenges; however, it is recommended to test TDM efficiency in time and space for the lack of field measurements.

As this synthetic model built on one rock type, it is recommended to test TDM on multi rock types and under crossflow scenarios, as well as TDM must be tested on different history matching partitioning. 


\section{REFERENCES}

Alenezi, F., \& Mohaghegh, S. (2017). Developing a Smart Proxy for the SACROC Water-Flooding Numerical Reservoir Simulation Model. SPE. doi:10.2118/185691-MS

Al-Kaabi, A.-A. U., \& Lee, W. J. (1993). Using Artificial Neural Networks To Identify the Well Test Interpretation Model (includes associated papers 28151 and 28165 ). Society of Petroleum Engineers, 237. doi:https://doi.org/10.2118/20332-PA

Aurenhammer, F. (1991). Voronoi Diagram- A Survey of a Fundamental Geometric Data Structure. Austria: ACM Computing Surveys.

Blekhman, V., Diaz, D., Carrica, P., Corbett, C., \& Coca, B. (2001). Calibrating Log-Derived Permeability Data to PTA for Geostatistical Integration into a Fluid-Flow Simulation Model. SPE, 1-3. doi:10.2118/69473-MS

Chia, M. P., Yakup, M. H., Tamin, M., Surin, N. A., Mazzlan, K. A., Rinadi, M., \& Hassan, A. A. (2019). Application of Novel Predictive Analytics for Data Allocation of Commingled Production in Smart Fields. SPE, 310. doi:10.2118/192078-MS

Davarpanah, A., Mirshekari, B., Behbahani, T. J., \& Hemmati, M. (2018). Integrated production logging tools approach for convenient experimental individual Layer permeability measurements in a multi-Layered fractured reservoir. Petroleum Exploration and Production Technology, 743-750. doi:https://doi.org/10.1007/s13202-017$0422-3$

Donald J. Ford, P. (2011). Training Industry. Retrieved from How the Brain Learns: https://trainingindustry.com/articles/content-development/how-the-brain-learns/

Haghighat, S. A., Mohaghegh, S. D., Gholami, V., \& Moreno, D. (2014). Production Analysis of a Niobrara Field Using Intelligent Top-Down Modeling. Society of Petroleum Engineers. doi:10.2118/169573-MS

Haykin, S. (2009). Neural Networks and Learning Machines. Ontario: Pearson Prentice Hall.

Hernandez, A. (2016, July 12). Calibration with Neural Networks. Retrieved from quantlib: https://www.quantlib.org/slides/qlum161/hernandez.pdf

Jamshidi, M., Vadiee, N., \& Ross, T. J. (1993). Prentice Hall Series On Environmental And Intelligent Manufacturing Systems. New Jersey : PTR Prentice Hall. 
Kechut, N. I., Hassan, A. A., Izyan, W. F., Zamri, W. M., Raub, M. R., Tewari, R. D., . . Alessio, L. D. (2017). Advanced Methods for Determining the Value of Information of Surveillance Data Acquisition Using Predictive Analytics. SPE, 10-16. doi:10.2118/186304-MS

Maysami, M., Gaskari, R., \& Mohaghegh, S. D. (2013). Data Driven Analytics in Powder River Basin, WY. Society of Petroleum Engineers. doi:10.2118/166111-MS

Mohaghegh, S. D. (2009). Quantifying Uncertainties Associated With Reservoir Simulation Studies Using a Surrogate Reservoir Model. Society of Petroleum Engineers. doi:10.2118/102492-MS

Mohaghegh, S. D. (2017). Data-Driven Reservoir Modeling. Texas: Society of Petroleum Engineers.

Schuld, M., \& Petruccione, F. (2016). Supervised Learning with Quantum Computers. Springer.

Sullivan, M. J., Belanger, D. L., Dunn, P. C., Jenkins, S. D., \& Skalinski, M. (2006). Permeability From Production Logs - Method and Application. SPE, 1-10. doi:10.2118/102894-MS

Widarsono, B., Atmoko, H., Yuwono, I. P., Saptono, F., Tunggal, _., \& Ridwan, _. (2005). Application of Fuzzy Logic for Determining Production Allocation in Commingle Production Wells. SPE, 1-5. doi:10.2118/93275MS 


\section{APPENDIX}
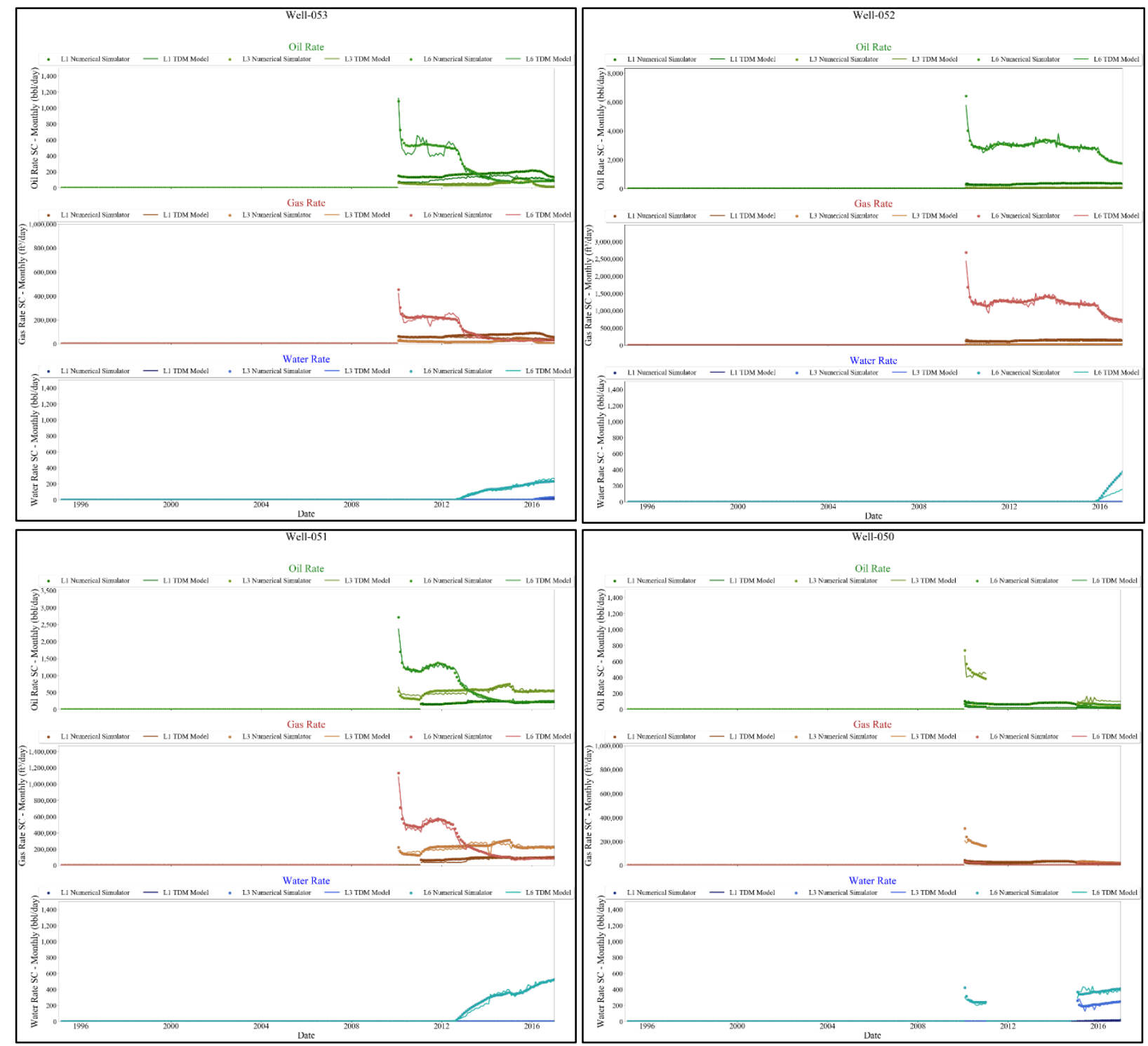

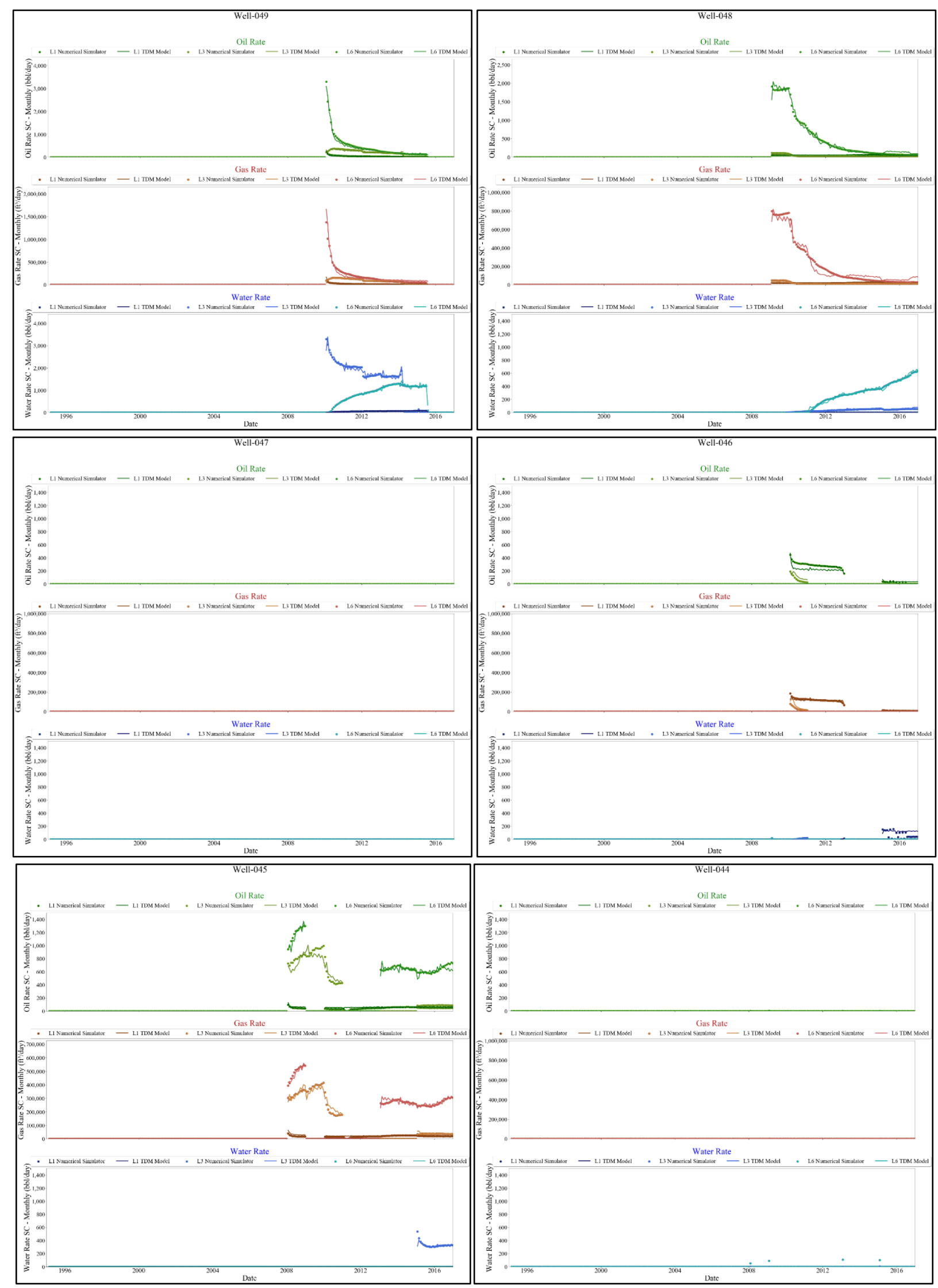

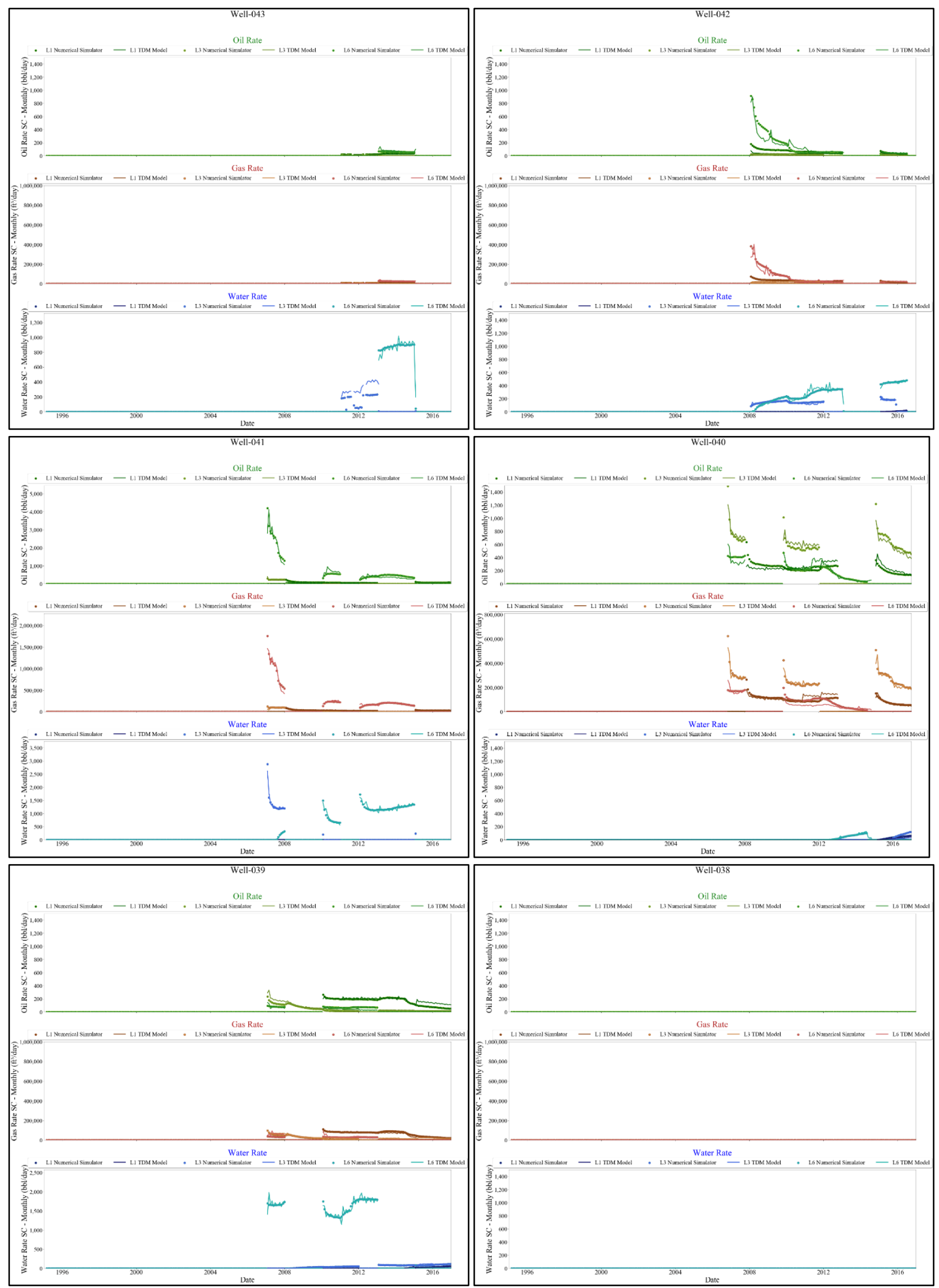

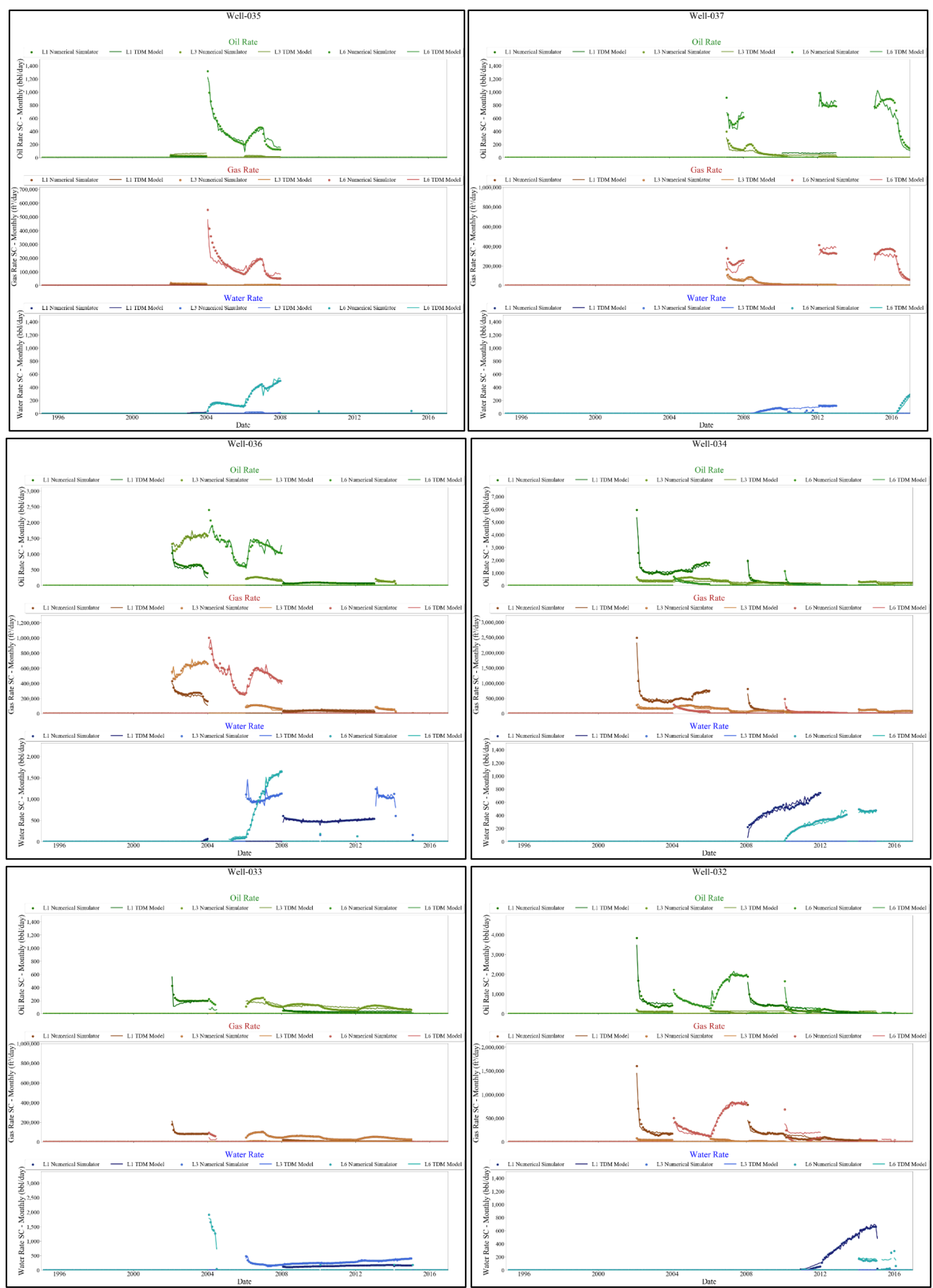

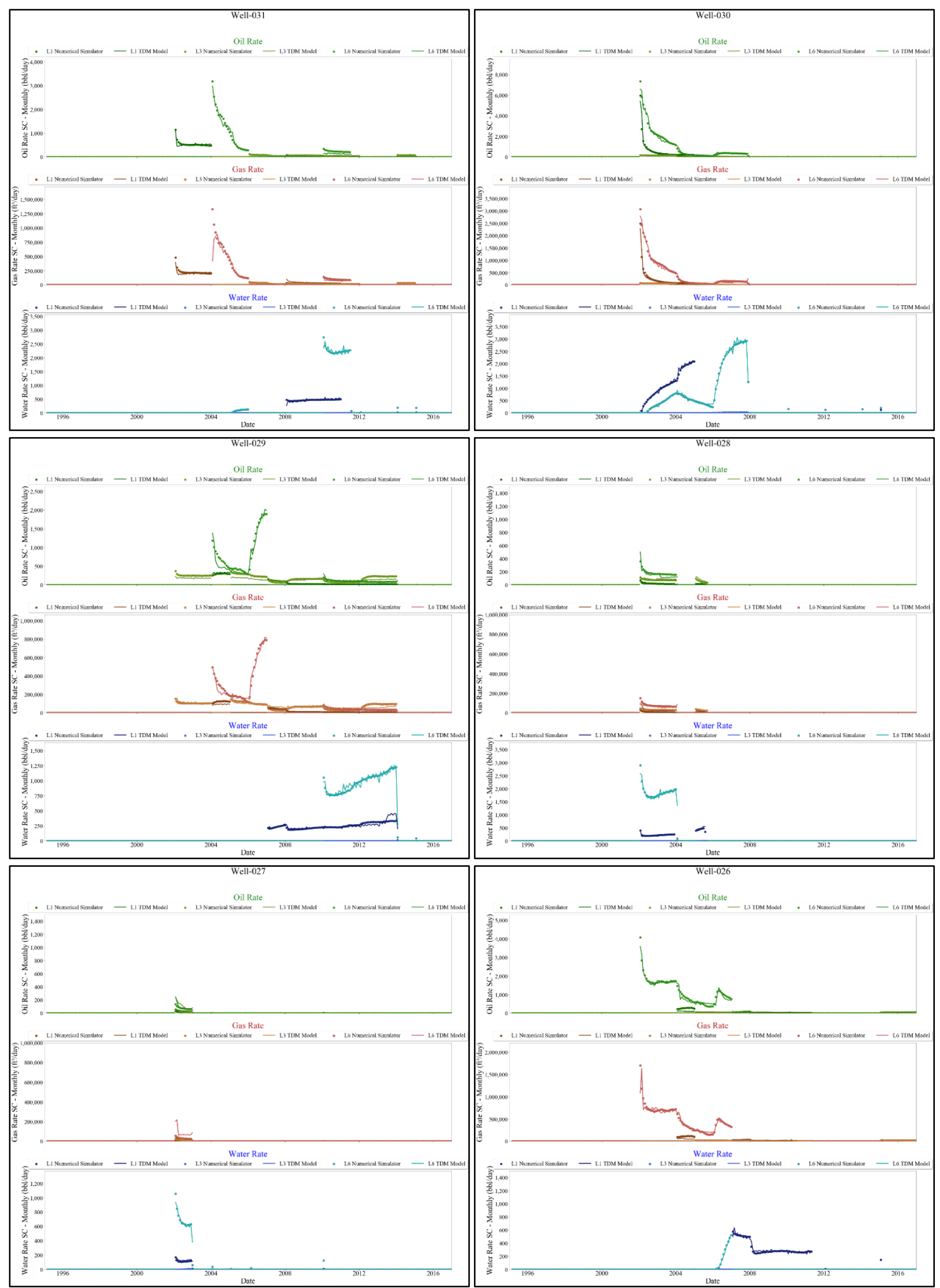

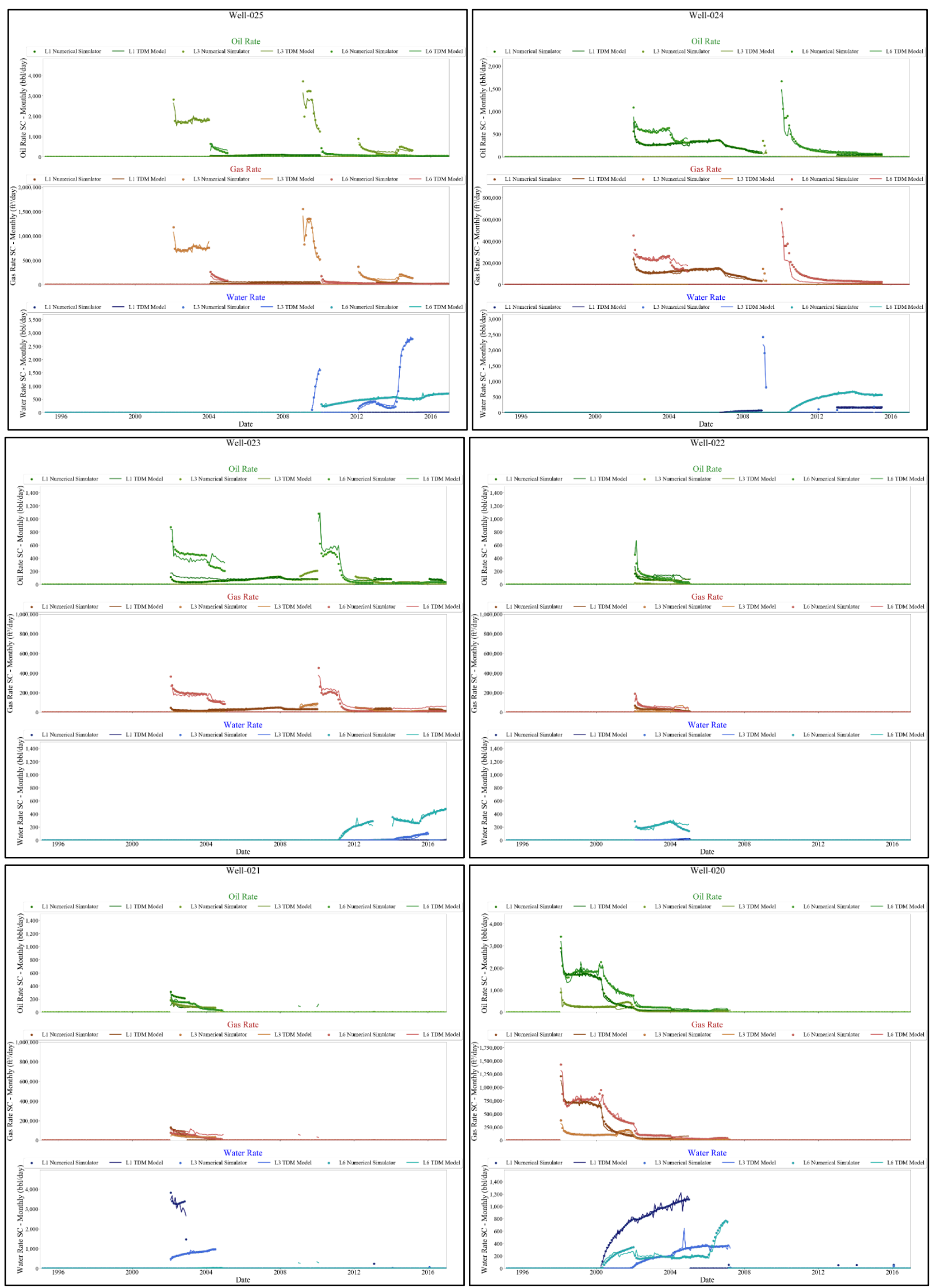

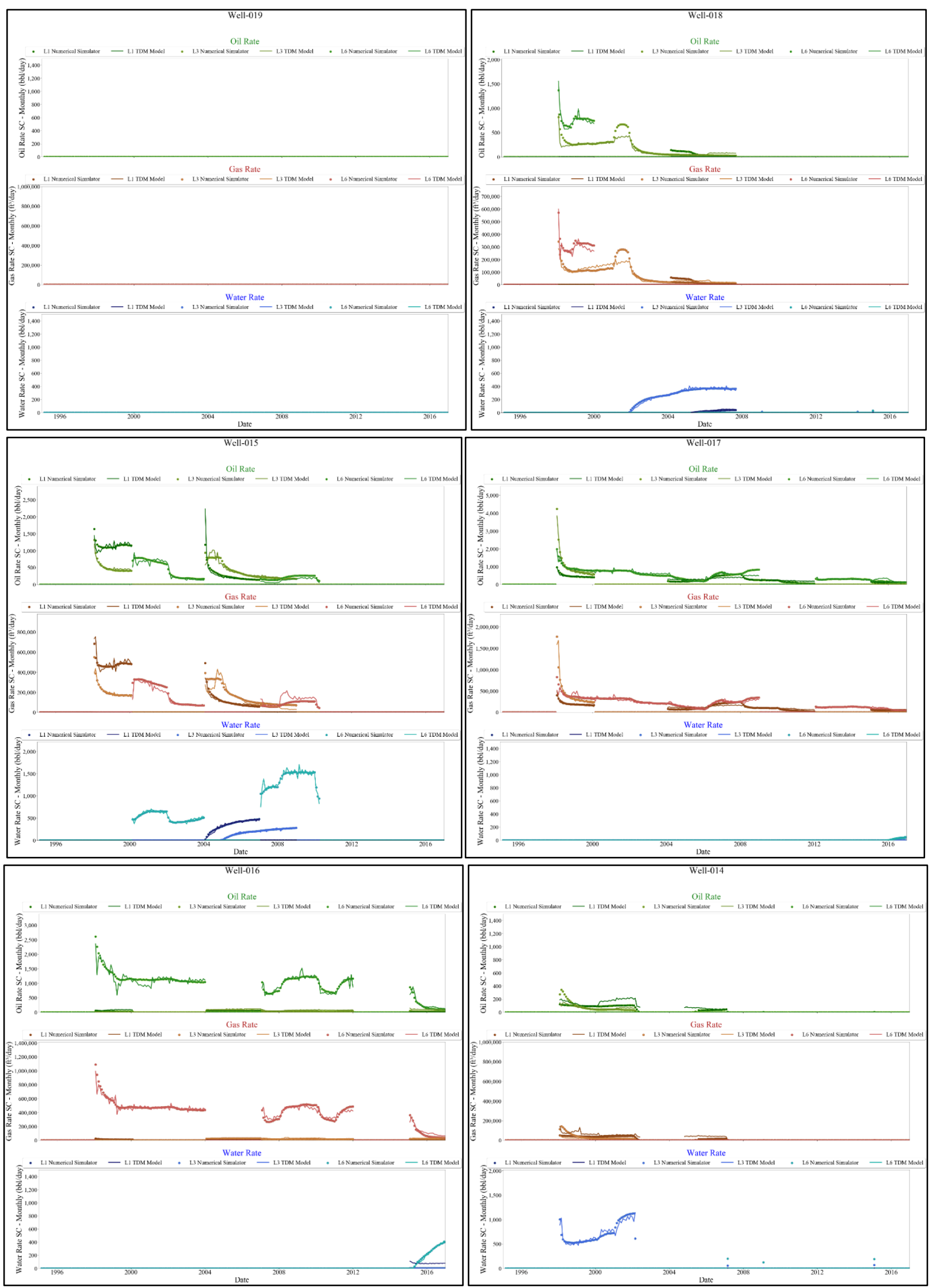

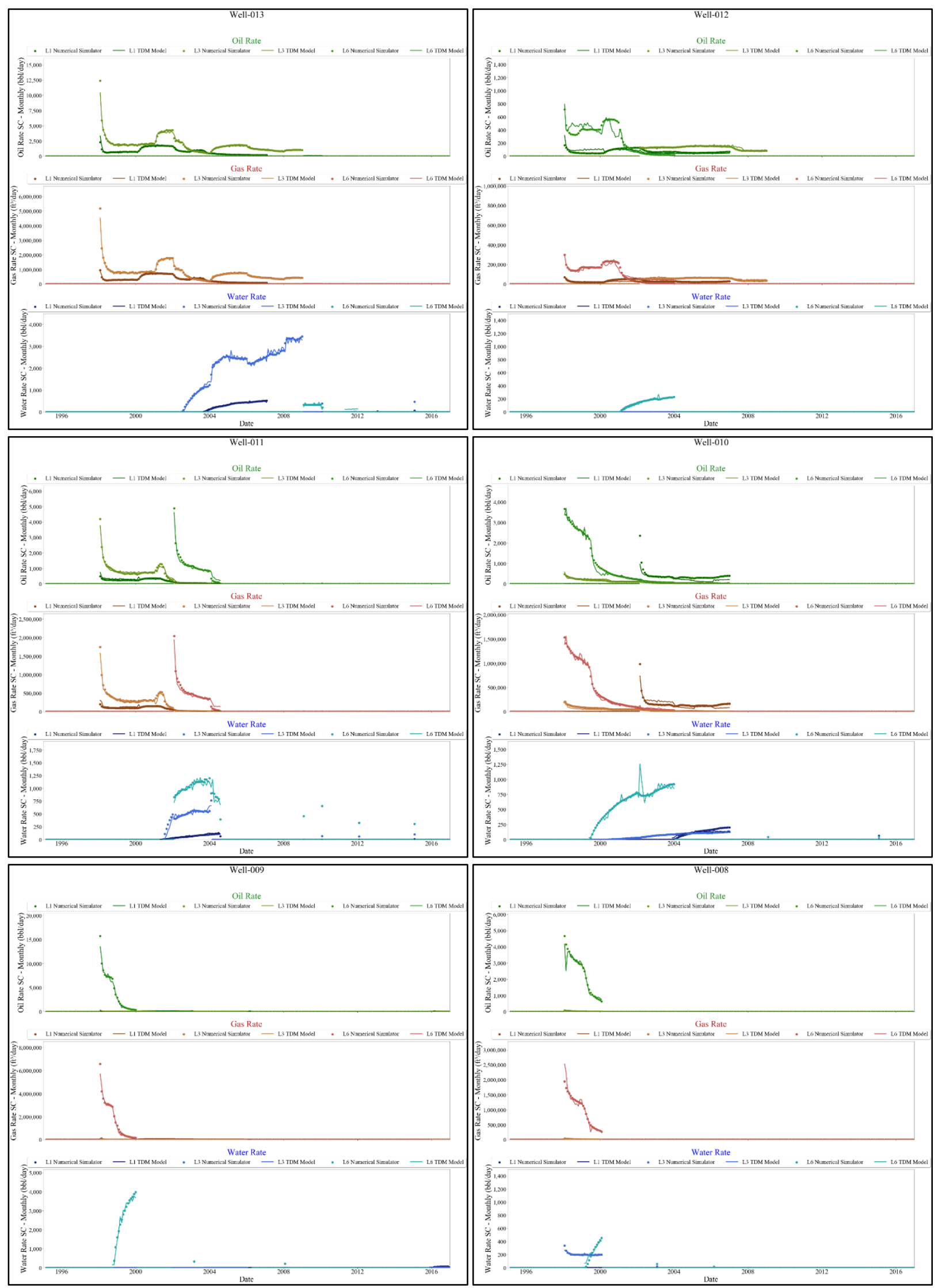

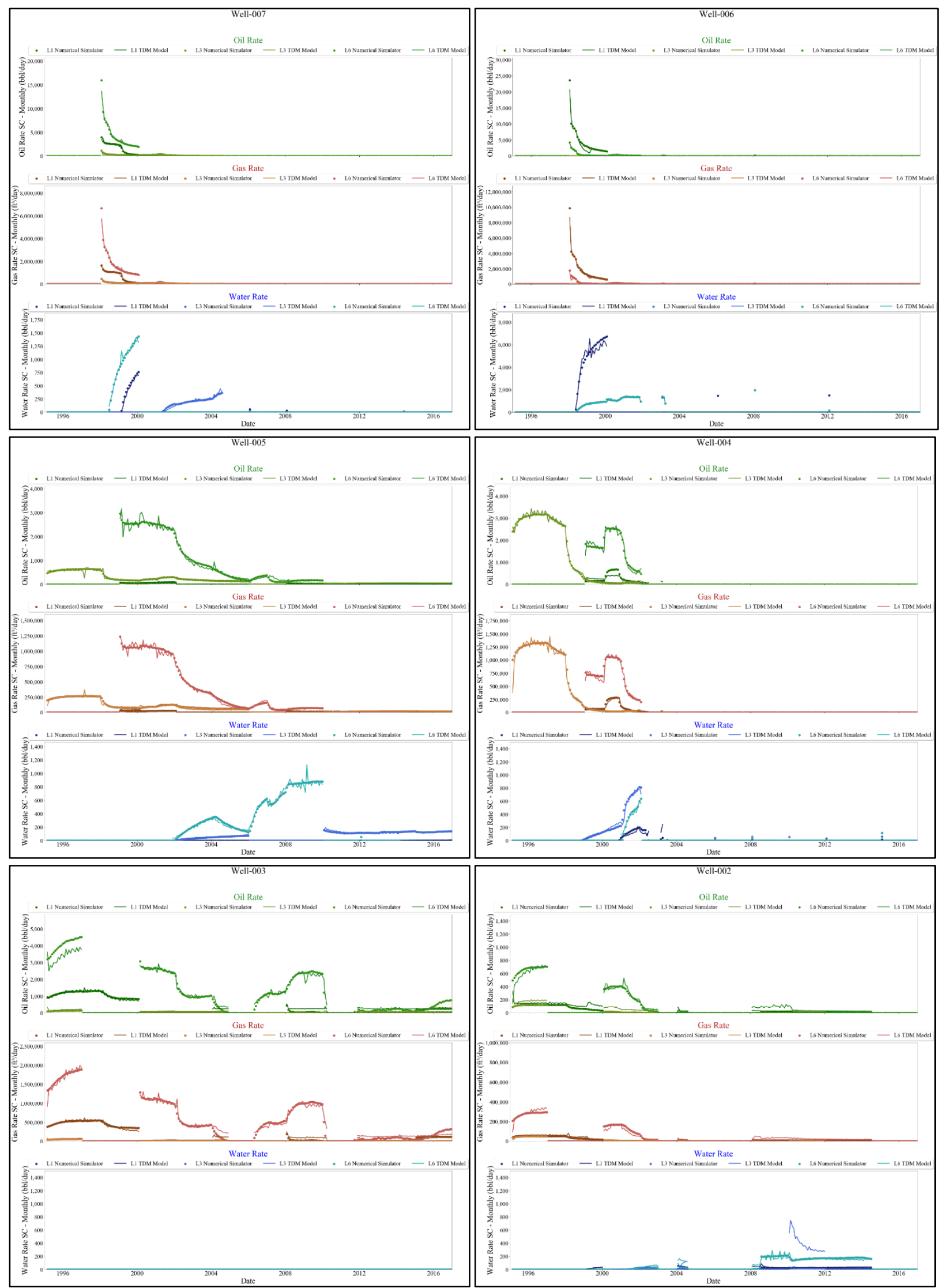


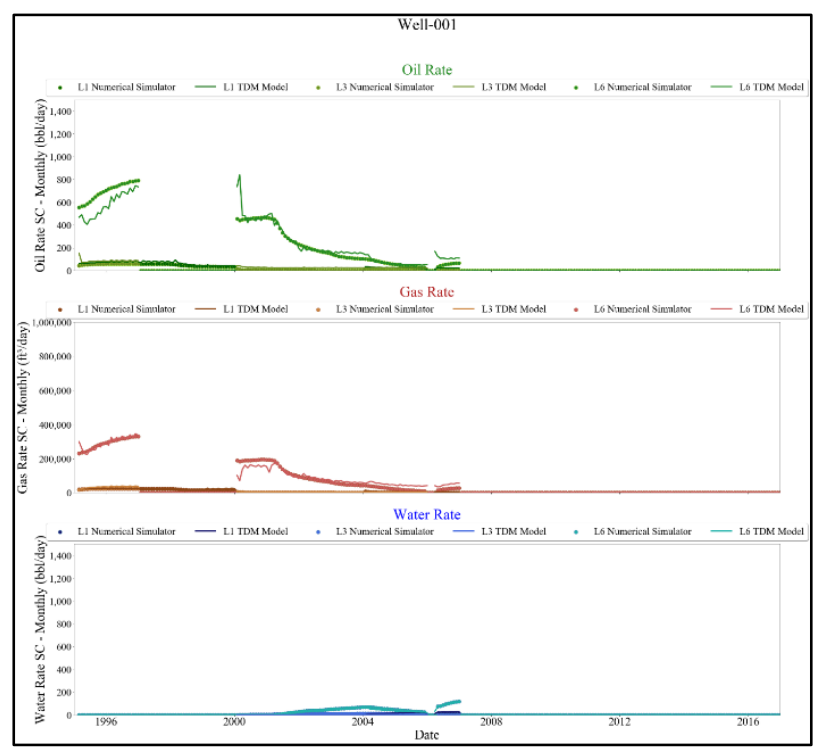

